\title{
Enthesis tissue engineering: biological requirements meet at the interface
}

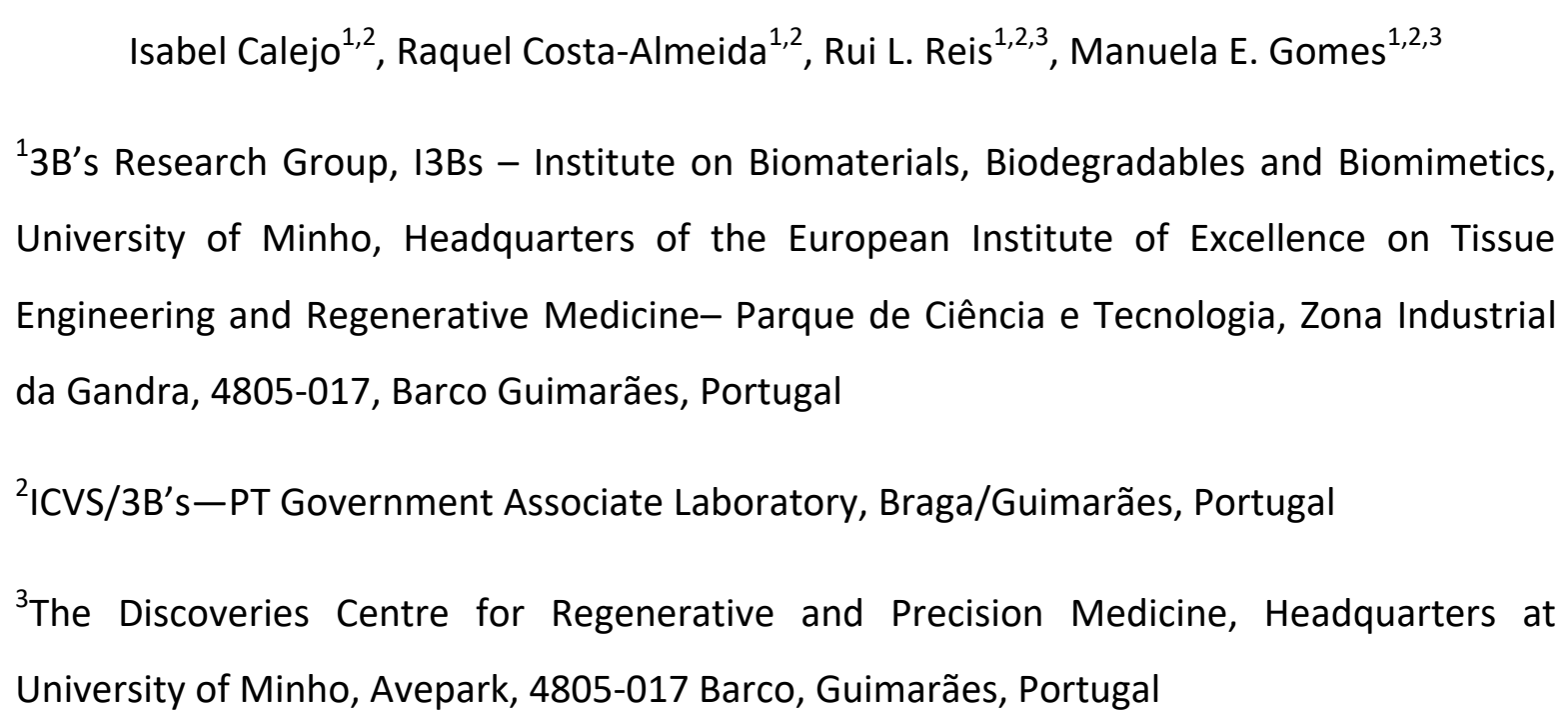



compositional organization maintained by a heterogeneous cellular environment. Orthopedic surgeons have been facing several challenges when treating tendon pullout or tear from the bony insertion due to unsatisfactory surgical outcomes and high re-tear rates. The limited understanding of enthesis hinders the development of new treatment Abstract options toward enhancing regeneration. Mimicking the natural tissue structure and composition is still a major challenge to be overcome. In this review, we critically assess current tendon-to-bone interface tissue engineering strategies through the use of biological, biochemical or biophysical cues, which must be ultimately combined into sophisticated gradient systems. Cellular strategies are described, focusing on cell sources and co-cultures to emulate a physiological heterotypic niche, as well as hypoxic environments, alongside with growth factor delivery and the use of platelet-rich hemoderivatives. Biomaterials design considerations are revisited, highlighting recent progresses in tendon-to-bone scaffolds. Mechanical loading is addressed to uncover prospective engineering advances. Finally, research challenges and translational aspects are considered. In summary, we highlight the importance of deeply investigating enthesis biology toward establishing foundational expertise and integrate cues from the native niche into novel biomaterial engineering, aiming at moving today's research advances into tomorrow's regenerative therapies. 
Impact Statement

The main goal of this review is to give an overview of cell-based and tissue engineered strategies for tendon-to-bone interface. The essential role of cells in tendon-to-bone interface development, healing, and regeneration, is underpinned by the physiological status of the junction. Therefore, recent studies underlining the effect of oxygen concentration and production of growth factors are reviewed. A critical view is made on the use of two-dimensional versus three-dimensional culture systems and mechanical stimulation. An overview of advances on bioengineered strategies in light of the biological/cellular requirements of enthesis will contribute to innovations in tendon-tobone engineering and regeneration.

Keywords: 2D vs 3D culture, cell-based strategies; Gradient Biomaterials; Growth factors; Tendon-to-bone interface; Tissue Engineering. 
Table of contents

1. Introduction

2. Multi-scale structural and compositional organization

3. Cell-based strategies

3.1. General considerations

3.2. Cell sources: From stem cells to differentiated cells

3.3. Co-culture systems

3.3.1. Co-cultures using terminally differentiated cells

3.3.2. Co-culture of terminally differentiated cells with stem cells

3.3.3. Co-cultures using biomaterials

3.4. Hypoxic environment

3.5. Growth factors

4. Two- or three-dimensional (2D/3D): a biomaterials approach

4.1. 2D nanofiber-based materials

4.2. 3D bio-instructive scaffolds

5. Static or dynamic? The role of mechanical stimulation

6. Clinical translation

7. Conclusions/ Future trends 


\section{Introduction}

Soft-to-hard tissue interfaces, such as tendon-to-bone insertions, are compelled to deal with large mismatch mechanical needs of two widely different tissues and, therefore, known to be under increased failure chances. Orthopedic surgeons frequently face the challenge of torn enthesis (tendon/ligament-to-bone interface), partial or complete rupture of tendons and ligaments and bone avulsions. Statistically, $20 \%-80 \%$ of the general population above 50 to 80 years has been diagnosed with a rotator cuff tear [1]. Similarly, younger patients are affected by acute or overuse sports injuries, such as tennis and golfer's elbow, jumper's knee and Achilles insertional tendinopathies [2,3]. Nevertheless, the enthesis can also be affected by extrinsic and intrinsic factors (such as trauma, systemic illness, age-related degeneration or pharmacotherapy) resulting in general insertional disorders, known as enthesopathies, and/or enthesitis, if an inflammatory process is involved [4]. Current methods to manage enthesis pathologies include, in a first approach, conservative treatments (e.g., rest, mechanical conditioning, corticosteroids injection, orthotics, among others) normally with limited success, or surgical interventions through the routine application of grafts (auto-, allo- and synthetic grafts). However, surgical repair still presents several major problems, including tissue harvesting, host tissue reaction, risk of disease transmission, slow or lack of tissue integration and donor tissue availability $[5,6]$. Additionally, following repair, grafts are associated with high recurrence rates due to formation of neo-fibrovascular tissue, compromising the stability and consequently mechanical performance of the newly formed tissue $[6,7]$. As a result, high probability of re-injury, deformation, pull-out and long rehabilitation periods are associated with these common surgical procedures $[6,8]$. Thus, given the importance of this interface within the skeleton and all the clinical challenges concerning its repair, there is a crucial need to regenerate this critical soft-to-hard tissue transition.

In the past decades, a new field of tissue engineering has arisen, called interfacial tissue engineering, aiming at the recreation of complex and hierarchical interfacial tissues in order to repair or to regenerate diseased or damaged junctions [9]. Many attempts have been made to improve the repair and ultimately regenerate the enthesis, but challenges still exist toward mimicking the micro- and nano-structure of the native interface, as well 
as replicating the spatial distribution of signaling factors and cellular interactions, which are essential for a normal interfacial function and homeostasis $[10,11]$. A variety of interdependent tissue engineered strategies have been proposed over the years [12-14] and can be roughly grouped into four connected categories: (1) scaffold-based strategies, (2) cell-based strategies, (3) growth factors and gene therapy and, finally, (4) mechanical stimulation. However, up to now, the existing challenges faced in the clinics, when trying to restore musculoskeletal interfaces functionality, including graft laxity and inferior mechanical properties associated with a lack in the identification of appropriate healing factors and time of administration at the repair site, have led to a preference toward stem cell-mediated treatments, due to their regenerative and differentiation potential as Nature tissue engineers. As cells are the major players in orchestrating tissue regeneration, this review will discuss current cell-based strategies with and without biomaterial constructs for tendon-to-bone repair. In light of this, cellular/biological, biochemical and biophysical components (Figure 1) will be discussed. Instead of extensively analyzing currently explored strategies, this review intends to collect insights illustrating the usefulness of cellbased approaches and highlight main challenges and prospective successes.

\section{Multi-scale structural and compositional organization}

The enthesis is a musculoskeletal structure that allows a smooth transition between two widely different tissues, displaying a gradient in composition, tissue organization and, therefore, mechanical properties. Hence, this interface displays a unique microenvironment, which maintains specific cellular phenotypes throughout different localizations within the tissue, playing an important role in its composition, maintenance and regeneration. A close look reveals a well-organized structure with spatiotemporal distribution of extracellular proteins and biochemical signals produced by distinct cell populations that work in synchrony to enable the biological function of the whole tissue.

The most commonly found enthesis, denominated as fibrocartilogenous, is described as a four-divided zone structure (Figure 2). Firstly, the tendinous part is composed by collagen type I, proteoglycans, decorin and biglycan, being populated by tendon cells aligned in the direction of tendon tension [15]. Strikingly, advanced imaging techniques have 
demonstrated a $\sim 500 \mu \mathrm{m}$ zone where tendon crimped fibers unravel into smoother and thinner interface fibers before attaching to bone [16] (Figure 3). This small area is constituted by two distinct zones, the unmineralized and mineralized fibrocartilage. The unmineralized zone is populated by fibrochondrocytes that are responsible for ECM production of collagens type I and II, together with aggrecan [17]. Interestingly, mineral deposition and calcification starts at the mineralized fibrocartilage with a clearly visible straight line, called as tidemark, that delimitates the true transition between mineralized and unmineralized tissue [18]. The mineralized fibrocartilage consists of collagens type II and $\mathrm{X}$ and aggrecan produced by resident hypertrophic chondrocytes. Finally, the fourth zone corresponds to bone, which is constituted by a dense mineralized collagen type I matrix populated by bone cells (osteoblasts, osteoclasts, osteocytes).

Overall, besides matrix mineralization increase along the interface, a gradient in collagen fibers orientation is observed from the tendon (fiber alignment) to bone. This allows the mitigation at the interface of stress concentrations [19]. Moreover, the collagen fibrils mineral arrangement, either extrafibrillar or intrafibrillar, leads to a controlled and graded increase of stiffness, resulting in a smooth load transfer [20].

Interestingly, the fibrocartilogenious insertion is regarded as avascular and aneural recalling the nature of articular cartilage [21], which can be explained by the levels of compression it is subjected to or by the presence of aggrecan, known by its axonal growth inhibitory effect in the nervous system [22]. However, tissue microdamage is very common to occur and appears to be responsible for vessel ingrowth, thus leading to immune cells infiltration and the onset of inflammatory events [23]. Moreover, the presence of vessels and nerve ingrowth have been also reported in enthesis of elderly human Achilles tendons as a consequence of degenerative changes [24]. Therefore, altered vascularity may provide an anatomic explanation for enthesis-related diseases and damage. Additionally, many fibrocartilage sites present fat pad near the insertion site which, in combination with the bursa, serve to promote frictionless movements $[25,26]$, being this movements compromised in patients with entheseal degenerative diseases $[25,26]$. Nevertheless, fat pad present other functions in the enthesis such as proprioceptive function in monitoring 
changes in the insertional angle, immune function due to its rich macrophage population and source of pain in enthesopathies [21].

When trying to mimic the native tissue, one of the major challenges is the replication of all the structural features of the enthesis, as well as meeting the specific requirements for each cell type. Although tendon and bone exhibit their own cellular niche and cell populations, cells residing at the enthesis present distinctive features. Up to now, there are no single cell RNA sequencing studies for enthesis cell populations, thus the heterogenicity of resident cells is still poorly understood. Nonetheless, integration of transcriptomics and proteomics data has recently shown that enthesis cells express cartilage-related markers, including aggrecan, chondroadherin, collagen type II and versican, and markers of terminally differentiated hyperthophic chondrocytes, such as runt-related transcription factor 2 (RUNX2), integrin binding sialoprotein (IBSP) and matrix metallopeptidase 13 (MMP13), suggesting a chondrocyte-like phenotype $[15,16]$.

Therefore it is important to develop tissue engineered constructs that not only support the deposition and formation of compositionally different tissues in an organized, continuous and graded manner but also sustain a spatially-varying cellular content, which play a critical role in orchestrating the formation and repair of interfacial tissues.

\section{Cell-based strategies}

\subsection{General considerations}

Cell-based strategies for tendon-to-bone interface face some challenges due to the complexity of the cellular environment, tissue vascularization and oxygen tension, and different mechanical requirements associated with the distinct tissues.

The search for a single cell source or the use of mixed cultures along with the determination of adequate cell ratios are being explored. In particular, the use of cocultured cells has shown promising outcomes while trying to overcome the limitations associated with the mimicry of the heterotypic communications occurring within the native junction. However, many challenges still have to be addressed before stem cells, or even terminally differentiated cells, can break the barrier between the laboratory and the 
clinics. There is still a real need to evaluate the efficacy of cells and cell-based products in long-term safety and well controlled tendon-to-bone healing animal models. Therewithal, it is important to have in mind that, even though evidences show a substancial development in cell-based therapies and these are recognized as new biotechnological innovations, the translation to the clinical environment still faces very strict and complex global regulatory issues [27].

In the following sections, recent advances regarding cell- and culture-based strategies for tendon-to-bone regeneration will be further illustrated and discussed in detail.

\subsection{Cell sources: From stem cells to terminally differentiated cells}

Stem cells, normally from mesenchymal origin, are widely used in interfacial tissue engineering. These cells can be isolated from a wide number of human tissues (including bone, tendon, cartilage, ligament, adipose, synovial), have self-replication capability and are able to differentiate toward mature cells of different lineages such as tendon, bone and cartilage [28]. Several studies have demonstrated an improvement in tendon-to-bone healing and mechanical properties after transplantation of bone marrow mesenchymal stem cells (BMSCs) [29-31]. Still, other stem cell sources have been exploited for tendonto-bone healing, mainly in animal models.

An interesting example is the emerging use of anterior cruciate ligament ( $A C L)$-derived stem cells. These cells have been isolated from $A C L$ and exhibit stem cell properties, such as clonogenecity, self-renewal and multidifferentiation capability [32]. Recently, ACLderived $\mathrm{CD}_{3}{ }^{+}$stem cells were identified in injured $\mathrm{ACL}$ tissues, displaying higher expansion and multidifferentiation potential [33]. The efficacy of these cells has been tested on tendon-to-bone healing. Injections of adult human $\mathrm{ACL}$-derived $\mathrm{CD} 34^{+}$stem cells into nude mice after $\mathrm{ACL}$ reconstruction resulted in an increased number of fibrocartilage cells, enhanced angiogenesis and osteogenesis in the presence of CD34+ cells and non-sorted cells in comparison with control groups (PBS and CD34 groups) and similar failure load as uninjured ACL [34]. However, migration of cells to other tissues was reported. Alternatively, the use of cell sheet technology by incorporating $\mathrm{ACL}$-derived $\mathrm{CD} 34^{+}$in a cell sheet wrapped tendon graft demonstrated the potential application of these cells in $\mathrm{ACL}$ 
reconstruction and recovery [35]. This strategy resulted in ex vivo gradual cell migration within grafted tendon and bone tunnel site, as well as in vivo promotion of angiogenesis and osteogenesis, together with accelerated early remodeling observed by the faster recovery time, graft maturation and biochemical strength [35].

Tendon-derived stem cells (TDSCS) have also demonstrated great potential to form enthesis-like tissues, alone or in the presence of a carrier. In vivo studies, including treatment with bone morphogenetic protein (BMP)-2 and subcutaneous transplantation in immunocompromised mice [36] or even incorporation in knitted silk-collagen sponge scaffold for rotator cuff regeneration in a rabbit model [37], led to improved mechanical and structural properties in comparison with controls and possible formation of a osteotendinous-like tissue [36,37]. Even though TDSCs and ACL-derived stem cells seem to constitute promising cell types for tendon-to-bone junction regeneration, donor site morbidity, cell number and the need for long expansion periods together with consequent phenotypic drift are still a limiting factor for future clinical applications [38]. Furthermore, the impracticality of isolating these stem cell populations for further exogenous applications still poses a limiting step owing to the need for invasive collection procedures.

Alternatively, synovial mesenchymal stem cells (sMSCs) and periosteum-derived stem cells (PDSCs) have been reported in the literature as reliable cell populations for tendon-tobone healing [39-41]. Although there is still a limited number of studies, some encouraging outcomes have been reported. For example, in vivo injection of SMSCs in a bone tunnel enhanced the production of collagen fibers and Sharpey's fibers between tendon and bone [41]. However, after 4 weeks, bone and tendon were attached together, without the presence of SMSCs or the formation of a fibrocartilage transition region [41]. In this case, even though these cells have shown an effective potential to improve tissue healing, they failed in the regeneration of the proper tissue. On the other hand, PDSCs are progenitor cells found in the inner layer of the periosteum with the capability to differentiate, under appropriate stimulus, toward de chondrogenic and osteogenic lineages $[42,43]$. The combination of these cells along with the appropriate stimulus, e.g. growth factors, has been applied to enhance tendon-to-bone healing. Injectable hydrogels containing PDSCs and BMP-2 were reported to have a strong inductive ability along with 
an enhanced tendon-to-bone healing at 8 weeks postoperatively through the formation of fibrocartilage in a rabbit rotator cuff healing model [39]. More recently, PDSCs cell sheets were evaluated in a rabbit extra-articular bone tunnel model. Results demonstrated enhanced deposition of collagen and glycosaminoglycans with fibrocartilage formation at 4 weeks postoperatively, showing the promising application of periosteum-derived cells monolayer in tendon-to-bone healing [40]. But the question still remains in the isolation method and either or not a mixture of cells is obtained from the different layers of the periosteum, and in the limited differentiation capability demonstrated by clonal cultures of periosteum-derived cells [44].

A well-known alternative is the use of adipose-derived stem cells (ASCs). This stem cell population is more readily accessible from adipose tissue through a minimally invasive method, providing higher yield and lower morbidity and pain, as well as higher proliferation rate and lower senescence upon in vitro expansion [45]. Recent studies have also demonstrated the feasibility of using ASCs and ASCs subpopulations for the generation of tendon- [46-48], bone- [49-51] and cartilage-like tissues [52-54] and the potential use of ASCs for tendon-to-bone regeneration has been under study [55-59]. A recent report by Kosaka et al. [58], where ASCs were locally injected in a rabbit $\mathrm{ACL}$ reconstruction model, demonstrated a temporal improvement of tendon-to-bone integration with the appearance of a more organized and cartilaginous-like tissue in the ASCs-treated group, accompanied by a significantly better failure load 2 and 4 weeks after surgery, in comparison to controls [58]. Additionally, ASCs multilineage differentiation potential has been also demonstrated after seeding onto a micropore surface of a porous membrane with a dual reverse gradient of growth factors concentrations (PDGF-BB gradient from the left to right side of the membrane and BMP-2 gradient from the right to left side) to generate a tendon-to-bone like construct [57]. This strategy allowed a spatially-modulated differentiation of ASCs toward tenogenic and osteogenic lineages according to the gradient of growth factor concentration along the construct.

Rather than applying a multipotent cell source, the interposition of chondrocytes between two tissues (tendon and bone) to mimic the cellular environment found in the native niche, has shown great promise in tissue engineering. In a rabbit partial patellectomy 
model, Wong et al. investigated the use of an allogeneic chondrocyte pellet in restoring the transitional fibrocartilage and tendon-to-bone healing, demonstrating an early integration and formation of a fibrocartilage-like zone, without immune rejection, suggesting a possible stimulatory effect of these cells [60]. Comparably, Nourissat et al. [61] studied the ability of chondrocytes to restore the normal function of tendon-to-bone while comparing it with the ability of BMSCs. An Achilles tendon repair model was induced in rats by destroying the enthesis; afterwards chondrocytes and BMSCs were injected and the healing rate, tissue remodelling and biomechanical load were assessed [61]. The injection of both cell types resulted in the production of enthesis-like tissue as soon as 15 days, which was not observed in control groups (not injected rats) [61]. However, only MSCs-injected were able to recapitulate the enthesis organization with columnar chondrocytes as observed in uninjured tissues [61]. Nonetheless, the ability of chondrocytes to improve tendon-to-bone healing is still relatively unexplored.

As said before, several cell sources are being explored to restore the normal function of tendon-to-bone interface through the improvement of fibrocartilage formation and enhancement of mechanical properties. The use of stem cells for tendon-to-bone interface tissue engineering presents several advantages compared to terminally differentiated cells. Multipotent stem cells can be expanded until a sufficient number for transplantation is achieved, whereas terminally differentiated cells present limited expansion, and can be induced to differentiate into the distinct phenotypes found at the enthesis. Moreover, a lack of immunological reaction, together with their capability to "empower" other cell types residing at the injured tissue makes them an optimal option while trying to be incorporated in vivo.

\subsection{Co-culture systems}

The use of novel multi-cell type co-culture systems can substantially facilitate the formation of transition regions of the tendon-to-bone interface, while giving better insights about the developmental process of enthesis insertion site.

Generally, culture systems can be divided in two-dimensional (2D) or 3D [62]. Particularly, co-culture systems can be further divided into direct and indirect contact co-cultures 
(Figure 1). Direct contact co-cultures are based on cell-cell interactions, paracellular diffusion of paracrine factors and also cell-ECM communication [62]. On the other hand, in indirect contact or noncontact co-cultures, cells are separated by a porous membrane (normally a transwell), thus only the culture medium is shared, allowing the study of paracrine interactions between different cell populations [62]. Other approaches are based on conditioned media from one type of cells that can be used to culture other type of cells, and even the use of decellularized matrices [63]. These strategies can be applied to assess the effect of paracrine factors without the need of pre-labelling the different cell populations [63]. In interface tissue engineering, usually two types of strategies are applied: co-culture of terminally differentiated cells and co-culture of terminally differentiated cells with stem cells [62]. Table 1 highlights main outcomes regarding 2D and $3 \mathrm{D}$ co-culture systems for tendon-to-bone tissue engineering and regenerative medicine applications.

The role of stem cells in these systems goes beyond their multidifferentiation capacity. Normally, in co-cultures, stem cells are the target cells to differentiate and eventually synthetize ECM or metabolites favorable to a tissue. The employment of co-cultures using terminally differentiated cells with stem cells underwent significant advances in the last years. However, even though exogenous factors are applied to induce a more controlled cellular response, the crosstalk between the different cell types turns this phenomena more complex than it was initially believed. Therefore, novel co-culture strategies based on the manipulation of the in vitro supplementation to modulate the communication occurring between these cell types is of major importance.

\subsubsection{Co-cultures using terminally differentiated cells}

In the field of tendon-to-bone tissue engineering, there are few studies reporting the use of co-culture systems for tendon-to-bone regeneration. Wang et al. [64] studied the interactions occurring between osteoblasts and ligament fibroblasts using a direct contact co-culture model. Primary osteoblasts and fibroblasts, obtained from trabecular bone fragments and $A C L$, respectively, were first seeded using 1:1 ratio in a tissue culture plate separated by a hydrogel divider to mimic the interface region, which upon confluency, was 
removed, allowing cells to migrate and interact directly (Figure $4 \mathrm{~A}-\mathrm{B}$ ). Cells were prelabelled to control cell migration and subsequent interactions. After 14 days, three regions could be distinguished: fibroblasts, fibroblasts plus osteoblasts (interface) and osteoblasts [64], demonstrating the effectiveness of direct cell-cell physical contact in the establishment of different regions. ALP activity and mineralization by fibroblasts seemed to be influenced by the presence of osteoblasts, suggesting that osteoblast-fibroblast interactions may lead to fibroblasts trans-differentiation [64] (Figure 4 C-E). Furthermore, at the gene level, an up-regulation of collagen type II, aggrecan and cartilage-oligomeric protein (COMP), interface-relevant markers, was observed in the interface region, in comparison with the regions containing only osteoblasts or fibroblasts [64]. Despite these interesting results regarding the expression of interface-related markers, using only terminally differentiated cells was not proven to be sufficient to trigger the formation of an interface-like region in vitro [64]. Interestingly, another approach by Cooper et al. [65] demonstrated the importance of medium supplementation for an appropriate matrix deposition in a multiphased co-culture setup. In this case, cell lines of NIH 3T3 fibroblasts and MC 3 T3 osteoblasts were used and the medium supplemented with $3 \mathrm{mM}$ betaglycerophosphate and $25 \mu \mathrm{g} / \mathrm{mL}$ ascorbic acid to reduce fibroblasts mineralization while enhancing the osteoblasts response.

Overall, co-culture studies using terminally differentiated cells can represent simplified in vitro models of native tissue physiology. Altogether, these results have shown that the crosstalk between fibroblasts and osteoblasts, representing tendon and bone cellular environments, respectively, can induce phenotypic alterations, particularly through fibroblast mineralization. Nonetheless, this constitutes a less controlled response given that these systems frequently require the use of cell-specific conditions or additional supplementation, challenging tissue engineering protocols.

\subsubsection{Co-culture of terminally differentiated cells with stem cells}

Alternatively to the sole use of differentiated cells, the crosstalk between these and stem cells has been increasingly exploited under the rationale that the intricate communication occurring within these systems will ultimately lead to stem cell differentiation into relevant 
phenotypes. In turn, stem cells are expected to contribute with key signaling molecules, "empowering" native cell populations. In this context, a tri-culture model has been developed using primary fibroblasts and osteoblasts in combination with BMSCs; cells were seeded in opposing sides of the tissue culture well and fibroblasts or BMSCs embedded in an agarose-gel and placed in the middle region of the plate, allowing for individual analysis [66]. Additionally, the effect of fibroblasts-osteoblasts physical contact on BMSCs differentiation was studied using a mixture of fibroblasts-osteoblasts (1:1 ratio) in both sides of the agarose gel, resulting in three different regions: fibroblastsosteoblasts, BMSCs and fibroblasts-osteoblasts [66]. Interestingly, in contrast to fibroblasts, BMSCs in tri-culture were found to express interface-relevant markers (such as proteoglycans, as well as collagen types I and II at the gene level) throughout time in culture [66]. Matrix mineralization potential was reduced, but BMSCs exhibited higher ALP activity in comparison with fibrochondrocytes and fibroblasts; and, in contrast to ALP activity in tri-culture, the highest ALP activity was delayed in time suggesting an enzyme suppression, resulting from osteoblasts-fibroblasts interaction [66]. Moreover, gene expression of SOX9, collagen type II and production of proteoglycans was significantly upregulated in the mixed tri-culture demonstrating an important role of cell-cell communication in BMSCs differentiation toward fibrochondrogenic phenotype [66]. Together, these results support the hypothesis that the direct crosstalk between differentiated and stem cells within the system can potentiate fibrochondrogenic commitment characteristic of the chondrocyte-like phenotype observed for native enthesis cells [15]. Furthermore, conditioned media from parallel cultures of fibroblastsonly, osteoblasts-only, and fibroblast-osteoblast co-culture were collected and added to monocultures of BMSCs to evaluate the effect of paracrine communication [66]. Strikingly, glycosaminoglycan deposition was reduced when BMSCs were exposed to conditioned media from co-culture of fibroblasts and osteoblasts. The same decrease was observed in BMSCs proliferation and ALP activity in the presence of both osteoblast- and fibroblastconditioned media [66]. Overall, fibroblasts-osteoblasts direct interactions seem to play an important role in regulating stem cell commitment . 
Additionally, the use of mixed culture media in co-cultures of human tendon-derived cells (hTDCs) and pre-osteoblasts (pre-OBs, osteogenically induced ASCs) has been studied to assess medium composition influence on the expression of tendon-, bone- and interfacerelated markers [67]. An intermediate condition of 1:1 ratio of basal medium and osteogenic medium was reported as optimal for the maintenance of tenogenic and osteogenic phenotypes in single cultures of hTDCs and pre-OBs, respectively [67]. A direct co-culture model with hTDCs and pre-OBs (1:1 cell ratio) was then established. Interestingly, the presence of osteogenic medium seemed to increase the expression of bone-related markers (osteopontin, SPP1, and Runt-related transcription factor 2, RUNX2) in comparison with pre-OBs expression levels, suggesting the existence of a bi-directional cellular communication. Moreover, the expression of interface-relevant markers (aggrecan, ACAN, and COMP) was also increased in comparison with single cultures, suggesting a possible targeting toward chondrogenesis [67].

Altogether, the effect of medium supplementation and cell-cell interations played an important role on the modulation of cells phenotype with future application in more complex systems to promote the formation of a enthesis-like tissue. These results constitute promising outcomes in light of recent descriptions of enthesis cells phenotype, which resemble chondrocyte-like cells $[15,16]$ and the use of an optimal culture condition that can maintain different phenotypes at the same time is a major advantage supporting the combination of stem cells with differentiated cells.

\subsubsection{Co-cultures using biomaterials}

The development of scaffold-based strategies along with the use of co-cultures has been also explored to overcome the structural complexity of tendon-to-bone junction. A biomimetic continuous triphasic scaffold was designed aiming at the regeneration of ACLto-bone interface, consisting of three phases: phase A (soft tissue) formed from polyglactin 10:90 knitted mesh sheets; phase B (interface) made from poly(D-L-lactide-coglycolide) (PLGA) 85:15 copolymer microspheres; and phase C (hard tissue) comprised of composite microspheres consisting of a 4:1 ratio of PLGA and 45S5 bioactive glass [68]. Human hamstring tendon fibroblasts and primary human osteoblasts were seeded on the 
extremities of the scaffold and allowed to migrate during culture time. Cell tracking results showed that fibroblasts adhered to phase $A$ and osteoblasts to phase $C$, and cells continuously proliferated, resulting in fibroblast-osteoblast interaction within phase B [68]. Higher ALP activity and mineralization were mainly restricted to phase $C$, confirming the osteoconductivity effect of this phase provided by the bioactive glass, while higher amounts of collagen type I were observed in the presence of fibroblasts in phase $A$, together with a controlled phase-specific distribution of ECM over time [68]. Unfortunately, the expression of fibrocartilage-related markers was not assessed in the interface region, limiting the interpretation of in vitro cellular crosstalk effects alone. Notwithstanding, in vivo implantation studies of this multi-phasic scaffold tri-cultured with fibroblasts, chondrocytes and osteoblasts were performed to evaluate the formation of a fibrocartilage-like structure [69]. Three experimental groups were considered: tri-cultured, co-cultured (fibroblasts and osteoblasts only) and acellular scaffolds. Seeded scaffolds were cultured for 4 days prior to implantation and implanted subcutaneously in rats for 8 weeks. Immunohistological stainings demonstrated the deposition of collagenous-rich matrix in all phases of the scaffold in co- and tri-cultures, in opposition to acellular scaffolds, with collagen type III majorly found in phase A [69]. Moreover, tissues mineral distribution by micro-CT confirmed the mineralization confinement in phase $\mathrm{C}$ in all experimental groups [69]. Interestingly, the presence of a tri-culture led to an enhanced degradation of phase $A$, resulting in the formation of a fibrocartilage-like region revealed by the presence of collagen types I, II and X [69].

Another relevant approach is the combination of stem cells, terminally differentiated cells and scaffolds. For ligament-bone regeneration, He et al. [70] used knitted silk scaffolds tricultured with rabbit BMSCs, fibroblasts and osteoblasts. Separate scaffolds were firstly seeded individually and cultured for 7 days; the three parts were then knitted together and a scaffold composed of 5 distinct regions (osteoblasts only, BMSCs plus osteoblasts, BMSCs only, BMSCs plus fibroblasts and fibroblasts only) was obtained. A gradual transition was formed from the region where BMSCs directly interacted with fibroblasts to the opposite region where BMSCs interacted with osteoblasts and BMSCs were found to 
differentiate toward the fibrocartilage lineage, exhibiting at gene level an up-regulation of collagen type II, SOX9 and aggrecan in comparison with monocultures of BMSCs [70].

Altogether, these results anticipate the potential of controlling cellular interactions while changing scaffolds porosity, architecture and composition which allowed selective cell ingrowth, stimulating the production of a heterogeneous cell matrix along the scaffold and, therefore, the generation of a gradual transition between a soft and hard tissue. Overall, the combination of co-cultures with scaffold design constitutes a multidisciplinary approach for studying possible cell-cell and cell-matrix interactions occurring in the native tissue.

Even tough co-cultures are presented as important in vitro cell culture methodologies, there is still a lack of understanding regarding the mechanisms governing tendon-to-bone interface development and regeneration. Therefore, further studies should first focus on the characterization of important cellular interactions while using co- or tri-cultures, as a relevant in vitro platform to mimic as close as possible the cellular environment found at tendon-to-bone interface.

\subsection{Hypoxic environment}

Oxygen concentration is an important signal for the development and maintenance of several tissues. Tendon-to-bone interface presents a "critical zone" near the proximal tendon/bone attachment, poorly vascularized, where the oxygen supply is very low. Similarly, tendons are also poorly vascularized tissues $[72,73]$ while, in contrast, bone is highly vascularized [74]. Oxygen concentrations ranging from $5.5 \%$ to $15 \%$ have been estimated in bone tissue [75-77]. In contrast, as muscles oxygen tension varies between $3.6-4.0 \%$, tendon oxygen saturation falls below this value $[78,79]$. This is corroborated by the quantification of oxygen consumption in tendons $(5.3 \% / \mathrm{min})$ and muscles $(10.5 \% / \mathrm{min})$ during rest $[80,81]$. Over the past years, studies have been focusing on the effect of hypoxia on tenogenic [82-84], chondrogenic [85-88] and osteogenic [88-92] differentiation of stem cells. Interestingly, in vitro studies comparing different oxygen tensions, revealed distinct cell responses. For instance, human tendon-derived stem cells cultured in 2D monolayers under low oxygen tension (2\%-5\%) exhibited higher 
proliferation and increased number of colonies in comparison with cells maintained under normoxia (20-21\% oxygen) [82-84]. The multilineage differentiation capability of this cell population seemed to be influenced by a myriad of oxygen concentrations $(20 \%, 10 \%, 5 \%$, $2 \%, 0.5 \%)$ both in vitro and in vivo [82-84]. Indeed, when expanded in vitro at $5 \% \mathrm{O}_{2}$ and afterwards implanted in vivo using an engineered tendon matrix, cells expressed osteogenic-, adipogenic- and chondrogenic- markers, such as osteocalcin, adiponectin, collagen type II, respectively, even though in lower levels compared to cells maintained at $20 \% \mathrm{O}_{2}$ prior in vivo implantation (control) [82]. Interestingly, these cells were found to be more prone to express tenogenic-markers, such as collagen type I, than the correspondent controls [82]. In contrast, this phenotypic commitment seemed to be inhibited in in vitro cultures maintained under lower oxygen concentrations $\left(0.5-2 \% \mathrm{O}_{2}\right)[83,84]$.

Moreover, the influence of hypoxia in an indirect co-culture using tenocytes and ASCs was also studied to get deeper in the potential effect of oxygen concentration and paracrine factors on tenogenic differentiation of ASCs [93]. The expression of hypoxia-inducible factor-1 alpha (HIF-1 $\alpha$ ) was analyzed and, under hypoxic conditions, it seemed to play an important role in the differentiation of ASCs toward the tenogenic phenotype. Indeed, after HIF-1 $\alpha$ inhibition, gene expression of collagen type I and III, tenomodulin, thrombospondin-4 and scleraxis, relevant tenogenic markers, was significantly inhibited in comparison with the control group, suggesting a potential role of HIF-1 $\alpha$ on ASCs tenogenic differentiation under hypoxia [93]. Similarly, low oxygen tensions $(1,3,5$, and $10 \% \mathrm{O}_{2}$ concentration) seemed to have a negative effect on the osteogenic differentiation of human stem cells, given that a reduction in the expression of osteogenic-related markers, such as $R U N X 2$, matrix mineralization and ALP activity has been described [89,94-96]. Likewise, at $2 \% \quad \mathrm{O}_{2}$ concentration, murine ASCs exhibited decreased chondrogenic and osteogenic potential, in comparison with cells cultured under normoxia [97]. Intringuingly, some reports in the literature have shown an enhancement of osteogenic differentiation of human and rat BMSCs under hypoxic conditions ( $1 \%$ and $5 \%$ ). In both cases, low oxygen concentrations influenced BMSCs migration, enhancing cell attachment and survival, accompanied by increased cell proliferation, matrix mineralization, enhanced calcium content and ALP activity $[98,99]$. Aditionally, at gene 
level, human BMSCs expressed higher levels of osteocalcin and osteopontin, while, in constrast chrondogenic- (COMP and aggrecan) and adipogenic-related (adipsin, FASN) markers levels were significantly reduced [98]. Collectively, the lack of standardized cell isolation methods, experimental parameters, stem cells source and different oxygen concentrations contribute to the challenge inherent to the determination of the role of oxygen in stem cells differentiation.

Notwithstanding, an interesting phenomenon was the influence of $2 \mathrm{D}$ and $3 \mathrm{D}$ cultures under hypoxic condition observed in human ASCs. In the presence of $1 \%-5 \% \mathrm{O}_{2}$ tension, ASCs presented a downregulation in the expression of osteogenic markers (ALP activity, mineralization and gene expression of $R U N X 2$, collagen type 1, alpha chain 1 (COL1A1) and bone gamma-carboxyglutamate [gla] protein or osteocalcin (Bglap)) in both 2D and 3D cultures, even though osteogenic differentiation in 2D was clearly more enhanced in comparison with 3D cultures [91]. However, differences in the osteogenic markers revealed a temporal change under different oxygen conditions. The expression of collagen type I was higher under $21 \%$ oxygen environment in $3 \mathrm{D}$ cultures than in $2 \mathrm{D}$, increasing up to week 2 , but even though $5 \%$ and $1 \%$ displayed lower expression levels, at each time point the expression was similar to that observed in 2D [91]. Moreover, in contrast with TDSCs, ASCs showed an independent HIF-1 $\alpha$ inhibition of osteogenic differentiation, observed by a downregulation of osteogenic markers in both $1 \%$ and $2 \%$ oxygen in $2 \mathrm{D}$ and 3D cultures [100].

Therefore, oxygen variations in the culture environment seem to play an important role in stem cell fate. Hence, it is of major importance to have in mind the gradual heterotypic cellular environment that is found in tendon-to-bone interface. Future approaches should not only focus on the individual oxygen concentration found in tendon and bone but come up with a balanced concentration to support the tenogenic, chondrogenic and osteogenic phenotypes when trying to generate or regenerate this graded tissue. 


\subsection{Growth factors}

Growth factors also play an important role in the repair and development of a functional tissue as regulators of cell differentiation, proliferation and matrix deposition [101]. Interestingly, during tendon-to-bone healing process, a temporal expression of several growth factors seems to occur, as reported by different enthesis repair in vivo studies (Table 2). Therefore, the best time for growth factors delivery must be studied since it can potentiate the effectiveness of future treatments. Moreover, the correct combination of growth factors or the most effective growth factor must also be determined.

In a first approach, several in vitro studies have been focusing on the optimization of cell culture medium supplementation. Bone morphogenetic protein (BMP)-2 [102], BMP-7 $[103,104]$ and transforming growth factor (TGF)- $\beta 3$ [105] are some examples of relevant growth factors used for medium supplementation that affect cell behavior in vitro. Supplementation with BMP-7 was tested in a co-culture model of murine osteoblasts and fibroblasts cell lines; agarose dividers were used for two days and BMP-7 added at three different concentrations $(100,250$ or $500 \mathrm{ng} / \mathrm{mL}$ ) [104]. BMP-7 supplementation resulted in a suppression of Spp1 (osteopontin) expression at the osteoblast region, while upregulating alkaline phosphatase $(A L P L)$ and COL1A1, as well as, BGLAP and RUNX2 at the interface region; on the fibroblast region, Alpl, Bglap and Runx2 were highly expressed [104]. Interestingly, the presence of BMP-7 seemed to influence Col1A1 expression in all the regions, suggesting a possible increase in ECM formation and maturation [104]. In a similar study, Thomopoulos et al. [105] reported the importance of growth factor supplementation using tensile cyclic and compressive stresses for rat MSC differentiation in the presence and absence of TGF- $\beta 3$. Actually, it was clearly observed that Sox 9 and aggrecan were only expressed by cells maintained with medium supplemented with TGF$\beta 3$, in constrast with cells only maintaned under influence of tensile and compressive stress [105]. Indeed, medium supplementation seems to play an important role in cell behavior. Thus, it is imperative to study the possible synergistic effects that may occur between mechanical cues and biochemical factors in tendon-to-bone healing. 
Another important challenge that must be overcome is the study and development of sustained-release vehicles for growth factor delivery. An interesting approach for a continuous and stable release of growth factors was introduced by gene therapy based on stem cells. This genetic intervention has shown promising results in comparison with the direct administration of growth factors to promote tendon-to-bone healing. Autologous MSCs transfected with platelet-derived growth factor-B (PDGF-B) [106], BMP-2 [107-109], TGF- $\beta$ [110] and the combination of two different growth factors [111] genes have been reported in the literature for tendon-to-bone healing. Even though, transfected stem cells secrete several growth factors in a steadily and continuous way, a decrease of the growth factor with time may lead to a loss of the primary objective after several weeks. Moreover, in vivo application involves delivering the vector directly into the cells of the tissue, which can lead to uncontrollable side effects, such as mutagenesis or development of malignancy $[112,113]$. Instead, the use of biomaterials has been alternatively exploited for the controlled delivery of growth factors envisioning tendon-to-bone healing. Most of the reported literature is focused on in vivo studies to assess the influence of growth factors during different stages of tendon-to-bone healing. These studies use different gels, cements and glues for the local delivery of growth factors. Such systems overcome several limitations associated to bolus injections of growth factors, including rapid leakage, short half-life of soluble factors, denaturation, injection risks and the use of supraphysiological dosages. However, for example, rotator cuff surgeries are performed by arthroscopic surgery, therefore involving the placement trough cannulas, making the previous vehicles less appropriate and desired in comparison with scaffolds and patches. Diverse animal injury and repair models have been developed and overall, the presence of growth factors appear to increase the cellularity and tissue quality at the injury site. Table 3 summarizes the major outcomes obtained in these studies.

More recently, blood derivatives have been receiving increased attention as cost-effective sources of human therapeutic factors that can be used in both autologous and allogeneic applications in regenerative medicine [114]. There is a wide range of platelet containing products with different biological characteristics, including platelet-rich plasma (PRP), platelet poor plasma (PPP), platelet lysate (PL) $[115,116]$. The use of such blood 

form of soluble preparations or gels. Table 4 summarizes the major outcomes of in vivo studies applying PRP preparations to enthesis healing models. In general, studies on PRP administration demonstrate conflicting results with some studies presenting improved tissue healing through enhanced cellular response and mechanical performance, while others report no differences in tissue healing response. Furthermore, clinical reports have demonstrated conflicting outcomes, including mid-term positive outcomes upon rotator cuff tendinopathy treatment using multiple PRP injections, but no differences in tissue integrity [117] or on re-tear rate [118]. Although contradictory results have been frequently found, the use of blood derivatives other than PRP in in vitro settings has been gaining attention to modulate cell behaviour, particularly for tendon tissue engineering (TTE). Indeed, PL can be a more stable alternative since it shows a comparatively lower batch-to-batch variability in batches prepared from platelet concentrates of different donors [119], potentially resulting in more predicatable clinical outcomes. Although no studies exist concerning the application of $\mathrm{PL}$ preparations for enthesis repair, PL membranes have been reported to result in an up-regulation of tenogenic genes and deposition of tendon-related ECM proteins by hTDCs [120]. Furthermore, nanocomposite hydrogels based on PL have been reported to modulate the behavior of ASCs according to nanofillers content [121], suggesting prospective applications for the development of gradient tissue engineered constructs in vitro.

Overall, studies have shown that several growth factors have the ability to increase the "quality" of repaired tissues in animal models. Given the complexity of tendon-to-bone interface, tissue repair is most probably orchestrated by a multitude of growth factors released in a temporally and spatially controlled manner. Hence, it has become clear that the application of multiple growth factors may be needed to regenerate the insertion site between tendon and bone. However, parameters such as optimal delivery time and vehicle are not effective. Although the use of growth factor gradients is being explored for providing adequate biochemical cues [12], this strategy can only be explored in combination with adequate cells and biomaterials, limiting their application in vivo. 
Even though, growth factor therapy remains an important therapeutic for tendon-to-bone healing and regeneration and needs to be further exploited in light of the discussed current limitations.

\section{Two- or three-dimensional (2D/3D): a biomaterials approach}

In vitro 2D culture systems are an oversimplified version of the human physiological conditions [158]. Indeed, shifting from 2D to 3D has a significant impact on cell proliferation, differentiation, survival and mechanical response. Novel 3D cell culture approaches were developed to mimic as close as possible the in vivo complex interactions of tissues and organs, opening new possibilities to study both biochemical and biomechanical signals [159]. Particularly, interfacial tissue engineering has put efforts to develop structures that mimic the anisotropic structural properties observed in interface tissues, such as the one found in tendon-to-bone interface. Therefore, biomimetic scaffolds with graded morphology/architecture, topography and composition are useful, especially when physical and chemical factors affect the fate of cultured cells in 3D scaffolds in a spatially orchestrated manner. interfacial tissue engineering is going beyond the production of multi-phasic scaffolds with the fabrication of graded biomaterials, capable of mimicking the gradual transition of interface tissues while supporting both heterotypic and homeotypic cell-cell interactions and cell-matrix integration. Common approaches include the fabrication of aligned nanofibers scaffolds with the incorporation of mineral gradients [160-163], scaffolds with gradations in fiber organization [163-165], bi- and tri-phasic scaffolds $[68,71,166,167]$ and graded hydrogels $[56,168,169]$.

\subsection{D nanofiber-based materials}

Conventional eletrospinning process has evolved during the last years. Even though there is a pressing need for the development of 3D structures, approaches using $2 \mathrm{D}$ environment have demonstrated to be useful in mimicking the nanostructure and composition of tendon-to-bone junction. One interesting approach for 2D nanofibers was developed applying a 2-spinnerette device to create a nonwoven mat of PCL nanofibers containing a gradient of amorphous calcium phosphate nanoparticles (nACP). Here, increasing nACP concentration resulted in increased proliferation of MC3T3-E1 murine pre-osteoblasts 
along the gradient, which suggested that the presence of nACP potentiated the adhesion and proliferation of osteoblasts [160]. Similarly, a nonwoven mat of electrospun PCL nanofibers was developed and submersed in 10 times concentrated simulated body fluid (SBF) solution to create a calcium phosphate gradient, resulting in an increase of Young's modulus [161], mimicking the spatially graded mineral composition and mechanics of enthesis. Likewise, Liu et al. [162] developed aligned PLGA electrospun mats with a similar SBF mineral gradient and also demonstrated the ability to spatially control the differentiation of a single stem cell source. Indeed, ASCs exhibited increased ALP activity, as well as Runx2 and OCN expression, indicating that osteogenic differentiation of ASCs was attained along the increasing mineral concentration on the scaffold [162].

Supplementation with growth factors has also been used as a potential approach for tendon-to-bone regeneration. Interestingly, Perikamana et al. [59] focused on the spatially combinatory effect of a matrix-bound growth factor (platelet-derived growth factor, PDGF), matrix alignment and calcium deposition to mimic tendon-to-bone regeneration in an in vitro system. Briefly, random-aligned-random poly(lactic acid) (PLLA) nanofibers meshes were produced and PDGF immobilized using an asymmetrical polydopamine gradient. Using a precision syringe pump infusion method, the extremities of the nanofiber meshes were immersed in SBF solution creating a gradient of mineral deposition in both margins. After seeding of ASCs, higher adhesion, ALP activity and osteogenic gene levels were observed in the both ends of the nanofibers meshes in comparison with the middle region (unmineralized zone) which lacked mineral deposition [59]. However, no results were shown concerning the tenogenic commitment of ASCs when in contact with the middle part of the nanofiber mesh where the immobilization took place.

Understanding the development of the nano-scale structure of tendon-to-bone interface may provide novel insights for the improvement of repair strategies. However, even though, biological evidences have shown the possible use of nanofibers to induce a spatially controlled cell differentiation on eletrospun scaffolds, structures with 3D orientations mimicking the proper tissue are an upcoming topic in the fabrication of enthesis tissue engineered scaffolds. 


\subsection{D bio-instructive scaffolds}

Remarkably, a 3D scaffold for bone-ligament applications was developed by coating the random part of $\mathrm{PCL}$ nanofibers with $5 \mathrm{x}$ SBF on a "random-aligned-random" scaffold structure [170]. Using two spin cones eletrospinning design, non-aligned nanofibers were obtained, while the gap in between consisted mainly in aligned fibers, resulting in the generation of a transitional zone [170]. Higher ultimate tensile strength, tensile modulus and strain at break were observed in the aligned region in comparison with the random regions [170]. Scaffolds were then seeded with human BMSCs, which aligned following the direction of fibers alignment, with more spindle shaped cells at the aligned part and polygonal or round shaped cells in the random regions of the scaffold [170]. Moreover, through gene expression analysis, tendon-related markers (tenomodulin and mohawk) were found to be up-regulated in the aligned region in comparison with the random and mineralized regions, where bone-related markers (runx-2, osteocalcin and osteopontin) were highly expressed [170]. Therefore, both chemical and structural characteristics of the scaffold seemed to influence the phenotype of hBMSCs toward tenogenic and osteogenic lineages. Another approach to obtain a 3D cylindrical composite scaffold was developed using an eletrospinning set-up with a dual-drum collector [171]. Two spinnerets were used in a first approach to form a single transition zone, and a 3-spinnerets design was afterwards used to create two transition regions, while shields were placed in the dual drum to control the size of the transition regions [171]. The obtained 2D meshes of PCL and PLGA were cut into small pieces, rolled around a guide (20G needle) and withdran and bathed in 20\% polyethylene glycol diacrylate (PEGDA) solution and PEGDA/Irgacure 2959 solution, respectively; the needle was removed afterwards originating a 3D cylindrical composite scaffold [171]. Mechanical testing was perfomed for both 2D meshes and 3D scaffolds, showing that 3D cylindrical composites were more mechanically robust but failed due to the stress concentration on the aligned region of the scaffold while 2D meshes presented the opposite mechanical behviour [171]; however, the biological behavior of cells in contact with the 3D composites was not assessed in this study.

Multi-phasic scaffolds have been also improving on the gradual transition between different tissues to try to mimic, as close as possible, the three zones observed in enthesis. 
For example, Tellado et al. [166] fabricated biphasic silk fibroin scaffolds with anisotropic and isotropic porous alignment, by directional freezing and salt leaching, to mimic the gradient in collagen molecule alignment found in tendon-to-bone interface. Aligned porosity represented the tendon/ligament side, while random porosity was designed for the bone side [166]. Young's modulus varied along the construct and culture with hASCs clearly demonstrated the cytoskeleton organization according to pore alignment [166]. Moreover, changes in gene expression of tendon, enthesis and cartilage markers in the different regions of the scaffold were observed. In this regard, Sox9 was more expressed in the isotropic region of the scaffold and Scx in the anisotropic part, suggesting the potential gradual cell differentiation to the chondrogenic and tenogenic lineages along the scaffold [166].

Up to now, efforts have been concentrated on the developemnt of 3D scaffods which replicate either the multi-structural alignment of the interface, the spatially mineral distribution or mechanical stimulation to drive cells differentiation to the different lineages. However, the conjugation of all factors to create bio-intructive scaffolds would be of great matter as demonstrated by Caliari et al. [172] through the development of an osteotendinous biomaterial based on a collagen-GAG (CG) scaffold platform. Using freezedrying method a CG scaffold was created mimicking the gradients of mineralization with calcium phosphate and geometric anisotropy which allowed, within a unique 3D biomaterial, to control the spatially selective tenogenic and osteogenic stem cells differentiation [172] (Figure 5). Moreover, uniaxial tensile strain was also found to specifically guide along the scaffold the MSCs differentiation thoughout the osteotendinous lineages [172].

New material designs for tendon-to-bone regeneration are also focused on the use of hydrogel gradient systems. Hydrogels present tunable chemical and physical properties suitable for tailoring the 3D cellular microenvironment. Therefore, the generation of biochemical and physical gradients within a hydrogel has become an attractive tool to generate a graded tissue. The development of hydrogels with spatially controlled patterning of cells has been explored for co-culturing different cell types $[56,173]$. Hammoudi et al. [173] designed tissue-scalable oligo(polyethylene glycol)- 
fumarate:poly(ethylene glycol)-diacrylate hydrogel-based scaffold for long-term 3D coculture of primary tendon fibroblasts and BMSCs, showing their viability up to 2 weeks [173]. Additionally, hydrogels as magnetic-responsive materials have been also developed as a way to provide structures with the ability to modulate the biochemical, physical and mechanical properties of the surrounding tissues. For example, a magnetic-responsive hydrogel composed of methacrylated chondroitin sulfate (MA-CS) enriched with plateletlysate $(\mathrm{PL})$ was developed to encapsulate osteogenically differentiated human adiposederived stem cells (O-ASC) or hTDCs within distinct hydrogel compartments [56]. Swelling, degradation and release of growth factors were modulated by the application of an external magnetic field (EMF), showing impact on both cell morphology and the expression of tendon- (decorin) and bone-related (osteopontin) genes in the different sections of the hydrogel after EMF application [56].

Textile techniques have been also used to produce more complex 3D structures. Knitting and braiding are some examples of textile assembly that have been applied to produce scaffolds and showed great similarity with, for example, tendons considering its architectural features, mechanical properties, and biological functionality $[174,175]$. Interestingly, these techniques have been used to produce knitted silk scaffolds for ACL regeneration [176-178]. However, these scaffolds were still unable to be competent and did not complety reproduce the structural integrity and functionality of the proper tissue.

Current advances in the development of 3D biomaterials with a combination of compositional, architectural and topographical properties allow the control over cell behavior without the need for external supplementation in all dimensions. Collectively, it is evident that scaffold topographies and composition influence both the morphology and differentiation capability of cells. However, several features still need to be optimized and further research of in vitro and in vivo effects on cell behavior could generate new insights to achieve a perfectely functional regenerated tissue. Nonetheless, the complexity of tendon-to-bone insertion, as well as of other musculoskeletal interfaces, requires the coordination between such systems and more complex and controllable factors, including oxygen concentration and biochemical factors, as discussed above. 


\section{Static or dynamic? The role of mechanical stimulation}

There is still limited knowledge on the material properties of tendon-to-bone interface and the specific demands to achieve its full repair and regeneration. During developmental stage, biophysical cues influence the development of tendon, bone and cartilage [179183]. First evidences were described in cortical bone with numerous studies demonstrating the importance of stress environment on the architecture of trabecular bone and thickness of cortical bone [184,185]. Similarly, a comparable responsiveness was demonstrated on tendon, where the total removal of load led to structural and compositional changes and a fast deterioration of tendon strength [186]. Indeed, all cells found along tendon-to-bone interface are known to be mechanoresponsive, thus mechanobiology is expected to play an important role in the development and healing of this tissue interface. Several studies have shown the importance of mechanical loading in the development of enthesis in murine models. In a study by Galatz et al. [187], the effect of the mechanical environment was evaluated by paralyzing the supraspinatus muscle in a rat model of rotator cuff injury and repair. The complete removal of load and immobilization clearly had a detrimental effect on rotator cuff healing, in comparison with rats with free range of motion, in which structural properties increased and modest improvements in biomechanical properties were observed [187]. The role of muscular loading in the development of tendon-to-bone interface has been described using a murine shoulder model $[188,189]$. Intramuscular injections of botulinum toxin A or laceration were used to paralyze rotator cuff muscles in postnatal mice and salineinjections were used as controls $[188,189]$. Diminished muscle loading led to a reduction in mineral deposition and deficient fibrocartilage formation, with disorganized fiber distribution and inferior tendon mechanical properties at the enthesis $[188,189]$. In the absence of mechanical loading, a decrease in bone volume and a change in bone architecture were also noticed $[188,189]$. Interestingly, the effect of muscle loading did not seem to be necessary for initiating enthesis development; however, the signal from tendons has an important effect, whereas mechanical loading has an impact on growth and maturation of enthesis [188-192]. Hence, it is evident that mechanical loading contributes to a gradation in structure and cellular environment, which for itself will turn 
to a gradation in mechanical properties along the enthesis, enabling an efficient load transfer and reduced stress concentration [10,193].

Normally, interfacial tissue engineered strategies are based on dynamic cultures to better mimic the human physiology in an organ-specific context. For this purpose, bioreactors have been designed to spatially control biomechanical and physical signals to guide cell proliferation, differentiation and, ultimately, tissue formation [194-198], with the application of uniaxial tensile loads and dynamic compressive loading to emulate tendon and bone mechanophysiology, respectively. Using this concept, MSCs have been differentiated in several scaffolds under the influence of different biomechanical stimuli provided in bioreactors [199-202]. Several strategies have focused on the use of diffusingbased bioreactors to co-differentiate cells along a unique platform creating an interface $[197,203,204]$, but, no studies are still available with the use of these dynamic plataforms for tendon-to-bone interface. Instead, static cell cultures are commonly used to study the developmental stage and mechanical loading influence on tendon-to-bone development and healing is often disregarded. Therefore, the development of bioreactors for enthesis engineering is a major need, due to the advantageous application of such dynamic systems to create a graded interface along a single unit while controlling the environment, presenting some advantageous characteristics over the currently used in vitro cultures. Finer spatial control should also be focused to enhance knowledge on the effect of several chemical stimulus and, therefore, improving local cellular modulation and control.

\section{Clinical translation}

Clinical translation of in vivo results is still a very slow process even though there is growing evidence of the benefits of cell-based therapies in tendon-to-bone healing. Few victories have been also observed in the clinics using scaffolds for human enthesis repair. Many preclinical devices, such as interpositional grafting [205] and rotator cuff augmentation $[206,207]$, have failed to restore the normal function of the tissue due to inadequate mechanical forces and structural properties of the grafts. Moreover, variations between small and larger tears in some follow up studies makes comparisons impossible $[208,209]$. Nevertheless, commercial scaffolds have focused on tendon/ligament repair for 
rotator cuff and $A C L$ augmentation, not properly restoring the interface. For example, porcine small-intestinal submucosa (SIS) patches such as Restore ${ }^{\mathrm{TM}}$ SIS (DePuy Orthopedics, West Chester, PA, USA) were implanted in 62 patients with rotator cuff tear characteristics [210]. An evaluation after 1 year did not reveal significant differences in strength and motion between patients treated with SIS and non-treated groups [210]. Similarly, lannotti et al. [211] tested Restore ${ }^{\mathrm{TM}}$ SIS in human rotator cuff repair and found inferior tendon healing accompanied of increasing pain, thus not recommending the use of these patches for augmentating massive chronic rotator cuff tears [211]. Contrarily, GraftJacket (Wright Medical Arlington, TN, USA), made from a human cadaveric dermis ECM scaffold, demonstrated significant improvements in pain scores, forward flexion, external rotation strength with full incorporation of the graft as observed by Bond et al. [51] and Burkhead et al. [212]. But, overall these technologies fail when mechanical properties are tested, suggesting limited mechanical performance of existing biological scaffolds for rotator cuff augmentation.

Interestingly, few clinical studies investigated the use of stem cells in enthesis healing or regeneration. However, once more studies focused solely on tendon/ligament repair when targeting interface regeneration and functional recovery. For example, Hernigou et al. [213] evaluated the efficiency of biological augmentation of rotator cuff repair with iliac MSCs in forty-five patients for a period of 10 years and a significant improvement of tendon integrity with lower levels of re-tear was observed while using concentrates containing MSCs. More recently, in a cohort study, among 182 patients treated through arthroscopic surgery for a rotator cuff tear, 35 received an injection of ASCs loaded in fibrin glue [214]. In contrast to the previous study, no differences were found between the conventional repaired group and the injection group with respect to the internal rotation at the back and the functional measures of the constant score and final follow-up [214]. Nonetheless, a higher re-tear rate was observed in the conventional group in comparison with the injection group, even though no clinical differences were found in the follow-up [214].

Despite the promising results of these clinical therapies, achieving regeneration of tendonto-bone interface still remains in its infancy. Several basic challenges have to be overcome, 
including understading the differences in cellular responses between acute and chronic injuries along with the identification of the best strategies. Overall, current clinical outcomes support the need for more refined tissue engineering strategies that should integrate the complexity of this interface. Furthermore, the knowledge gap regarding the molecular characterization of resident cell populations, as mentioned above, has been limiting the understanding of cellular differentiation strategies and the evaluation of bioengineered strategies effectiveness. Hence, it is of utmost importance to investigate deeper the biology of these tissues toward establishing foundational expertise, aiming at moving today's research advances into tomorrow's regenerative therapies.

\section{Conclusions/ Future trends}

Despite biotechnological advances of tissue engineering, it is well-recognized that there is still a critical need to understand the development and healing of tendon-to-bone interface. Over the years, tissue engineers have been trying to replicate the complexity of different tissues by attempting to understand the signals involved in the initiation of regenerative processes. However, the field of tendon-to-bone biology is lagging far behind owing to the peculiarities of this multi-tissue transition. We highlighted that it is of major importance to understand the heterotypic cellular interactions occurring in the native tissues, particularly the role of cell-cell and cell-ECM contacts and production of paracrine factors, for the development of a functional tissue. Co-culture systems have been increasingly exploited as platforms to study bidirectional communication. Although disparities on selection of cell sources and culture conditions have been hampering the establishment of an optimal in vitro system, stem cells of mesenchymal origin have been gaining increasing attention for the generation of bioengineered strategies, overcoming main limitations of tissue-specific cell populations. In vitro studies using differentiated cells and stem cells have been opening new avenues toward understanding the crosstalk between distinct cell types in directing pro-regenerative responses, either by stem cell differentiation or through synergistic effects in promoting fibrocartilage-like phenotype. Furthermore, given the mechanical nature of tendon-to-bone interface, (bio)physical elements are postulated to be needed in combination with cellular therapies. Different signals can be considered, from mechanical loading to biomaterial properties. Biomaterial 
properties can be tuned through different fabrication strategies to emulate structural, architectural and topographical signals of native interfacial tissue. Nonetheless, the application of adequate mechanical signals requires refinement and efforts should be focused on understanding the mechanical interplay and its implications on biological functions toward the development of sophisticated platforms to support the development of functional and physiologically relevant tendon-to-bone tissue engineered constructs.

The establishment of relevant animal models for translation of novel treatments is also a need, as researchers, providers and regulatory agencies should come up with a standardized animal model. In this regard, the definition of optimal rehabilitation periods and/or sex determining role on healing as variables of tendon-to-bone healing is of major importance. Preclinical data is still a crucial step toward clinical translation. However, suitable strategies for tendon-to-bone healing and/or regeneration require not only the use of graded biomaterials but also the ideal combination of cells, growth factors and culture conditions. Nevertheless, simple and ease handling constructs need to be developed and integrate appropriate biophysical, biological and biochemical signals to promote tissue integration and regeneration. Still, regulatory constraints and cost considerations will always be a concern while developing the best tissue engineering strategies. Strikingly, issues concerning the developed technologies, such as feasible sterilization, tracking and storage need to be addressed and optimized for efficient translation. 


\section{Acknowledgements}

Authors thank the support from the European Union Framework Programme for Research and Innovation HORIZON2020 [TEAMING Grant agreement No 739572 - The Discoveries CTR]; FCT-Fundação para a Ciência e a Tecnologia for the PhD grant of IC [PD/BD/128088/2016]; the Project NORTE-01-0145-FEDER-000021:“Accelerating tissue engineering and personalized medicine discoveries by the integration of key enabling nanotechnologies, marine-derived biomaterials and stem cells", supported by Norte Portugal Regional Operational Programme (NORTE 2020), under the PORTUGAL 2020 Partnership Agreement, through the European Regional Development Fund (ERDF) and the ERC Consolidator grant of ME [ERC-2017-CoG-772817]. 


\section{References}

[1] A. Yamamoto, K. Takagishi, T. Osawa, T. Yanagawa, D. Nakajima, H. Shitara, T. Kobayashi, Prevalence and risk factors of a rotator cuff tear in the general population, J. Shoulder Elb. Surg. 19 (2010) 116-120. doi:10.1016/j.jse.2009.04.006.

[2] M. Benjamin, T. Kumai, S. Milz, B.M. Boszczyk, A.A. Boszczyk, J.R. Ralphs, The skeletal attachment of tendons-tendon 'entheses', Comp Biochem Physiol A Mol Integr Physiol. 133 (2002) 931-945. doi:10.1016/S1095-6433(02)00138-1.

[3] M. Benjamin, H. Toumi, J.R. Ralphs, G. Bydder, T.M. Best, S. Milz, Where tendons and ligaments meet bone: attachment sites ('entheses') in relation to exercise and/or mechanical load, J Anat. 208 (2006) 471-490. doi:10.1111/j.14697580.2006.00540.x.

[4] M. Benjamin, D. McGonagle, The anatomical basis for disease localisation in seronegative spondyloarthropathy at entheses and related sites, J. Anat. 199 (2001) 503-526. doi:10.1046/j.1469-7580.2001.19950503.x.

[5] A. Robertson, R.W. Nutton, J.F. Keating, Current trends in the use of tendon allografts in orthopaedic surgery, J Bone Jt. Surg Br. 88 (2006) 988-992. doi:10.1302/0301-620X.88B8.

[6] C.C. Kaeding, B. Aros, A. Pedroza, E. Pifel, A. Amendola, J.T. Andrish, W.R. Dunn, R.G. Marx, E.C. McCarty, R.D. Parker, R.W. Wright, K.P. Spindler, Allograft Versus Autograft Anterior Cruciate Ligament Reconstruction: Predictors of Failure From a MOON Prospective Longitudinal Cohort, Sports Health. 3 (2011) 73-81. doi:10.1177/1941738110386185.

[7] P.P. Lui, P. Zhang, K. Chan, L. Qin, Biology and augmentation of tendon-bone insertion repair, J. Orthop. Surg. Res. 5 (2010). doi:10.1186/1749-799X-5-59.

[8] S. Thomopoulos, Tendon to Bone Healing: Differences in Biomechanical, Structural, and Compositional Properties Due to a Range of Activity Levels, J. Biomech. Eng. 125 (2003) 106. doi:10.1115/1.1536660. 
[9] E.D. Bonnevie, R.L. Mauck, Physiology and Engineering of the Graded Interfaces of Musculoskeletal Junctions, Annu. Rev. Biomed. Eng. 20 (2018) 403-429. doi:10.1146/annurev-bioeng-062117-121113.

[10] H.H. Lu, S. Thomopoulos, Functional attachment of soft tissues to bone: development, healing, and tissue engineering., Annu. Rev. Biomed. Eng. 15 (2013) 201-26. doi:10.1146/annurev-bioeng-071910-124656.

[11] E. Zelzer, E. Blitz, M.L. Killian, S. Thomopoulos, Tendon-to-bone attachment: from development to maturity, Birth Defects Res C Embryo Today. 102 (2014) 101-112. doi:10.1002/bdrc.21056.

[12] S. Tellado, E.R. Balmayor, M. Van Griensven, Strategies to engineer tendon/ligament-to-bone interface: Biomaterials, cells and growth factors, Adv Drug Deliv Rev. 94 (2015) 126-140. doi:10.1016/j.addr.2015.03.004.

[13] L. Smith, Y. Xia, L.M. Galatz, G.M. Genin, S. Thomopoulos, Tissue-engineering strategies for the tendon/ligament-to-bone insertion, Connect Tissue Res. 53 (2012) 95-105. doi:10.3109/03008207.2011.650804.

[14] N. Lee, J. Robinson, H. Lu, Biomimetic strategies for engineering composite tissues, Curr. Opin. Biotechnol. 40 (2016) 64-74. doi:10.1016/j.copbio.2016.03.006.

[15] L.A. Kuntz, L. Rossetti, E. Kunold, A. Schmitt, R. von Eisenhart-Rothe, A.R. Bausch, R.H. Burgkart, Biomarkers for tissue engineering of the tendon-bone interface, PLoS One. 13 (2018) 1-24. doi:10.1371/journal.pone.0189668.

[16] L. Rossetti, L.A. Kuntz, E. Kunold, J. Schock, K.W. Müller, H. Grabmayr, J. StolbergStolberg, F. Pfeiffer, S.A. Sieber, R. Burgkart, A.R. Bausch, The microstructure and micromechanics of the tendon-bone insertion, Nat. Mater. 16 (2017) 664-670. doi:10.1038/nmat4863. 
[17] L. Galatz, S. Rothermich, K. VanderPloeg, B. Petersen, L. Sandell, S. Thomopoulos, Development of the supraspinatus tendon-to-bone insertion: localized expression of extracellular matrix and growth factor genes, J Orthop Res. 25 (2007) 1621-1628. doi:10.1002/jor.20441.

[18] S. Thomopoulos, J.P. Marquez, B. Weinberger, V. Birman, G.M. Genin, Collagen fiber orientation at the tendon to bone insertion and its influence on stress concentrations, J. Biomech. 39 (2006) 1842-1851. doi:10.1016/j.jbiomech.2005.05.021.

[19] G.M. Genin, A. Kent, V. Birman, B. Wopenka, J.D. Pasteris, P.J. Marquez, S. Thomopoulos, Functional grading of mineral and collagen in the attachment of tendon to bone, Biophys J. 97 (2009) 976-985. doi:10.1016/j.bpj.2009.05.043.

[20] Y. Liu, S. Thomopoulos, C. Chen, V. Birman, M.J. Buehler, G.M. Genin, Modelling the mechanics of partially mineralized collagen fibrils, fibres and tissue, J. R. Soc. Interface. 11 (2014). doi:10.1098/rsif.2013.0835.

[21] H.M. Shaw, R.M. Santer, A.H.D. Watson, M. Benjamin, Adipose tissue at entheses: The innervation and cell composition of the retromalleolar fat pad associated with the rat Achilles tendon, J. Anat. 211 (2007) 436-443. doi:10.1111/j.14697580.2007.00791.x.

[22] W.E.B. Johnson, B. Caterson, S.M. Eisenstein, S. Roberts, Human intervertebral disc aggrecan inhibits endothelial cell adhesion and cell migration in vitro, Arthritis Rheum. 46 (2002) 2658-2664. doi:10.1002/art.10585.

[23] M. Benjamin, H. Toumi, D. Suzuki, S. Redman, P. Emery, D. McGonagle, Microdamage and altered vascularity at the enthesis-bone interface provides an anatomic explanation for bone involvement in the HLA-B27-associated spondylarthritides and allied disorders, Arthritis Rheum. 56 (2007) 224-233. doi:10.1002/art.22290.

[24] A. Rufai, J.R. Ralphs, M. Benjamin, Ultrastructure of fibrocartilages at the insertion of the rat Achilles tendon., J. Anat. 189: Part (1996) 185-91. 
[25] P. Theobald, G. Bydder, C. Dent, L. Nokes, N. Pugh, M. Benjamin, The functional anatomy of Kager's fat pad in relation to retrocalcaneal problems and other hindfoot disorders, J. Anat. 208 (2006) 91-97. doi:10.1111/j.14697580.2006.00510.x.

[26] J.J. Canoso, N. Liu, M.R. Traill, V.M. Runge, Physiology of the retrocalcaneal bursa, Ann. Rheum. Dis. 47 (1988) 910-912. doi:10.1136/ard.47.11.910.

[27] D.G.M. Coppens, M.L. De Bruin, H.G.M. Leufkens, J. Hoekman, Global Regulatory Differences for Gene- and Cell-Based Therapies: Consequences and Implications for Patient Access and Therapeutic Innovation, Clin. Pharmacol. Ther. 103 (2018) 120127. doi:10.1002/cpt.894.

[28] N.W. Marion, J.J. Mao, Mesenchymal Stem Cells and Tissue Engineering, in: Methods Enzymol., Academic Press, 2006: pp. 339-361. doi:10.1016/S00766879(06)20016-8.

[29] T. Kanazawa, T. Soejima, K. Noguchi, K. Tabuchi, M. Noyama, K.-I. Nakamura, N. Shiba, Tendon-to-bone healing using autologous bone marrow-derived mesenchymal stem cells in ACL reconstruction without a tibial bone tunnel-A histological study-., Muscles. Ligaments Tendons J. 4 (2014) 201-6.

[30] H.W. Ouyang, J.C.H. Goh, E.H. Lee, Use of Bone Marrow Stromal Cells for Tendon Graft-to-Bone Healing, Am. J. Sports Med. 32 (2004) 321-327. doi:10.1177/0095399703258682.

[31] Y.-G. Li, J.-N. Wei, J. Lu, X.-T. Wu, G.-J. Teng, Labeling and tracing of bone marrow mesenchymal stem cells for tendon-to-bone tunnel healing, Knee Surgery, Sport. Traumatol. Arthrosc. 19 (2011) 2153-2158. doi:10.1007/s00167-011-1506-0.

[32] J. Zhang, T. Pan, H.J. Im, F.H. Fu, J.H.C. Wang, Differential properties of human ACL and MCL stem cells may be responsible for their differential healing capacity, BMC Med. 9 (2011) 68. doi:10.1186/1741-7015-9-68. 
[33] T. Matsumoto, S.M. Ingham, Y. Mifune, A. Osawa, A. Logar, A. Usas, R. Kuroda, M. Kurosaka, F.H. Fu, J. Huard, Isolation and Characterization of Human Anterior Cruciate Ligament-Derived Vascular Stem Cells, Stem Cells Dev. 21 (2012) 859-872. doi:10.1089/scd.2010.0528.

[34] Y. Mifune, T. Matsumoto, S. Ota, M. Nishimori, A. Usas, S. Kopf, R. Kuroda, M. Kurosaka, F.H. Fu, J. Huard, Therapeutic potential of anterior cruciate ligamentderived stem cells for anterior cruciate ligament reconstruction, Cell Transplant. 21 (2012) 1651-1665. doi:10.3727/096368912X647234.

[35] Y. Mifune, T. Matsumoto, K. Takayama, S. Terada, N. Sekiya, R. Kuroda, M. Kurosaka, F.H. Fu, J. Huard, Tendon graft revitalization using adult anterior cruciate ligament $(A C L)$-derived $C D 34+$ cell sheets for $A C L$ reconstruction, Biomaterials. 34 (2013) 5476-5487. doi:10.1016/j.biomaterials.2013.04.013.

[36] Y. Bi, D. Ehirchiou, T.M. Kilts, C.A. Inkson, M.C. Embree, W. Sonoyama, L. Li, A.I. Leet, B.-M. Seo, L. Zhang, S. Shi, M.F. Young, Identification of tendon stem/progenitor cells and the role of the extracellular matrix in their niche, Nat. Med. 13 (2007) 1219-1227. doi:10.1038/nm1630.

[37] W. Shen, J. Chen, Z. Yin, X. Chen, H. Liu, B.C. Heng, W. Chen, H.-W. Ouyang, Allogenous Tendon Stem/Progenitor Cells in Silk Scaffold for Functional Shoulder Repair, Cell Transplant. 21 (2012) 943-958. doi:10.3727/096368911X627453.

[38] P.P.Y. Lui, O.T. Wong, Tendon stem cells: experimental and clinical perspectives in tendon and tendon-bone junction repair., Muscles. Ligaments Tendons J. 2 (2012) $163-8$.

[39] C.H. Chen, C.H. Chang, K.C. Wang, C.I. Su, H.T. Liu, C.M. Yu, C.B. Wong, I.C. Wang, S.W. Whu, H.W. Liu, Enhancement of rotator cuff tendon-bone healing with injectable periosteum progenitor cells-BMP-2 hydrogel in vivo, Knee Surgery, Sport. Traumatol. Arthrosc. 19 (2011) 1597-1607. doi:10.1007/s00167-010-1373-0. 
[40] C.-H. Chang, C.-H. Chen, H.-W. Liu, S.-W. Whu, S.-H. Chen, C.-L. Tsai, G.-H. Hsiue, Bioengineered Periosteal Progenitor Cell Sheets to Enhance Tendon-Bone Healing in A Bone Tunnel, Biomed. J. 35 (2012) 473. doi:10.4103/2319-4170.104412.

[41] Y.-J. Ju, T. Muneta, H. Yoshimura, H. Koga, I. Sekiya, Synovial mesenchymal stem cells accelerate early remodeling of tendon-bone healing, Cell Tissue Res. 332 (2008) 469-478. doi:10.1007/s00441-008-0610-z.

[42] C. Ferretti, V. Borsari, M. Falconi, A. Gigante, R. Lazzarini, M. Fini, R. Di Primio, M. Mattioli-Belmonte, Human Periosteum-Derived Stem Cells for Tissue Engineering Applications: The Role of VEGF, Stem Cell Rev. Reports. 8 (2012) 882-890. doi:10.1007/s12015-012-9374-7.

[43] Y.-S. Choi, S.-M. Lim, H.-C. Shin, C.-W. Lee, S.-L. Kim, D.-I. Kim, Chondrogenesis of human periosteum-derived progenitor cells in atelocollagen, Biotechnol. Lett. 29 (2007) 323-329. doi:10.1007/s10529-006-9240-2.

[44] S. Stich, A. Loch, S.-J. Park, T. Häupl, J. Ringe, M. Sittinger, Characterization of single cell derived cultures of periosteal progenitor cells to ensure the cell quality for clinical application, PLoS One. 12 (2017) 1-17. doi:10.1371/journal.pone.0178560.

[45] Y. Zhu, T. Liu, K. Song, X. Fan, X. Ma, Z. Cui, Adipose-derived stem cell: a better stem cell than BMSC, Cell Biochem Funct. 26 (2008) 664-675. doi:10.1002/cbf.1488.

[46] G. Yang, B.B. Rothrauff, H. Lin, R. Gottardi, P.G. Alexander, R.S. Tuan, Enhancement of tenogenic differentiation of human adipose stem cells by tendon-derived extracellular matrix, Biomaterials. 34 (2013) 9295-9306. doi:10.1016/j.biomaterials.2013.08.054.

[47] R. James, S.G. Kumbar, C.T. Laurencin, G. Balian, A.B. Chhabra, Tendon tissue engineering: adipose-derived stem cell and GDF-5 mediated regeneration using electrospun matrix systems, Biomed Mater. 6 (2011) 25011. doi:10.1088/1748$6041 / 6 / 2 / 025011$. 
[48] A.I. Gonçalves, P.M. Gershovich, M.T. Rodrigues, R.L. Reis, M.E. Gomes, Human adipose tissue-derived tenomodulin positive subpopulation of stem cells: A promising source of tendon progenitor cells, J. Tissue Eng. Regen. Med. 12 (2018) 762-774. doi:10.1002/term.2495.

[49] O. Jeon, J.W. Rhie, I.K. Kwon, J.H. Kim, B.S. Kim, S.H. Lee, In vivo bone formation following transplantation of human adipose-derived stromal cells that are not differentiated osteogenically, Tissue Eng Part A. 14 (2008) 1285-1294. doi:10.1089/ten.tea.2007.0253.

[50] C.M. Cowan, Y.-Y. Shi, O.O. Aalami, Y.-F. Chou, C. Mari, R. Thomas, N. Quarto, C.H. Contag, B. Wu, M.T. Longaker, Adipose-derived adult stromal cells heal critical-size mouse calvarial defects, Nat. Biotechnol. 22 (2004) 560. doi:10.1038/nbt958.

[51] Y.D. Halvorsen, D. Franklin, A.L. Bond, D.C. Hitt, C. Auchter, A.L. Boskey, E.P. Paschalis, W.O. Wilkison, J.M. Gimble, Extracellular matrix mineralization and osteoblast gene expression by human adipose tissue-derived stromal cells, Tissue Eng. 7 (2001) 729-741. doi:10.1089/107632701753337681.

[52] E.G. Popa, V.E. Santo, M.T. Rodrigues, M.E. Gomes, Magnetically-responsive hydrogels for modulation of chondrogenic commitment of human adipose-derived stem cells, Polymers (Basel). 8 (2016). doi:10.3390/polym8020028.

[53] H.A. Awad, M.Q. Wickham, H.A. Leddy, J.M. Gimble, F. Guilak, Chondrogenic differentiation of adipose-derived adult stem cells in agarose, alginate, and gelatin scaffolds, Biomaterials. 25 (2004) 3211-3222. doi:10.1016/j.biomaterials.2003.10.045.

[54] T. Rada, P.P. Carvalho, T.C. Santos, A.G. Castro, R.L. Reis, M.E. Gomes, Chondrogenic potential of two hASCs subpopulations loaded onto gellan gum hydrogel evaluated in a nude mice model., Curr. Stem Cell Res. Ther. 8 (2013) 357-64. doi:10.2174/1574888X113089990049. 
[55] R. McGoldrick, A. Chattopadhyay, C. Crowe, G. Chiou, K. Hui, S. Farnebo, C. Davis, A. Le Grand, M. Jacobs, H. Pham, J. Chang, The Tissue-Engineered Tendon-Bone Interface: In Vitro and In Vivo Synergistic Effects of Adipose-Derived Stem Cells, Platelet-Rich Plasma, and Extracellular Matrix Hydrogel, Plast Reconstr Surg. 140 (2017) 1169-1184. doi:10.1097/prs.0000000000003840.

[56] E.D. Silva, P.S. Babo, R. Costa-Almeida, R.M.A. Domingues, B.B. Mendes, E. Paz, P. Freitas, M.T. Rodrigues, P.L. Granja, M.E. Gomes, Multifunctional magneticresponsive hydrogels to engineer tendon-to-bone interface, Nanomedicine. (2017). doi:10.1016/j.nano.2017.06.002.

[57] H.K. Min, S.H. Oh, J.M. Lee, G.I. Im, J.H. Lee, Porous membrane with reverse gradients of PDGF-BB and BMP-2 for tendon-to-bone repair: in vitro evaluation on adipose-derived stem cell differentiation, Acta Biomater. 10 (2014) 1272-1279. doi:10.1016/j.actbio.2013.12.031.

[58] M. Kosaka, J. Nakase, K. Hayashi, H. Tsuchiya, Adipose-Derived Regenerative Cells Promote Tendon-Bone Healing in a Rabbit Model, Arthroscopy. 32 (2016) 851-859. doi:10.1016/j.arthro.2015.10.012.

[59] S.K.M. Perikamana, J. Lee, T. Ahmad, E.M. Kim, H. Byun, S. Lee, H. Shin, Harnessing biochemical and structural cues for tenogenic differentiation of adipose derived stem cells (ADSCs) and development of an in vitro tissue interface mimicking tendon-bone insertion graft, Biomaterials. 165 (2018) 79-93. doi:10.1016/j.biomaterials.2018.02.046.

[60] M.W.N. Wong, L. Qin, J.K.O. Tai, S.K.M. Lee, K.S. Leung, K.M. Chan, Engineered allogeneic chondrocyte pellet for reconstruction of fibrocartilage zone at bonetendon junction-A preliminary histological observation, J. Biomed. Mater. Res. Part B Appl. Biomater. 70B (2004) 362-367. doi:10.1002/jbm.b.30049. 
[61] G. Nourissat, A. Diop, N. Maurel, C. Salvat, S. Dumont, A. Pigenet, M. Gosset, X. Houard, F. Berenbaum, Mesenchymal Stem Cell Therapy Regenerates the Native Bone-Tendon Junction after Surgical Repair in a Degenerative Rat Model, PLoS One. 5 (2010) 1-11. doi:10.1371/journal.pone.0012248.

[62] N.K. Paschos, W.E. Brown, R. Eswaramoorthy, J.C. Hu, K.A. Athanasiou, Advances in tissue engineering through stem cell-based co-culture, J. Tissue Eng. Regen. Med. 9 (2015) 488-503. doi:10.1002/term.1870.

[63] R. Costa-Almeida, R. Soares, P.L. Granja, Fibroblasts as maestros orchestrating tissue regeneration, J. Tissue Eng. Regen. Med. 12 (2018) 240-251. doi:10.1002/term.2405.

[64] I.E. Wang, J. Shan, R. Choi, S. Oh, C.K. Kepler, F.H. Chen, H.H. Lu, Role of osteoblastfibroblast interactions in the formation of the ligament-to-bone interface, J Orthop Res. 25 (2007) 1609-1620. doi:10.1002/jor.20475.

[65] J.O. Cooper, J.D. Bumgardner, J.A. Cole, R.A. Smith, W.O. Haggard, Co-cultured tissue-specific scaffolds for tendon/bone interface engineering, J Tissue Eng. 5 (2014) 2041731414542294. doi:10.1177/2041731414542294.

[66] I.E. Wang, D.R. Bogdanowicz, S. Mitroo, J. Shan, S. Kala, H.H. Lu, Cellular Interactions Regulate Stem Cell Differentiation in Tri- Culture, Connect Tissue Res. 57 (2016) 476-487. doi:10.1080/03008207.2016.1230106.

[67] I. Calejo, R. Costa-almeida, A.I. Gonçalves, D. Berdecka, R.L. Reis, Bi-directional modulation of cellular interactions in an in vitro bone interface, (2018) 1-15. doi:10.1111/cpr.12493.

[68] J.P. Spalazzi, S.B. Doty, K.L. Moffat, W.N. Levine, H.H. Lu, Development of controlled matrix heterogeneity on a triphasic scaffold for orthopedic interface tissue engineering, Tissue Eng. 12 (2006) 3497-3508. doi:10.1089/ten.2006.12.3497. 
[69] J.P. Spalazzi, E. Dagher, S.B. Doty, X.E. Guo, S.A. Rodeo, H.H. Lu, In vivo evaluation of a multiphased scaffold designed for orthopaedic interface tissue engineering and soft tissue-to-bone integration, J. Biomed. Mater. Res. Part A. 86A (2008) 1-12. doi:10.1002/jbm.a.32073.

[70] P. He, K.S. Ng, S.L. Toh, J.C. Goh, In vitro ligament-bone interface regeneration using a trilineage coculture system on a hybrid silk scaffold, Biomacromolecules. 13 (2012) 2692-2703. doi:10.1021/bm300651q.

[71] G. Criscenti, A. Longoni, A. Di Luca, C. De Maria, C.A. van Blitterswijk, G. Vozzi, L. Moroni, Triphasic scaffolds for the regeneration of the bone-ligament interface, Biofabrication. 8 (2016) 15009. doi:10.1088/1758-5090/8/1/015009.

[72] I.M. Ahmed, M. Lagopoulos, P. McConnell, R.W. Soames, G.K. Sefton, Blood supply of the Achilles tendon, J Orthop Res. 16 (1998) 591-596. doi:10.1002/jor.1100160511.

[73] W. Petersen, V. Stein, B. Tillmann, Blood supply of the tibialis anterior tendon, Arch. Orthop. Trauma Surg. 119 (1999) 371-375. doi:10.1007/s004020050431.

[74] M.-H. Lafage-Proust, B. Roche, M. Langer, D. Cleret, A. Vanden Bossche, T. Olivier, L. Vico, Assessment of bone vascularization and its role in bone remodeling, Bonekey Rep. 4 (2015). doi:10.1038/bonekey.2015.29.

[75] P.M. Gross, D.D. Heistad, M.L. Marcus, Neurohumoral regulation of blood flow to bones and marrow, Am. J. Physiol. Circ. Physiol. 237 (1979) H440-H448. doi:10.1152/ajpheart.1979.237.4.H440.

[76] R.D. Ray, M. Kawabata, J. Galante, Experimental Study of Peripheral Circulation and Bone Growth: An Experimental Method for the Quantitative Determination of Bone Blood Flow PART III, Clin. Orthop. Relat. Res. 54 (1967).

[77] M. Marenzana, T.R. Arnett, The Key Role of the Blood Supply to Bone, Bone Res. 1 (2014) 203-215. doi:10.4248/br201303001. 
[78] R.S. Richardson, S. Duteil, C. Wary, D.W. Wray, J. Hoff, P.G. Carlier, Human skeletal muscle intracellular oxygenation: the impact of ambient oxygen availability, J. Physiol. 571 (2006) 415-424. doi:10.1113/jphysiol.2005.102327.

[79] T. Kiær, K.D. Kristensen, Intracompartmental pressure, Po2,Pco2and blood flow in the human skeletal muscle, Arch. Orthop. Trauma. Surg. 107 (1988) 114-116. doi:10.1007/BF00454498.

[80] K. Kubo, T. Ikebukuro, N. Tsunoda, H. Kanehisa, Changes in oxygen consumption of human muscle and tendon following repeat muscle contractions, Eur. J. Appl. Physiol. 104 (2008) 859. doi:10.1007/s00421-008-0841-4.

[81] R. Boushel, H. Langberg, J. Olesen, J. Gonzales-Alonzo, J. Bülow, M. Kjær, Monitoring tissue oxygen availability with near infrared spectroscopy (NIRS) in health and disease, Scand. J. Med. Sci. Sports. 11 (2001) 213-222. doi:10.1034/j.16000838.2001.110404.x.

[82] J. Zhang, J.H.C. Wang, Human Tendon Stem Cells Better Maintain Their Stemness in Hypoxic Culture Conditions, PLoS One. 8 (2013) e61424. doi:10.1371/journal.pone.0061424.

[83] Y. Yu, L. Lin, Y. Zhou, X. Lu, X. Shao, C. Lin, K. Yu, X. Zhang, J. Hong, Y. Chen, Effect of Hypoxia on Self-Renewal Capacity and Differentiation in Human Tendon-Derived Stem Cells, Med. Sci. Monit. 23 (2017) 1334-1339. doi:10.12659/MSM.903892.

[84] W.Y.W. Lee, P.P.Y. Lui, Y.F. Rui, Hypoxia-Mediated Efficient Expansion of Human Tendon-Derived Stem Cells In Vitro, Tissue Eng. Part A. 18 (2012) 484-498. doi:10.1089/ten.tea.2011.0130.

[85] T. Gómez-Leduc, M. Desancé, M. Hervieu, F. Legendre, D. Ollitrault, C. de Vienne, M. Herlicoviez, P. Galéra, M. Demoor, Hypoxia is a critical parameter for chondrogenic differentiation of human umbilical cord blood mesenchymal stem cells in type I/III collagen sponges, Int. J. Mol. Sci. 18 (2017) 1-23. doi:10.3390/ijms18091933. 
[86] F. Legendre, D. Ollitrault, T. Gomez-Leduc, M. Bouyoucef, M. Hervieu, N. Gruchy, F. Mallein-Gerin, S. Leclercq, M. Demoor, P. Galéra, Enhanced chondrogenesis of bone marrow-derived stem cells by using a combinatory cell therapy strategy with BMP2/TGF-B1, hypoxia, and COL1A1/HtrA1 siRNAs, Sci. Rep. 7 (2017) 1-16. doi:10.1038/s41598-017-03579-y.

[87] J. Shang, H. Liu, J. Li, Y. Zhou, Roles of Hypoxia During the Chondrogenic Differentiation of Mesenchymal Stem Cells, Curr. Stem Cell Res. Ther. 9 (2014) 141147. doi:10.2174/1574888X09666131230142459.

[88] E.J. Sheehy, C.T. Buckley, D.J. Kelly, Oxygen tension regulates the osteogenic, chondrogenic and endochondral phenotype of bone marrow derived mesenchymal stem cells, Biochem Biophys Res Commun. 417 (2012) 305-310. doi:10.1016/j.bbrc.2011.11.105.

[89] S. Hsu, C. Chen, Y. Wei, Inhibitory Effects of Hypoxia on Metabolic Switch and Osteogenic Differentiation of Human Mesenchymal Stem Cells, Stem Cells. 31 (2013) 2779-2788. doi:10.1002/stem.1441.

[90] E. Potier, E. Ferreira, R. Andriamanalijaona, J.-P. Pujol, K. Oudina, D. LogeartAvramoglou, H. Petite, Hypoxia affects mesenchymal stromal cell osteogenic differentiation and angiogenic factor expression, Bone. 40 (2007) 1078-1087. doi:10.1016/j.bone.2006.11.024.

[91] J. He, D.C. Genetos, C.E. Yellowley, J.K. Leach, Oxygen tension differentially influences osteogenic differentiation of human adipose stem cells in 2D and 3D cultures, J Cell Biochem. 110 (2010) 87-96. doi:10.1002/jcb.22514.

[92] S.S. Lin, S.W. Ueng, C.C. Niu, L.J. Yuan, C.Y. Yang, W.J. Chen, M.S. Lee, J.K. Chen, Effects of hyperbaric oxygen on the osteogenic differentiation of mesenchymal stem cells, BMC Musculoskelet Disord. 15 (2014) 56. doi:10.1186/1471-2474-15-56. 
[93] Y. Yu, Y. Zhou, T. Cheng, X. Lu, K. Yu, Y. Zhou, J. Hong, Y. Chen, Hypoxia enhances tenocyte differentiation of adipose-derived mesenchymal stem cells by inducing hypoxia-inducible factor-1alpha in a co-culture system, Cell Prolif. 49 (2016) 173184. doi:10.1111/cpr.12250.

[94] G. D'Ippolito, S. Diabira, G.A. Howard, B.A. Roos, P.C. Schiller, Low oxygen tension inhibits osteogenic differentiation and enhances stemness of human MIAMI cells, Bone. 39 (2006) 513-522. doi:10.1016/j.bone.2006.02.061.

[95] C. Merceron, C. Vinatier, P. Sophie, M. Martial, J. Amiaud, L. Guigand, Y. Chérel, W. Pierre, J. Guicheux, Differential effects of hypoxia on osteochondrogenic potential of human adipose-derived stem cells, Am. J. Physiol. Cell Physiol. 298 (2010) 355-364. doi:10.1152/ajpcell.00398.2009.

[96] A. Youssef, V.K.M. Han, Regulation of Osteogenic Differentiation of PlacentalDerived Mesenchymal Stem Cells by Insulin-Like Growth Factors and Low Oxygen Tension, Stem Cells Int. 2017 (2017) 1-17. doi:10.1155/2017/4576327.

[97] P. Malladi, Y. Xu, M. Chiou, A.J. Giaccia, M.T. Longaker, Effect of reduced oxygen tension on chondrogenesis and osteogenesis in adipose-derived mesenchymal cells, Am. J. Physiol. Physiol. 290 (2006) C1139-C1146. doi:10.1152/ajpcell.00415.2005.

[98] S. Hung, J.H. Ho, Y. V Shih, T. Lo, O.K. Lee, Hypoxia promotes proliferation and osteogenic differentiation potentials of human mesenchymal stem cells, J. Orthop. Res. 30 (2012) 260-266. doi:10.1002/jor.21517.

[99] D.P. Lennon, J.M. Edmison, A.I. Caplan, Cultivation of rat marrow-derived mesenchymal stem cells in reduced oxygen tension: Effects on in vitro and in vivo osteochondrogenesis, J. Cell. Physiol. 187 (2001) 345-355. doi:10.1002/jcp.1081.

[100] S. Sahai, A. Williams, M.L. Skiles, J.O. Blanchette, Osteogenic Differentiation of Adipose-Derived Stem Cells Is Hypoxia-Inducible Factor-1 Independent, Tissue Eng. Part A. 19 (2013) 1583-1591. doi:10.1089/ten.tea.2012.0378. 
[101] I.H. Ali, D.P. Brazil, Bone morphogenetic proteins and their antagonists: current and emerging clinical uses, Br J Pharmacol. 171 (2014) 3620-3632. doi:10.1111/bph.12724.

[102] T. Schwarting, D. Schenk, M. Frink, M. Benölken, F. Steindor, M. Oswald, S. Ruchholtz, P. Lechler, Stimulation with bone morphogenetic protein-2 (BMP-2) enhances bone-tendon integration in vitro, Connect. Tissue Res. 57 (2016) 99-112. doi:10.3109/03008207.2015.1087516.

[103] T. Schwarting, P. Lechler, J. Struewer, M. Ambrock, T.M. Frangen, S. Ruchholtz, E. Ziring, M. Frink, Bone morphogenetic protein 7 (BMP-7) influences tendon-bone integration in vitro, PLoS One. 10 (2015) e0116833. doi:10.1371/journal.pone.0116833.

[104] T. Schwarting, M. Benolken, S. Ruchholtz, M. Frink, P. Lechler, Bone morphogenetic protein-7 enhances bone-tendon integration in a murine in vitro co-culture model, Int Orthop. 39 (2015) 799-805. doi:10.1007/s00264-015-2688-8.

[105] S. Thomopoulos, R. Das, V. Birman, L. Smith, K. Ku, E.L. Elson, K.M. Pryse, J.P. Marquez, G.M. Genin, Fibrocartilage tissue engineering: the role of the stress environment on cell morphology and matrix expression, Tissue Eng Part A. 17 (2011) 1039-1053. doi:10.1089/ten.TEA.2009.0499.

[106] F. Li, H. Jia, C. Yu, ACL reconstruction in a rabbit model using irradiated Achilles allograft seeded with mesenchymal stem cells or PDGF-B gene-transfected mesenchymal stem cells, Knee Surgery, Sport. Traumatol. Arthrosc. 15 (2007) 12191227. doi:10.1007/s00167-007-0385-x.

[107] Y. Dong, Q. Zhang, Y. Li, J. Jiang, S. Chen, Enhancement of tendon-bone healing for anterior cruciate ligament $(\mathrm{ACL})$ reconstruction using bone marrow-derived mesenchymal stem cells infected with BMP-2, Int. J. Mol. Sci. 13 (2012) 1360513620. doi:10.3390/ijms131013605. 
[108] V. Martinek, C. Latterman, A. Usas, S. Abramowitch, S.L.-Y. Woo, F.H. Fu, J. Huard, Enhancement of Tendon-Bone Integration of Anterior Cruciate Ligament Grafts with Bone Morphogenetic Protein-2 Gene Transfer, J. BONE Jt. Surg. 84 (2002) 11231131.

[109] S. Shahab-Osterloh, F. Witte, A. Hoffmann, A. Winkel, S. Laggies, B. Neumann, V. Seiffart, W. Lindenmaier, A.D. Gruber, J. Ringe, T. Häupl, F. Thorey, E. Willbold, P. Corbeau, G. Gross, Mesenchymal Stem Cell-Dependent Formation of Heterotopic Tendon-Bone Insertions (Osteotendinous Junctions), Stem Cells. 28 (2010) 15901601. doi:10.1002/stem.487.

[110] R. Wang, B. Xu, H.-G. Xu, Up-Regulation of TGF- $\beta$ Promotes Tendon-to-Bone Healing after Anterior Cruciate Ligament Reconstruction using Bone Marrow-Derived Mesenchymal Stem Cells through the TGF- $\beta$ /MAPK Signaling Pathway in a New Zealand White Rabbit Model, Cell. Physiol. Biochem. 41 (2017) 213-226. doi:10.1159/000456046.

[111] B. Chen, B. Li, Y.-J. Qi, Q.-B. Ni, Z.-Q. Pan, H. Wang, L.-B. Chen, Enhancement of tendon-to-bone healing after anterior cruciate ligament reconstruction using bone marrow-derived mesenchymal stem cells genetically modified with bFGF/BMP2, Sci. Rep. 6 (2016) 25940. doi:10.1038/srep25940.

[112] J. Kimmelman, The ethics of human gene transfer, Nat. Rev. Genet. 9 (2008) 239244. doi:10.1038/nrg2317.

[113] R.G. Crystal, Transfer of Genes to Humans: Early Lessons and Obstacles to Success, Science (80-. ). 270 (1995) 404-410. doi:10.1126/science.270.5235.404.

[114] E. Anitua, R. Prado, G. Orive, Allogeneic Platelet-Rich Plasma: At the Dawn of an Offthe-Shelf Therapy?, Trends Biotechnol. 35 (2017) 91-93. doi:0.1016/j.tibtech.2016.11.001. 
[115] D.M.D. Ehrenfest, L. Rasmusson, T. Albrektsson, Classification of platelet concentrates: from pure platelet-rich plasma (P-PRP) to leucocyte- and platelet-rich fibrin (L-PRF), Trends Biotechnol. 27 (2009) 158-167. doi:10.1016/j.tibtech.2008.11.009.

[116] B.B. Mendes, M. Gómez-Florit, P.S. Babo, R.M. Domingues, R.L. Reis, M.E. Gomes, Blood derivatives awaken in regenerative medicine strategies to modulate wound healing, Adv. Drug Deliv. Rev. 129 (2018) 376-393. doi:10.1016/j.addr.2017.12.018.

[117] J.R. Ebert, A. Wang, A. Smith, R. Nairn, W. Breidahl, M.H. Zheng, T. Ackland, A Midterm Evaluation of Postoperative Platelet-Rich Plasma Injections on Arthroscopic Supraspinatus Repair: A Randomized Controlled Trial, Am. J. Sports Med. 45 (2017) 2965-2974. doi:10.1177/0363546517719048.

[118] J. Yang, Y. Sun, P. Xu, B. Cheng, Can patients get better clinical outcomes by using PRP in rotator cuff repair: a meta-analysis of randomized controlled trials, J Sport. Med Phys Fit. 56 (2016) 1359-1367.

[119] R. Crespo-Diaz, A. Behfar, G.W. Butler, D.J. Padley, M.G. Sarr, J. Bartunek, A.B. Dietz, A. Terzic, Platelet Lysate Consisting of a Natural Repair Proteome Supports Human Mesenchymal Stem Cell Proliferation and Chromosomal Stability, Cell Transplant. 20 (2011) 797-812. doi:10.3727/096368910X543376.

[120] R. Costa-Almeida, A.R. Franco, T. Pesqueira, M.B. Oliveira, P.S. Babo, I.B. Leonor, J.F. Mano, R.L. Reis, M.E. Gomes, The effects of platelet lysate patches on the activity of tendon-derived cells, Acta Biomater. 68 (2018) 29-40. doi:10.1016/j.actbio.2018.01.006.

[121] B.B. Mendes, M. Gómez-Florit, R.A. Pires, R.M.A. Domingues, R.L. Reis, M.E. Gomes, Human-based fibrillar nanocomposite hydrogels as bioinstructive matrices to tune stem cell behavior, Nanoscale. (2018). doi:10.1039/C8NR04273J. 
[122] L.M. Galatz, L.J. Sandell, S.Y. Rothermich, R. Das, A. Mastny, N. Havlioglu, M.J. Silva, S. Thomopoulos, Characteristics of the rat supraspinatus tendon during tendon-tobone healing after acute injury, J. Orthop. Res. 24 (2010) 541-550. doi:10.1002/jor.20067.

[123] M. Kobayashi, E. Itoi, H. Minagawa, N. Miyakoshi, S. Takahashi, Y. Tuoheti, K. Okada, Y. Shimada, Expression of growth factors in the early phase of supraspinatus tendon healing in rabbits, J. Shoulder Elb. Surg. 15 (2006) 371-377. doi:10.1016/j.jse.2005.09.003.

[124] Y. Yu, J.P. Bliss, W.J.M. Bruce, W.R. Walsh, Bone Morphogenetic Proteins and Smad Expression in Ovine Tendon-Bone Healing, Arthrosc. J. Arthrosc. Relat. Surg. 23 (2007) 205-210. doi:https://doi.org/10.1016/j.arthro.2006.08.023.

[125] C.C. Würgler-Hauri, L.M. Dourte, T.C. Baradet, G.R. Williams, L.J. Soslowsky, Temporal expression of 8 growth factors in tendon-to-bone healing in a rat supraspinatus model, J. Shoulder Elb. Surg. 16 (2007) 198-203. doi:10.1016/j.jse.2007.04.003.

[126] T. Kohno, Y. Ishibashi, E. Tsuda, T. Kusumi, M. Tanaka, S. Toh, Immunohistochemical demonstration of growth factors at the tendon-bone interface in anterior cruciate ligament reconstruction using a rabbit model, J. Orthop. Sci. 12 (2007) 67-73. doi:https://doi.org/10.1007/s00776-006-1088-8.

[127] C.B. Ma, S. Kawamura, X.-H. Deng, L. Ying, J. Schneidkraut, P. Hays, S.A. Rodeo, Bone Morphogenetic Proteins-Signaling Plays a Role in Tendon-to-Bone Healing: A Study of rhBMP-2 and Noggin, Am. J. Sports Med. 35 (2007) 597-604. doi:10.1177/0363546506296312.

[128] Y. Hashimoto, G. Yoshida, H. Toyoda, K. Takaoka, Generation of tendon-to-bone interface "enthesis" with use of recombinant BMP-2 in a rabbit model, J. Orthop. Res. 25 (2007) 1415-1424. doi:10.1002/jor.20447. 
[129] H.J. Seeherman, J.M. Archambault, S.A. Rodeo, A.S. Turner, L. Zekas, D. D'Augusta, X.J. Li, E. Smith, J.M. Wozney, rhBMP-12 accelerates healing of rotator cuff repairs in a sheep model, J. Bone Jt. Surg. - Ser. A. 90 (2008) 2206-2219. doi:10.2106/JBJS.G.00742.

[130] J.G. Kim, H.J. Kim, S.E. Kim, J.H. Bae, Y.J. Ko, J.H. Park, Enhancement of tendon-bone healing with the use of bone morphogenetic protein-2 inserted into the suture anchor hole in a rabbit patellar tendon model, Cytotherapy. 16 (2014) 857-867. doi:https://doi.org/10.1016/j.jcyt.2013.12.012.

[131] S. Thomopoulos, H.M. Kim, M.J. Silva, E. Ntouvali, C.N. Manning, R. Potter, H. Seeherman, R.H. Gelberman, Effect of bone morphogenetic protein 2 on tendon-tobone healing in a canine flexor tendon model, J. Orthop. Res. 30 (2012) 1702-1709. doi:10.1002/jor.22151.

[132] K.W. Lee, J.S. Lee, Y.S. Kim, Y.B. Shim, J.W. Jang, K. II Lee, Effective healing of chronic rotator cuff injury using recombinant bone morphogenetic protein-2 coated dermal patch in vivo, J. Biomed. Mater. Res. - Part B Appl. Biomater. 105 (2017) 1840-1846. doi:10.1002/jbm.b.33716.

[133] Y. Hirakawa, T. Manaka, K. Orita, Y. Ito, K. Ichikawa, H. Nakamura, The accelerated effect of recombinant human bone morphogenetic protein 2 delivered by $\beta$ tricalcium phosphate on tendon-to-bone repair process in rabbit models, J. Shoulder Elb. Surg. (2018). doi:https://doi.org/10.1016/j.jse.2017.11.025.

[134] K. Yukichi, M. Toru, S. Tsuyoshi, K. Yoshikazu, O. Ryo, A. Yuji, S. Koshiro, M. Ken-Ichi, K. Mitsuhiro, T. Yasuhiko, F. Hiroyoshi, K. Toshikazu, Stimulation of Rotator Cuff Repair by Sustained Release of Bone Morphogenetic Protein-7 Using a Gelatin Hydrogel Sheet, Tissue Eng. Part A. 21 (2015) 2025-2033. doi:10.1089/ten.tea.2014.0541. 
[135] M. Rickert, M. Jung, M. Adiyaman, W. Richter, H.G. Simank, A Growth and Differentiation Factor-5 (GDF-5)-coated Suture Stimulates Tendon Healing in an Achilles Tendon Model in Rats, Growth Factors. 19 (2001) 115-126. doi:10.3109/08977190109001080.

[136] D.H. Murray, E.N. Kubiak, L.M. Jazrawi, A. Araghi, F. Kummer, M.I. Loebenberg, J.D. Zuckerman, The effect of cartilage-derived morphogenetic protein 2 on initial healing of a rotator cuff defect in a rat model, J. Shoulder Elb. Surg. 16 (2007) 251254. doi:10.1016/j.jse.2006.07.002.

[137] S. Yamazaki, K. Yasuda, F. Tomita, H. Tohyama, A. Minami, The effect of transforming growth factor- $\beta 1$ on intraosseous healing of flexor tendon autograft replacement of anterior cruciate ligament in dogs, Arthrosc. - J. Arthrosc. Relat. Surg. 21 (2005) 1034-1041. doi:10.1016/j.arthro.2005.05.011.

[138] H. Arimura, C. Shukunami, T. Tokunaga, T. Karasugi, N. Okamoto, T. Taniwaki, H. Sakamoto, H. Mizuta, Y. Hiraki, TGF- $\beta 1$ Improves Biomechanical Strength by Extracellular Matrix Accumulation Without Increasing the Number of Tenogenic Lineage Cells in a Rat Rotator Cuff Repair Model, Am. J. Sports Med. 45 (2017) 23942404. doi:10.1177/0363546517707940.

[139] J.P. Yoon, C.-H. Lee, J.W. Jung, H.-J. Lee, Y.-S. Lee, J.-Y. Kim, G.Y. Park, J.H. Choi, S.W. Chung, Sustained Delivery of Transforming Growth Factor $\beta 1$ by Use of Absorbable Alginate Scaffold Enhances Rotator Cuff Healing in a Rabbit Model, Am. J. Sports Med. 0 (n.d.) 0363546518757759 . doi:10.1177/0363546518757759.

[140] X. You, Y. Shen, W. Yu, Y. He, Enhancement of tendon-bone healing following rotator cuff repair using hydroxyapatite with TGFbeta1., Mol. Med. Rep. (2018) 4981-4988. doi:https://dx.doi.org/10.3892/mmr.2018.8499.

[141] C.N. Manning, H.M. Kim, S. Sakiyama-Elbert, L.M. Galatz, N. Havlioglu, S. Thomopoulos, Sustained delivery of transforming growth factor beta three enhances tendon-to-bone healing in a rat model, J. Orthop. Res. 29 (n.d.) 10991105. doi:10.1002/jor.21301. 
[142] H.M. Kim, L.M. Galatz, R. Das, N. Havlioglu, S.Y. Rothermich, S. Thomopoulos, The role of transforming growth factor beta isoforms in tendon-to-bone healing, Connect. Tissue Res. 52 (2011) 87-98. doi:10.3109/03008207.2010.483026.

[143] S. Zhao, J. Zhao, S. Dong, X. Huangfu, B. Li, H. Yang, J. Zhao, W. Cui, Biological augmentation of rotator cuff repair using bFGF-loaded electrospun poly(lactide-coglycolide) fbrous membranes, Int. J. Nanomedicine. 9 (2014) 2373-2385. doi:10.2147/IJN.S59536.

[144] J. Ide, K. Kikukawa, J. Hirose, K. ichi lyama, H. Sakamoto, T. Fujimoto, H. Mizuta, The effect of a local application of fibroblast growth factor-2 on tendon-to-bone remodeling in rats with acute injury and repair of the supraspinatus tendon, J. Shoulder Elb. Surg. 18 (2009) 391-398. doi:10.1016/j.jse.2009.01.013.

[145] T. Tokunaga, C. Shukunami, N. Okamoto, T. Taniwaki, K. Oka, H. Sakamoto, J. Ide, H. Mizuta, Y. Hiraki, FGF-2 Stimulates the Growth of Tenogenic Progenitor Cells to Facilitate the Generation of Tenomodulin-Positive Tenocytes in a Rat Rotator Cuff Healing Model, Am. J. Sports Med. 43 (2015) 2411-2422. doi:10.1177/0363546515597488.

[146] T. Tokunaga, T. Karasugi, H. Arimura, R. Yonemitsu, H. Sakamoto, J. Ide, H. Mizuta, Enhancement of rotator cuff tendon-bone healing with fibroblast growth factor 2 impregnated in gelatin hydrogel sheets in a rabbit model, J. Shoulder Elb. Surg. 26 (2017) 1708-1717. doi:10.1016/j.jse.2017.03.020.

[147] J. Nakase, K. Kitaoka, K. Matsumoto, K. Tomita, Facilitated Tendon-Bone Healing by Local Delivery of Recombinant Hepatocyte Growth Factor in Rabbits, Arthrosc. J. Arthrosc. Relat. Surg. 26 (2010) 84-90. doi:https://doi.org/10.1016/j.arthro.2009.06.029.

[148] S. Buchmann, G.H. Sandmann, L. Walz, T. Reichel, K. Beitzel, G. Wexel, W. Tian, A. Battmann, S. Vogt, G. Winter, A.B. Imhoff, Growth factor release by vesicular phospholipid gels: In-vitro results and application for rotator cuff repair in a rat model, BMC Musculoskelet. Disord. 16 (2015) 1-10. doi:10.1186/s12891-015-0542-1. 
[149] D. Ross, T. Maerz, M. Kurdziel, J. Hein, S. Doshi, A. Bedi, K. Anderson, K. Baker, The Effect of Granulocyte-colony Stimulating Factor on Rotator Cuff Healing After Injury and Repair, Clin. Orthop. Relat. Res. 473 (2015) 1655-1664. doi:10.1007/s11999015-4218-9.

[150] I. Agir, M.N. Aytekin, F. Kucukdurmaz, B. Kocaoglu, S. Cetinel, M. Karahan, The effect of platelet-rich plasma in bone-tendon integration, Adv Clin Exp Med. 26 (2017) 193-199. doi:10.17219/acem/61384.

[151] J. Zhang, T. Yuan, N. Zheng, Y. Zhou, M. V. Hogan, J.H.-C. Wang, The combined use of kartogenin and platelet-rich plasma promotes fibrocartilage formation in the wounded rat Achilles tendon entheses, Bone Joint Res. 6 (2017) 231-244. doi:10.1302/2046-3758.64.bjr-2017-0268.r1.

[152] J. Beck, D. Evans, P.M. Tonino, S. Yong, J.J. Callaci, The Biomechanical and Histologic Effects of Platelet-Rich Plasma on Rat Rotator Cuff Repairs, Am. J. Sports Med. 40 (2012) 2037-2044. doi:10.1177/0363546512453300.

[153] E. Maman, Y. Zarfati, O. Chechik, O. Dolkart, T. Brosh, F. Alhajajra, A single dose of platelet-rich plasma improves the organization and strength of a surgically repaired rotator cuff tendon in rats, Arch. Orthop. Trauma Surg. 134 (2014) 1271-1277. doi:10.1007/s00402-014-2026-4.

[154] A. Ersen, M. Demirhan, A. Atalar, M. Kapicioglu, G. Baysal, Platelet-rich plasma for enhancing surgical rotator cuff repair: evaluation and comparison of two application methods in a rat model, Arch. Orthop. Trauma Surg. 134 (2013) 405-411. doi:10.1007/s00402-013-1914-3.

[155] Y. Wu, Y. Dong, S. Chen, Y. Li, Effect of platelet-rich plasma and bioactive glass powder for the improvement of rotator cuff tendon-to-bone healing in a rabbit model, Int. J. Mol. Sci. 15 (2014) 21980-21991. doi:10.3390/ijms151221980. 
[156] A.-J. Lee, W.-H. Chung, D.-H. Kim, K.-P. Lee, D.-J. Chung, S.H. Do, H.-Y. Kim, Anterior cruciate ligament reconstruction in a rabbit model using canine small intestinal submucosa and autologous platelet-rich plasma, J. Surg. Res. 178 (2012) 206-215. doi:10.1016/j.jss.2012.01.052.

[157] C. Teng, C. Zhou, D. Xu, F. Bi, Combination of platelet-rich plasma and bone marrow mesenchymal stem cells enhances tendon-bone healing in a rabbit model of anterior cruciate ligament reconstruction, J. Orthop. Surg. Res. 11 (2016) 96. doi:10.1186/s13018-016-0433-7.

[158] G.D. Prestwich, Simplifying the extracellular matrix for 3-D cell culture and tissue engineering: A pragmatic approach, J. Cell. Biochem. 101 (2007) 1370-1383. doi:10.1002/jcb.21386.

[159] K. Duval, H. Grover, L.-H. Han, Y. Mou, A.F. Pegoraro, J. Fredberg, Z. Chen, Modeling Physiological Events in 2D vs. 3D Cell Culture, Physiology. 32 (2017) 266-277. doi:10.1152/physiol.00036.2016.

[160] M. Ramalingam, M.F. Young, V. Thomas, L. Sun, L.C. Chow, C.K. Tison, K. Chatterjee, W.C. Miles, C.G. Simon Jr., Nanofiber scaffold gradients for interfacial tissue engineering, J Biomater Appl. 27 (2013) 695-705. doi:10.1177/0885328211423783.

[161] X. Li, J. Xie, J. Lipner, X. Yuan, S. Thomopoulos, Y. Xia, Nanofiber Scaffolds with Gradations in Mineral Content for Mimicking the Tendon-to-Bone Insertion Site, Nano Lett. 9 (2009) 2763-2768. doi:10.1021/nl901582f.

[162] W. Liu, J. Lipner, J. Xie, C.N. Manning, S. Thomopoulos, Y. Xia, Nanofiber scaffolds with gradients in mineral content for spatial control of osteogenesis, ACS Appl Mater Interfaces. 6 (2014) 2842-2849. doi:10.1021/am405418g.

[163] J. Xie, B. Ma, P.L. Michael, F.D. Shuler, Fabrication of Nanofiber Scaffolds With Gradations in Fiber Organization and Their Potential Applications, Macromol. Biosci. 12 (2012) 1336-1341. doi:10.1002/mabi.201200115. 
[164] J. Xie, X. Li, J. Lipner, C.N. Manning, A.G. Schwartz, S. Thomopoulos, Y. Xia, "Alignedto-random" nanofiber scaffolds for mimicking the structure of the tendon-to-bone insertion site, Nanoscale. 2 (2010) 923. doi:10.1039/c0nr00192a.

[165] S. Samavedi, C.O. Horton, S.A. Guelcher, A.S. Goldstein, A.R. Whittington, Fabrication of a model continuously graded co-electrospun mesh for regeneration of the ligament-bone interface, Acta Biomater. 7 (2011) 4131-4138. doi:10.1016/j.actbio.2011.07.008.

[166] S. Tellado, W. Bonani, E.R. Balmayor, P. Foehr, A. Motta, C. Migliaresi, M. van Griensven, Fabrication and Characterization of Biphasic Silk Fibroin Scaffolds for Tendon/Ligament-to-Bone Tissue Engineering, Tissue Eng Part A. 23 (2017) 859872. doi:10.1089/ten.TEA.2016.0460.

[167] B.S. Kim, E.J. Kim, J.S. Choi, J.H. Jeong, C.H. Jo, Y.W. Cho, Human collagen-based multilayer scaffolds for tendon-to-bone interface tissue engineering, J. Biomed. Mater. Res. Part A. 102 (n.d.) 4044-4054. doi:10.1002/jbm.a.35057.

[168] R. Newsham-West, H. Nicholson, M. Walton, P. Milburn, Long-term morphology of a healing bone?tendon interface: a histological observation in the sheep model, J Anat. 210 (2007) 318-327. doi:10.1111/j.1469-7580.2007.00699.x.

[169] R.I. Sharma, J.G. Snedeker, Biochemical and biomechanical gradients for directed bone marrow stromal cell differentiation toward tendon and bone, Biomaterials. 31 (2010) 7695-7704. doi:10.1016/j.biomaterials.2010.06.046.

[170] Z. Lin, X. Zhao, S. Chen, C. Du, Osteogenic and tenogenic induction of hBMSCs by an integrated nanofibrous scaffold with chemical and structural mimicry of the boneligament connection, J. Mater. Chem. B. 5 (2017) 1015-1027. doi:10.1039/C6TB02156E.

[171] S. Samavedi, P. Vaidya, P. Gaddam, A.R. Whittington, A.S. Goldstein, Electrospun meshes possessing region-wise differences in fiber orientation, diameter, chemistry and mechanical properties for engineering bone-ligament-bone tissues, Biotechnol. Bioeng. 111 (2014) 2549-2559. doi:10.1002/bit.25299. 
[172] S.R. Caliari, D.W. Weisgerber, W.K. Grier, Z. Mahmassani, M.D. Boppart, B.A.C. Harley, Collagen scaffolds incorporating coincident gradations of instructive structural and biochemical cues for osteotendinous junction engineering, Adv. Healthc. Mater. 4 (2015) 831-837. doi:10.1002/adhm.201400809.

[173] T.M. Hammoudi, H. Lu, J.S. Temenoff, Long-Term Spatially Defined Coculture Within Three-Dimensional Photopatterned Hydrogels, Tissue Eng. Part C Methods. 16 (2010) 1621-1628. doi:10.1089/ten.tec.2010.0146.

[174] M. Laranjeira, R.M.A. Domingues, R. Costa-Almeida, R.L. Reis, M.E. Gomes, 3D Mimicry of Native-Tissue-Fiber Architecture Guides Tendon-Derived Cells and Adipose Stem Cells into Artificial Tendon Constructs, Small. 13 (2017) 1700689. doi:10.1002/smll.201700689.

[175] M. Younesi, A. Islam, V. Kishore, J.M. Anderson, O. Akkus, Tenogenic Induction of Human MSCs by Anisotropically Aligned Collagen Biotextiles, Adv. Funct. Mater. 24 (2014) 5762-5770. doi:10.1002/adfm.201400828.

[176] H. Liu, H. Fan, Y. Wang, S.L. Toh, J.C.H. Goh, The interaction between a combined knitted silk scaffold and microporous silk sponge with human mesenchymal stem cells for ligament tissue engineering, Biomaterials. 29 (2008) 662-674. doi:10.1016/j.biomaterials.2007.10.035.

[177] W. Shen, X. Chen, Y. Hu, Z. Yin, T. Zhu, J. Hu, J. Chen, Z. Zheng, W. Zhang, J. Ran, B.C. Heng, J. Ji, W. Chen, H.W. Ouyang, Long-term effects of knitted silk-collagen sponge scaffold on anterior cruciate ligament reconstruction and osteoarthritis prevention, Biomaterials. 35 (2014) 8154-8163. doi:10.1016/j.biomaterials.2014.06.019.

[178] H. Li, J. Fan, L. Sun, X. Liu, P. Cheng, H. Fan, Functional regeneration of ligamentbone interface using a triphasic silk-based graft, Biomaterials. 106 (2016) 180-192. doi:10.1016/j.biomaterials.2016.08.012.

[179] E. Tanck, G. Hannink, R. Ruimerman, P. Buma, E.H. Burger, R. Huiskes, Cortical bone development under the growth plate is regulated by mechanical load transfer, J Anat. 208 (2006) 73-79. doi:10.1111/j.1469-7580.2006.00503.x. 
[180] I.A. Stokes, Mechanical effects on skeletal growth, J Musculoskelet Neuronal Interact. 2 (2002) 277-280.

[181] M.T. Galloway, A.L. Lalley, J.T. Shearn, The Role of Mechanical Loading in Tendon Development, Maintenance, Injury, and Repair, J Bone Jt. Surg Am. 95 (2013) 16201628. doi:10.2106/JBJS.L.01004.

[182] N.R. Schiele, J.E. Marturano, C.K. Kuo, Mechanical factors in embryonic tendon development: Potential cues for stem cell tenogenesis, Curr. Opin. Biotechnol. 24 (2013) 834-840. doi:10.1016/j.copbio.2013.07.003.

[183] Q. Liu, X. Hu, X. Zhang, X. Duan, P. Yang, F. Zhao, Y. Ao, Effects of mechanical stress on chondrocyte phenotype and chondrocyte extracellular matrix expression, Sci Rep. 6 (2016) 37268. doi:10.1038/srep37268.

[184] M. Brandt, M.I. Siegel, The effects of stress on cortical bone thickness in rodents, Am. J. Phys. Anthropol. 49 (1978) 31-34. doi:10.1002/ajpa.1330490106.

[185] L.M. McNamara, J.C. Van der Linden, H. Weinans, P.J. Prendergast, Stressconcentrating effect of resorption lacunae in trabecular bone, J Biomech. 39 (2006) 734-741. doi:10.1016/j.jbiomech.2004.12.027.

[186] S.L. Woo, M.A. Gomez, Y.K. Woo, W.H. Akeson, Mechanical properties of tendons and ligaments. II. The relationships of immobilization and exercise on tissue remodeling, Biorheology. 19 (1982) 397-408.

[187] L.M. Galatz, N. Charlton, R. Das, H.M. Kim, N. Havlioglu, S. Thomopoulos, Complete removal of load is detrimental to rotator cuff healing, J. Shoulder Elb. Surg. 18 (2009) 669-675. doi:10.1016/j.jse.2009.02.016.

[188] S. Thomopoulos, H.-M. Kim, S.Y. Rothermich, C. Biederstadt, R. Das, L.M. Galatz, Decreased muscle loading delays maturation of the tendon enthesis during postnatal development, J. Orthop. Res. 25 (2007) 1154-1163. doi:10.1002/jor.20418. 
[189] H.M. Kim, L.M. Galatz, R. Das, N. Patel, S. Thomopoulos, Musculoskeletal deformities secondary to neurotomy of the superior trunk of the brachial plexus in neonatal mice, J Orthop Res. 28 (2010) 1391-1398. doi:10.1002/jor.21128.

[190] A.M. Tatara, J.H. Lipner, R. Das, H.M. Kim, N. Patel, E. Ntouvali, M.J. Silva, S. Thomopoulos, The Role of Muscle Loading on Bone (Re)modeling at the Developing Enthesis, PLoS One. 9 (2014) 1-8. doi:10.1371/journal.pone.0097375.

[191] E. Blitz, S. Viukov, A. Sharir, Y. Shwartz, J.L. Galloway, B.A. Pryce, R.L. Johnson, C.J. Tabin, R. Schweitzer, E. Zelzer, Bone Ridge Patterning during Musculoskeletal Assembly Is Mediated through SCX Regulation of Bmp4 at the Tendon-Skeleton Junction, Dev. Cell. 17 (2009) 861-873. doi:10.1016/j.devcel.2009.10.010.

[192] B. Mikic, T.L. Johnson, A.B. Chhabra, B.J. Schalet, M. Wong, E.B. Hunziker, Differential effects of embryonic immobilization on the development of fibrocartilaginous skeletal elements, J Rehabil Res Dev. 37 (2000) 127-133.

[193] S. Thomopoulos, G.M. Genin, L.M. Galatz, The development and morphogenesis of the tendon-to-bone insertion What development can teach us about healing, J. Musculoskelet. Neuronal Interact. 10 (2010) 35-45.

[194] I. Martin, D. Wendt, M. Heberer, The role of bioreactors in tissue engineering, Trends Biotechnol. 22 (2004) 80-86. doi:10.1016/j.tibtech.2003.12.001.

[195] M. Peroglio, D. Gaspar, D.I. Zeugolis, M. Alini, Relevance of bioreactors and whole tissue cultures for the translation of new therapies to humans, J Orthop Res. (2017). doi:10.1002/jor.23655.

[196] M.C. McCorry, M.M. Mansfield, X. Sha, D.J. Coppola, J.W. Lee, L.J. Bonassar, A model system for developing a tissue engineered meniscal enthesis, Acta Biomater. 56 (2017) 110-117. doi:10.1016/j.actbio.2016.10.040.

[197] S.M. Goldman, G.A. Barabino, Spatial Engineering of Osteochondral Tissue Constructs Through Microfluidically Directed Differentiation of Mesenchymal Stem Cells, Biores. Open Access. 5 (2016) 109-117. doi:10.1089/biores.2016.0005. 
[198] S.M. Goldman, G.A. Barabino, Cultivation of agarose-based microfluidic hydrogel promotes the development of large, full-thickness, tissue-engineered articular cartilage constructs, J. Tissue Eng. Regen. Med. 11 (2014) 572-581. doi:10.1002/term.1954.

[199] L.A. McMahon, A.J. Reid, V.A. Campbell, P.J. Prendergast, Regulatory Effects of Mechanical Strain on the Chondrogenic Differentiation of MSCs in a Collagen-GAG Scaffold: Experimental and Computational Analysis, Ann. Biomed. Eng. 36 (2008) 185-194. doi:10.1007/s10439-007-9416-5.

[200] S.F. Carroll, C.T. Buckley, D.J. Kelly, Cyclic Tensile Strain Can Play a Role in Directing both Intramembranous and Endochondral Ossification of Mesenchymal Stem Cells, Front. Bioeng. Biotechnol. 5 (2017) 1-12. doi:10.3389/fbioe.2017.00073.

[201] A.C. Daly, B.N. Sathy, D.J. Kelly, Engineering large cartilage tissues using dynamic bioreactor culture at defined oxygen conditions, J. Tissue Eng. 9 (2018) 204173141775371. doi:10.1177/2041731417753718.

[202] Y. Qiu, J. Lei, T.J. Koob, J.S. Temenoff, Cyclic tension promotes fibroblastic differentiation of human MSCs cultured on collagen-fibre scaffolds, J. Tissue Eng. Regen. Med. 10 (2016) 989-999. doi:10.1002/term.1880.

[203] M. Samson, N. Porter, O. Orekoya, J.R. Hebert, S.A. Adams, C.L. Bennett, S.E. Steck, Next Generation Tissue Engineering of Orthopedic Soft Tissueto-Bone Interfaces, MRS Commun. 155 (2017) 3-12. doi:10.1007/s10549-015-3663-1.Progestin.

[204] W.L. Grayson, S. Bhumiratana, P.H. Grace Chao, C.T. Hung, G. Vunjak-Novakovic, Spatial regulation of human mesenchymal stem cell differentiation in engineered osteochondral constructs: effects of pre-differentiation, soluble factors and medium perfusion, Osteoarthr. Cartil. 18 (2010) 714-723. doi:10.1016/j.joca.2010.01.008.

[205] R. Omi, A. Gingery, S.P. Steinmann, P.C. Amadio, K.-N. An, C. Zhao, Rotator cuff repair augmentation in a rat model that combines a multilayer xenograft tendon scaffold with bone marrow stromal cells, J. Shoulder Elb. Surg. 25 (2016) 469-477. doi:10.1016/j.jse.2015.08.008. 
[206] D.R. Peterson, K.L. Ohashi, H.M. Aberman, P.A. Piza, H.C. Crockett, J.I. Fernandez, P.J. Lund, K.A. Funk, M.L. Hawes, B.G. Parks, R.-H. Mattern, Evaluation of a collagencoated, resorbable fiber scaffold loaded with a peptide basic fibroblast growth factor mimetic in a sheep model of rotator cuff repair, J. Shoulder Elb. Surg. 24 (2015) 1764-1773. doi:10.1016/j.jse.2015.06.009.

[207] S.A. Rodeo, H.G. Potter, S. Kawamura, A.S. Turner, H.J. Kim, B.L. Atkinson, Biologic augmentation of rotator cuff tendon-healing with use of a mixture of osteoinductive growth factors, J Bone Jt. Surg Am. 89 (2007) 2485-2497. doi:10.2106/JBJS.C.01627.

[208] I. Encalada-Diaz, B.J. Cole, J.D. Macgillivray, M. Ruiz-Suarez, J.S. Kercher, N.A. Friel, F. Valero-Gonzalez, Rotator cuff repair augmentation using a novel polycarbonate polyurethane patch: preliminary results at 12 months' follow-up, J Shoulder Elb. Surg. 20 (2011) 788-794. doi:10.1016/j.jse.2010.08.013.

[209] J.A. McCarron, R.A. Milks, X. Chen, J.P. Iannotti, K.A. Derwin, Improved time-zero biomechanical properties using poly-L-lactic acid graft augmentation in a cadaveric rotator cuff repair model, J. Shoulder Elb. Surg. 19 (2010) 688-696. doi:10.1016/j.jse.2009.12.008.

[210] D. Bryant, R. Holtby, K. Willits, R. Litchfield, D. Drosdowech, A. Spouge, D. White, G. Guyatt, A randomized clinical trial to compare the effectiveness of rotator cuff repair with or without augmentation using porcine small intestine submucosa for patients with moderate to large rotator cuff tears: a pilot study, J. Shoulder Elb. Surg. 25 (2016) 1623-1633. doi:10.1016/j.jse.2016.06.006.

[211] J.P. Iannotti, M.J. Codsi, Y.W. Kwon, K. Derwin, J. Ciccone, J.J. Brems, Porcine small intestine submucosa augmentation of surgical repair of chronic two-tendon rotator cuff tears. A randomized, controlled trial, J Bone Jt. Surg Am. 88 (2006) 1238-1244. doi:10.2106/jbjs.e.00524.

[212] W.Z. Burkhead, S.C. Schiffern, S.G. Krishnan, Use of Graft Jacket as an Augmentation for Massive Rotator Cuff Tears, Semin. Arthroplasty. 18 (2007) 11-18. doi:10.1053/j.sart.2006.11.017. 
[213] P. Hernigou, C.H. Flouzat Lachaniette, J. Delambre, S. Zilber, P. Duffiet, N. Chevallier, H. Rouard, Biologic augmentation of rotator cuff repair with mesenchymal stem cells during arthroscopy improves healing and prevents further tears: a casecontrolled study, Int Orthop. 38 (2014) 1811-1818. doi:10.1007/s00264-014-23911.

[214] Y.S. Kim, C.H. Sung, S.H. Chung, S.J. Kwak, Y.G. Koh, Does an Injection of AdiposeDerived Mesenchymal Stem Cells Loaded in Fibrin Glue Influence Rotator Cuff Repair Outcomes? A Clinical and Magnetic Resonance Imaging Study, Am. J. Sports Med. 45 (2017) 2010-2018. doi:10.1177/0363546517702863. 
Table 1. Examples of co-culture systems for tendon-to-bone TERM applications

\begin{tabular}{|c|c|c|c|c|}
\hline $\begin{array}{c}\text { In vitro/In } \\
\text { vivo }\end{array}$ & Cell types & $\begin{array}{l}\text { Culture } \\
\text { system }\end{array}$ & Main outcomes & References \\
\hline \multirow{2}{*}{ In vitro } & \multirow{2}{*}{$\begin{array}{l}\text { - Fibroblasts } \\
\text { (ligament/tend } \\
\text { on) } \\
\text { - Osteoblasts }\end{array}$} & $\begin{array}{l}\text { 2D using a } \\
\text { spacer until } \\
\text { confluent }\end{array}$ & $\begin{array}{l}\text { - After } 14 \text { days, } 3 \text { regions were distinguished: fibroblasts, } \\
\text { fibroblasts plus osteoblasts (interface) and osteoblasts; } \\
\text { - Presence of osteoblasts induced ALP activity and } \\
\text { mineralization by fibroblasts; } \\
\text { - Higher transcription levels of collagen type II, acan and } \\
\text { comp at the interface }\end{array}$ & [64] \\
\hline & & $\begin{array}{l}\text { 3D triphasic } \\
\text { scaffold } \\
\text { with cells } \\
\text { seeded at } \\
\text { different } \\
\text { extremities }\end{array}$ & $\begin{array}{l}\text { - Fibroblasts-osteoblasts interaction in phase B of the scaffold } \\
\text { (interface); } \\
\text { - Higher ALP activity and mineralization by osteoblasts in } \\
\text { phase C (hard tissue); } \\
\text { - Higher collagen type I expression by fibroblasts (phase A) }\end{array}$ & [71] \\
\hline
\end{tabular}




\begin{tabular}{|c|c|c|c|c|c|}
\hline 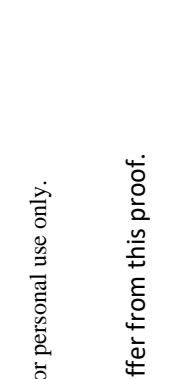 & & $\begin{array}{ll}\text { - } & \text { Fibroblasts } \\
\text { (NIH 3T3 line) } \\
\text { - Osteoblasts } \\
\text { (MC 3T3) }\end{array}$ & $\begin{array}{l}\text { 3D scaffolds } \\
\text { with cells } \\
\text { seeded at } \\
\text { different } \\
\text { extremities }\end{array}$ & $\begin{array}{l}\text { - The use of } 3 \mathrm{mM} \text { betaglycerophosphate and } 25 \mu \mathrm{g} / \mathrm{mL} \\
\text { ascorbic acid reduced fibroblasts mineralization while } \\
\text { enhancing osteoblasts response; } \\
\text { - Deposition of collagen and glycosaminoglycan at the } \\
\text { interface }\end{array}$ & [65] \\
\hline 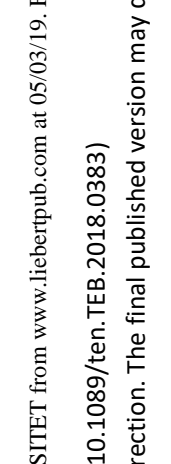 & In vivo & $\begin{array}{l}\text { - Fibroblasts } \\
\text { (ligament/tend } \\
\text { on) } \\
\text { - Chondrocytes } \\
\text { - Osteoblasts }\end{array}$ & $\begin{array}{l}\text { 3D triphasic } \\
\text { scaffolds }\end{array}$ & $\begin{array}{l}\text { - Deposition of collagenous-rich matrix in all phases; } \\
\text { - Higher deposition of collagen type III by fibroblasts (phase } \\
\text { A); } \\
\text { - Deposition of collagen types I, II and X phase B by } \\
\text { chondrocytes; } \\
\text { - Mineralization confinement in phase C (osteoblasts); }\end{array}$ & [69] \\
\hline
\end{tabular}




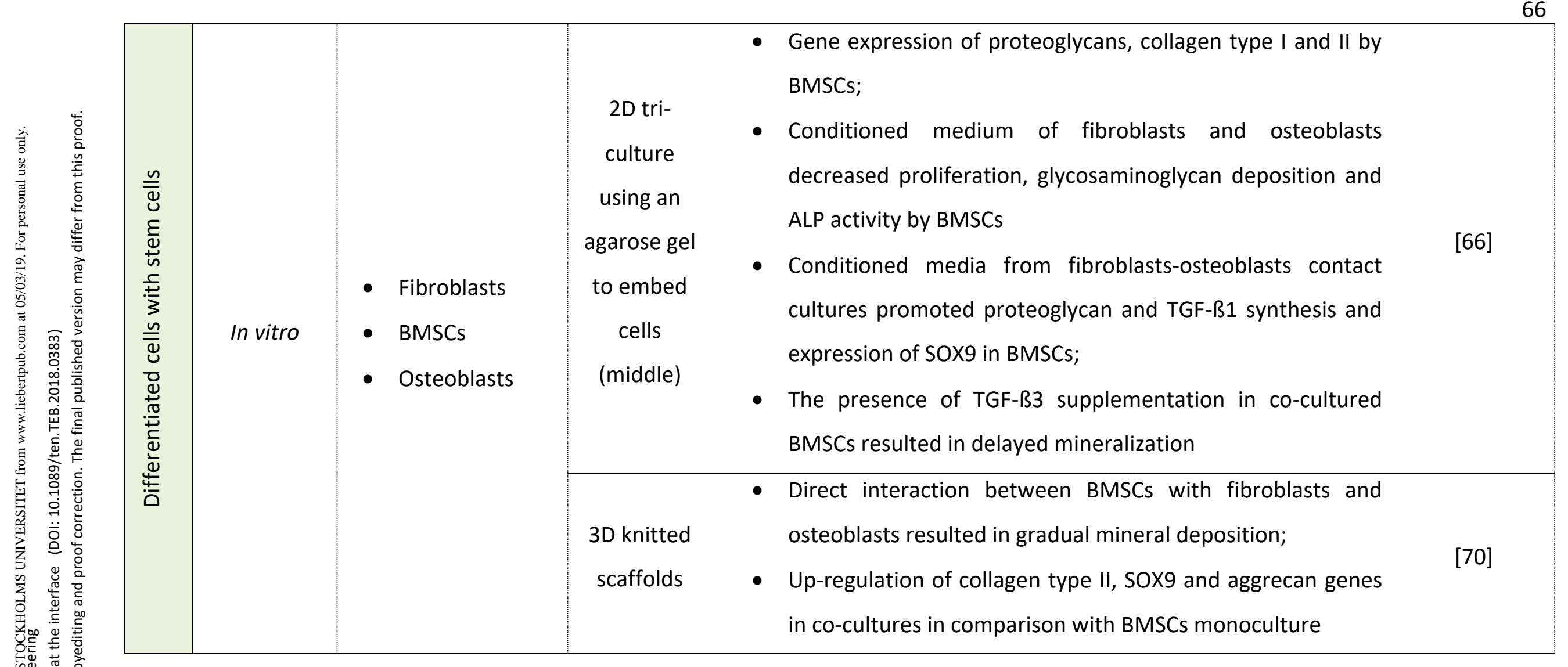




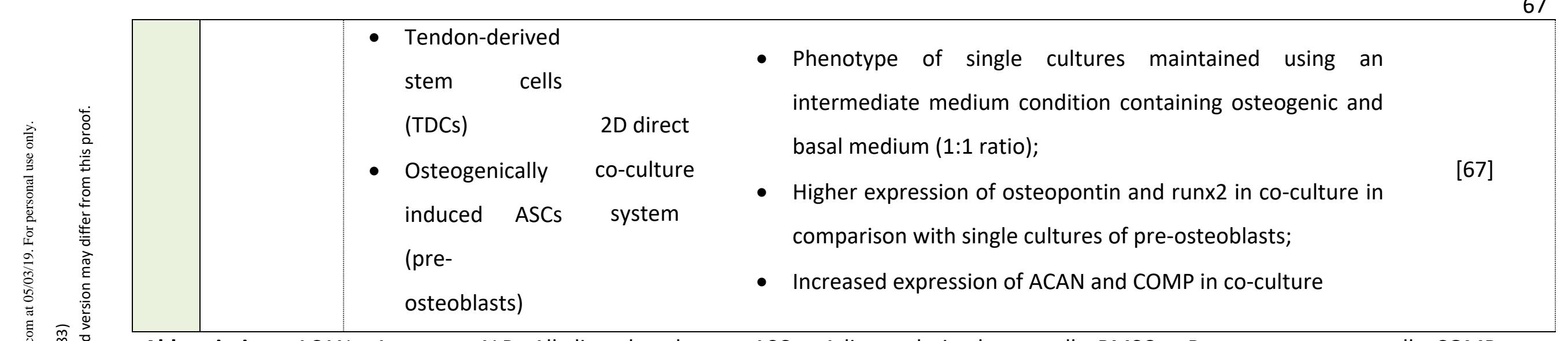

Abbreviations: ACAN - Aggrecan; ALP - Alkaline phosphatase; ASCs - Adipose-derived stem cells; BMSCs - Bone marrow stem cells; COMP Cartilage-oligomeric matrix protein; TDCs - Tendon-derived stem cells; TGF- $\beta 1 / 3$ - Transforming growth factor - beta $1 / 3$; SOX 9 - SRY-box 9 
Table 2. In vivo studies of the temporal expression of growth factors and tissue formation along the healing process.

\begin{tabular}{|c|c|c|c|c|}
\hline $\begin{array}{l}\text { Growth } \\
\text { factor }\end{array}$ & Model & $\begin{array}{l}\text { Time } \\
\text { period }\end{array}$ & Expression time-line & Ref. \\
\hline $\begin{array}{c}\text { TGF- } \beta 1 \\
\text { and TGF- } \beta 3\end{array}$ & $\begin{array}{l}\text { Rat bilateral } \\
\text { supraspinat } \\
\text { us tendon } \\
\text { transection }\end{array}$ & $\begin{array}{c}8 \\
\text { weeks }\end{array}$ & $\begin{array}{l}\text { Cell proliferation accompanied TGF- } \beta 1 \text { temporal } \\
\text { expression; Collagen remodeling, collagen types I and III } \\
\text { production; TGF- } \beta 1 \text { localized in the scar tissue and peaked } \\
\text { at } 10 \text { days; TGF- } \beta 3 \text { was not detected in the healing } \\
\text { insertion site. }\end{array}$ & [122] \\
\hline $\begin{array}{l}\text { bFGF, IGF- } \\
1, \text { PDGF } \\
\text { and TGF- } \beta\end{array}$ & $\begin{array}{l}\text { Rabbit } \\
\text { Rotator cuff } \\
\text { tendon tear }\end{array}$ & $\begin{array}{c}4 \\
\text { weeks }\end{array}$ & $\begin{array}{l}\text { Cell-specific expression: bFGF by fibroblast-like cells and } \\
\text { ECs, IGF-1 by blood cells and ECs, PDGF by ECs, and TGF- } \beta \\
\text { by blood cells; IGF-1 and TGF- } \beta \text { expressed during the } \\
\text { inflammation period; Sequential peak expression of } \\
\text { growth factors: TGF- } \beta \text {, IGF-1, bFGF, and PDGF. }\end{array}$ & [123] \\
\hline $\begin{array}{c}\text { BMP-2 } \\
\text { and BMP-7 }\end{array}$ & $\begin{array}{l}\text { Ovine Extra- } \\
\text { articular } \\
\text { patellar } \\
\text { tendon-to- } \\
\text { bone }\end{array}$ & $\begin{array}{c}6 \\
\text { weeks }\end{array}$ & $\begin{array}{l}\text { BMP-2 staining was more prominent at the tendon site at } \\
6 \text { weeks while BMP-7 was mainly observed at the } \\
\text { interface close to the bone. }\end{array}$ & [124] \\
\hline
\end{tabular}




\begin{tabular}{|c|c|c|c|c|}
\hline $\begin{array}{c}\text { BMP-12, - } \\
\text { 13, } \\
-14, \text { bFGF, } \\
\text { CTGF, } \\
\text { PDGF, TGF- } \\
\beta 1 \text { and } \\
\text { COMP }\end{array}$ & $\begin{array}{c}\text { Rat } \\
\text { Supraspinat } \\
\text { us tendon } \\
\text { insertion } \\
\text { defect }\end{array}$ & $\begin{array}{c}16 \\
\text { weeks }\end{array}$ & $\begin{array}{l}\text { At week 1: up regulation of all growth factors during } \\
\text { inflammation period; COMP peaked at } 1 \text { week; PDGF-B } \\
\text { expression at weeks } 1 \text { and } 8 \text {; TGF- } \beta 1 \text { expression at weeks } \\
1,2 \text { and } 8 \text { in the midsubstance; BMP-12 moderately } \\
\text { expressed at all time points; At } 16 \text { weeks, no expression of } \\
\text { studied growth factors. }\end{array}$ & [125] \\
\hline $\begin{array}{c}\text { bFGF, } \\
\text { VEGF, } \\
\text { BMP-2 } \\
\text { and BMP-7 }\end{array}$ & $\begin{array}{l}\text { Rabbit } \\
\text { Anterior } \\
\text { cruciate } \\
\text { ligament } \\
\text { repair }\end{array}$ & $\begin{array}{c}12 \\
\text { weeks }\end{array}$ & $\begin{array}{l}\text { At week 1, FGF-2, BMP-2 and VEGF expression by } \\
\text { fibroblasts and ECs at the interface; at week 3, VEGF } \\
\text { expression by fibroblasts, FGF-2, and VEGF expression by } \\
\text { osteoblasts; BMPs stained in fibroblasts and osteoblasts at } \\
\text { the interface; At week 6, bFGF and VEGF in fibroblasts and } \\
\text { osteoblasts at the interface; At week 12, bFGF and BMP-7 } \\
\text { residually expressed by fibroblasts and osteoblasts at the } \\
\text { interface; BMP-2 and BMP-7 in osteoblasts - expression } \\
\text { more confined to later phases characterizing bone } \\
\text { remodeling. }\end{array}$ & [126] \\
\hline
\end{tabular}


Abbreviations: bFGF - basic fibroblast growth factor; IGF-1 - insulin-like growth factor 1; PDGF - Platelet-derived growth factor; TGF- $\beta$ Transforming growth factor beta; BMP - Bone morphogenetic protein; CTGF - Connective tissue growth factor; COMP - Cartilage oligomeric matrix protein.

ECs- endothelial cells 
Table 3. In vivo studies using growth factors for tendon-to-bone healing.

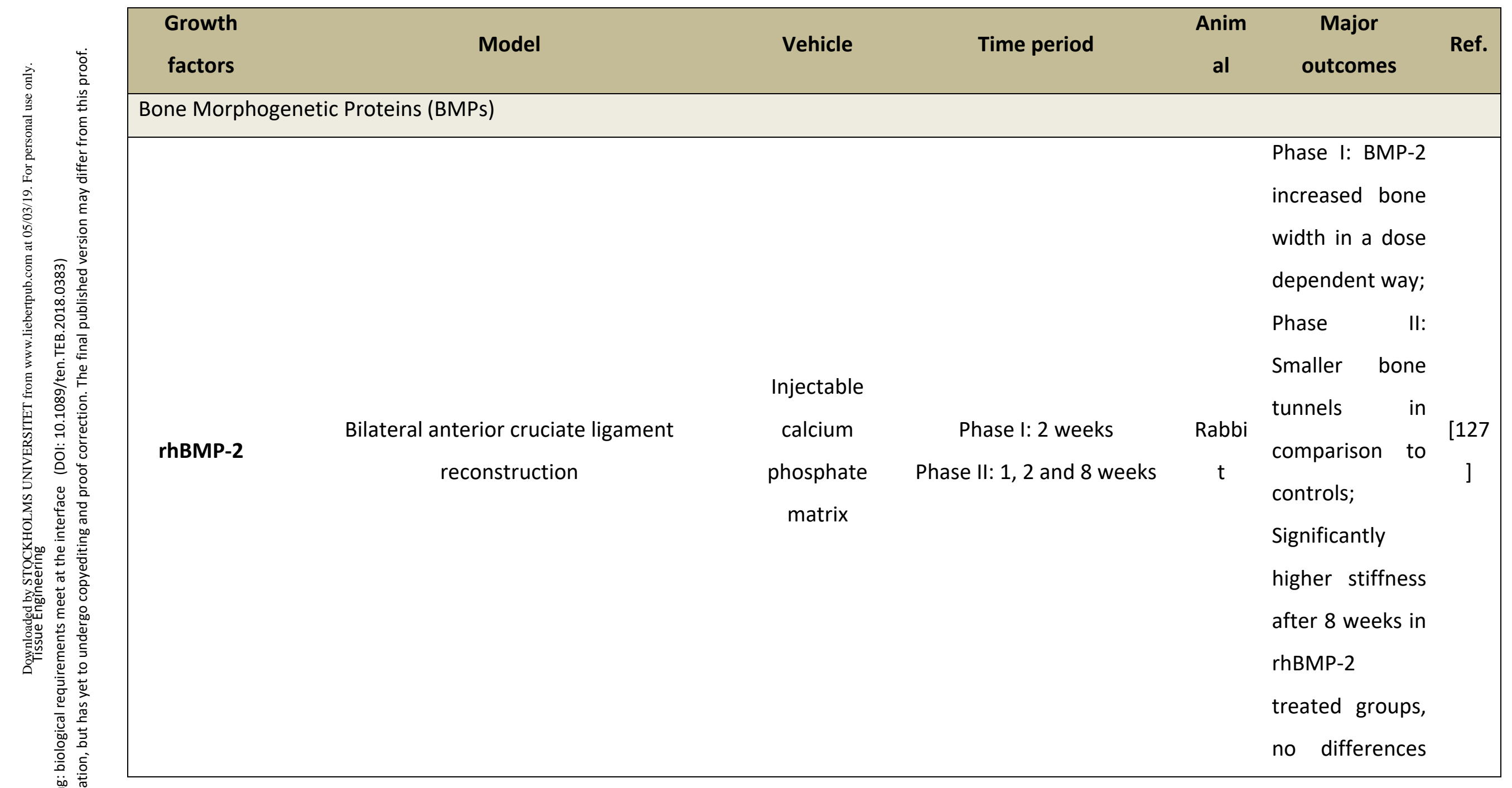




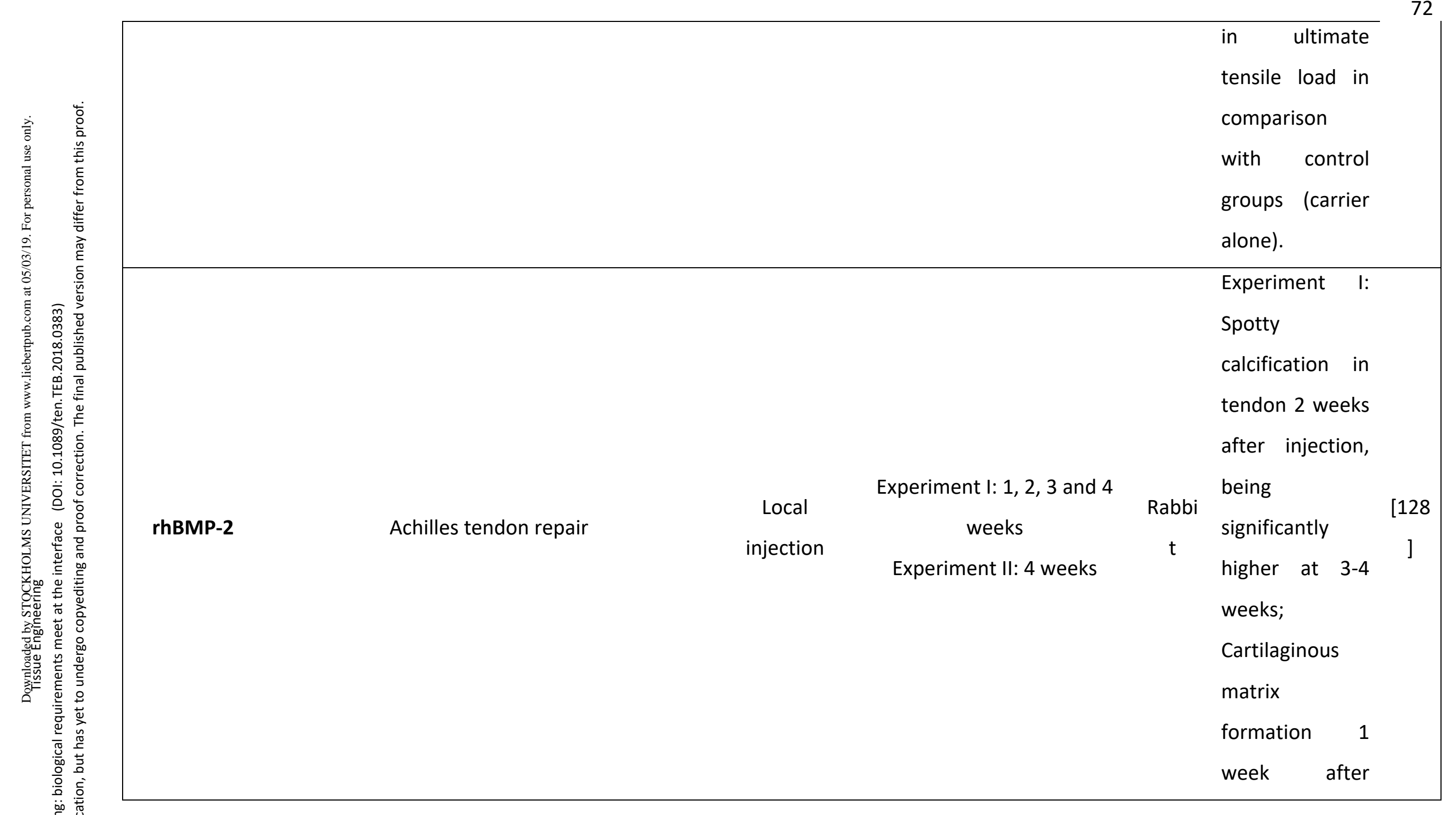




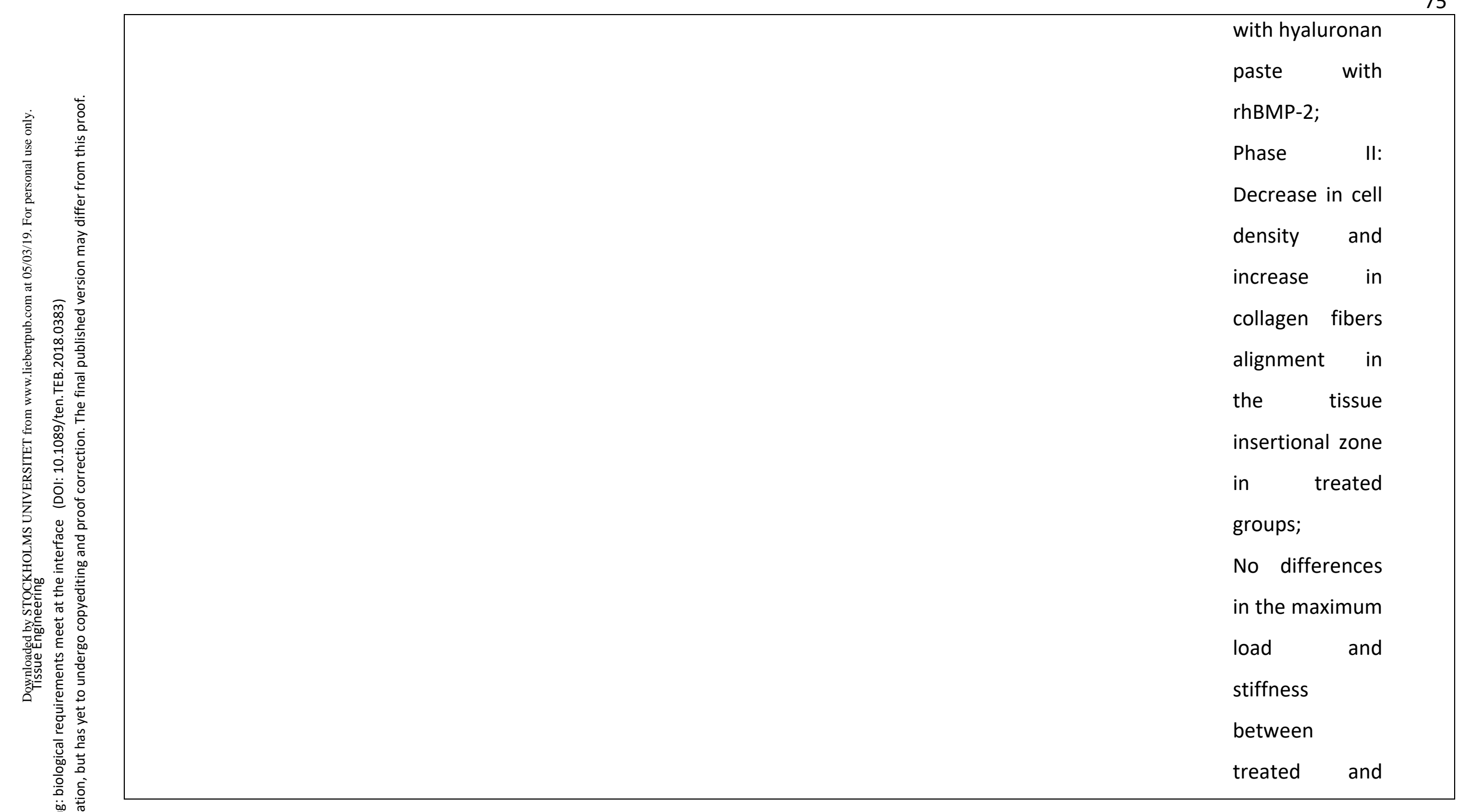




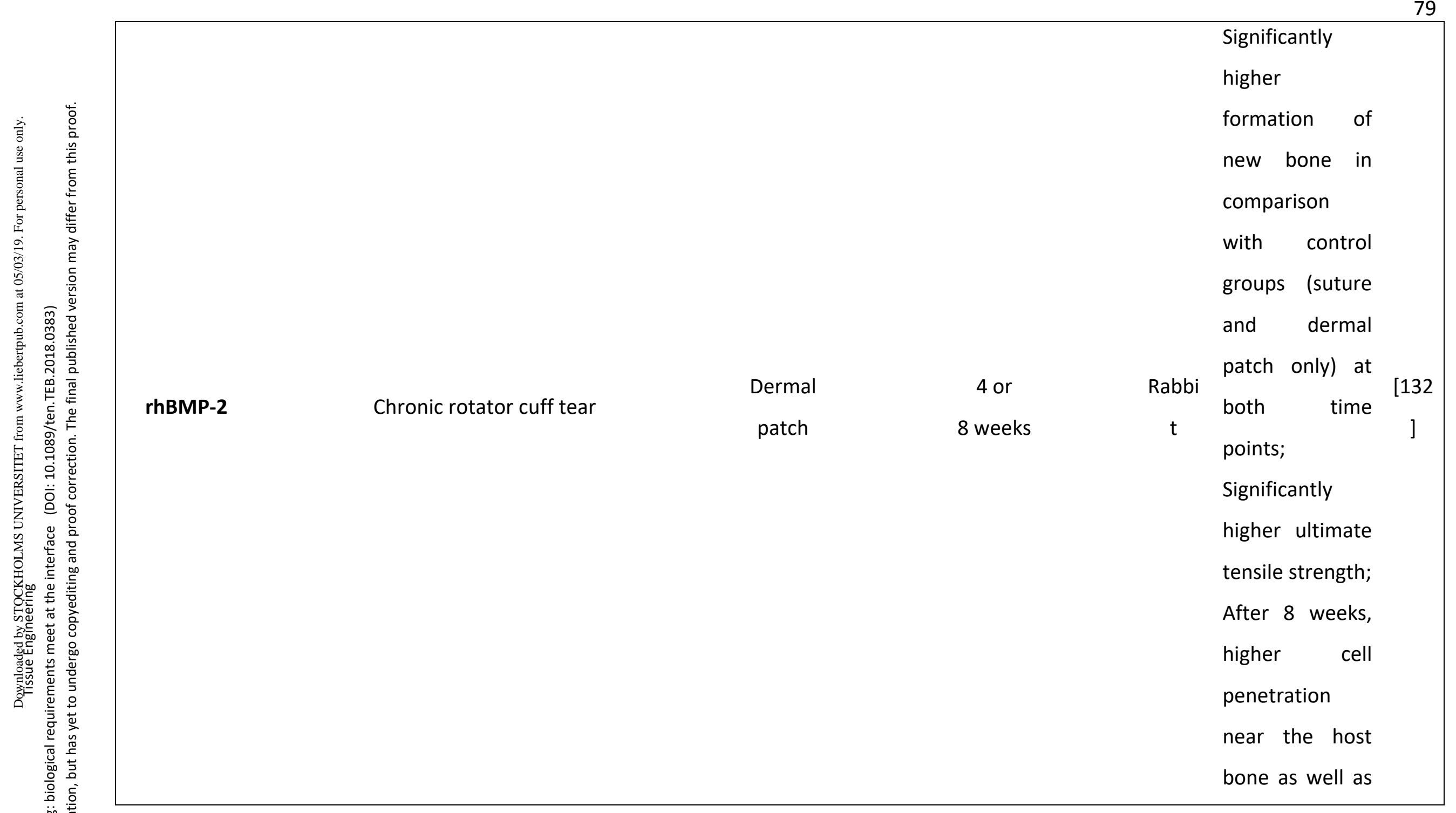




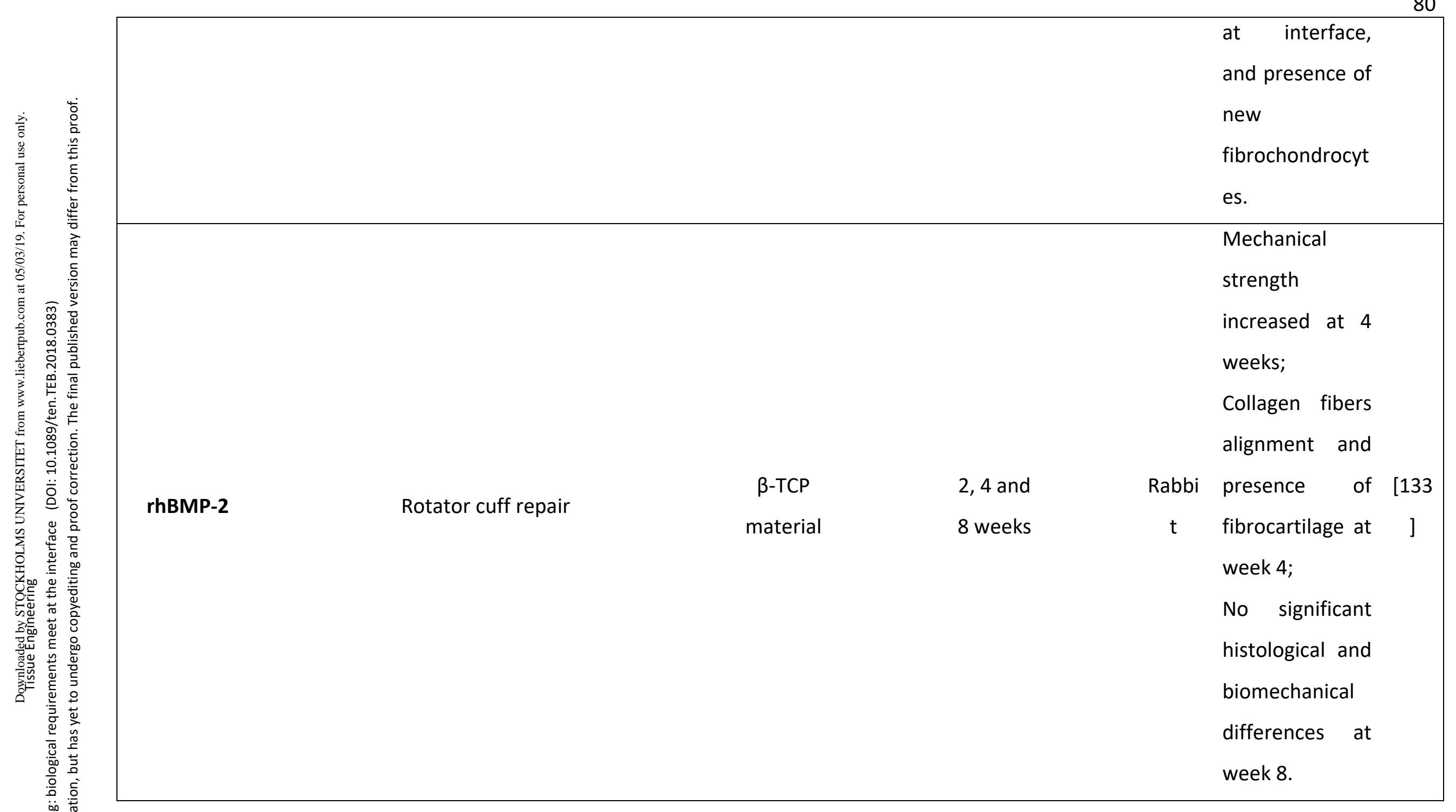




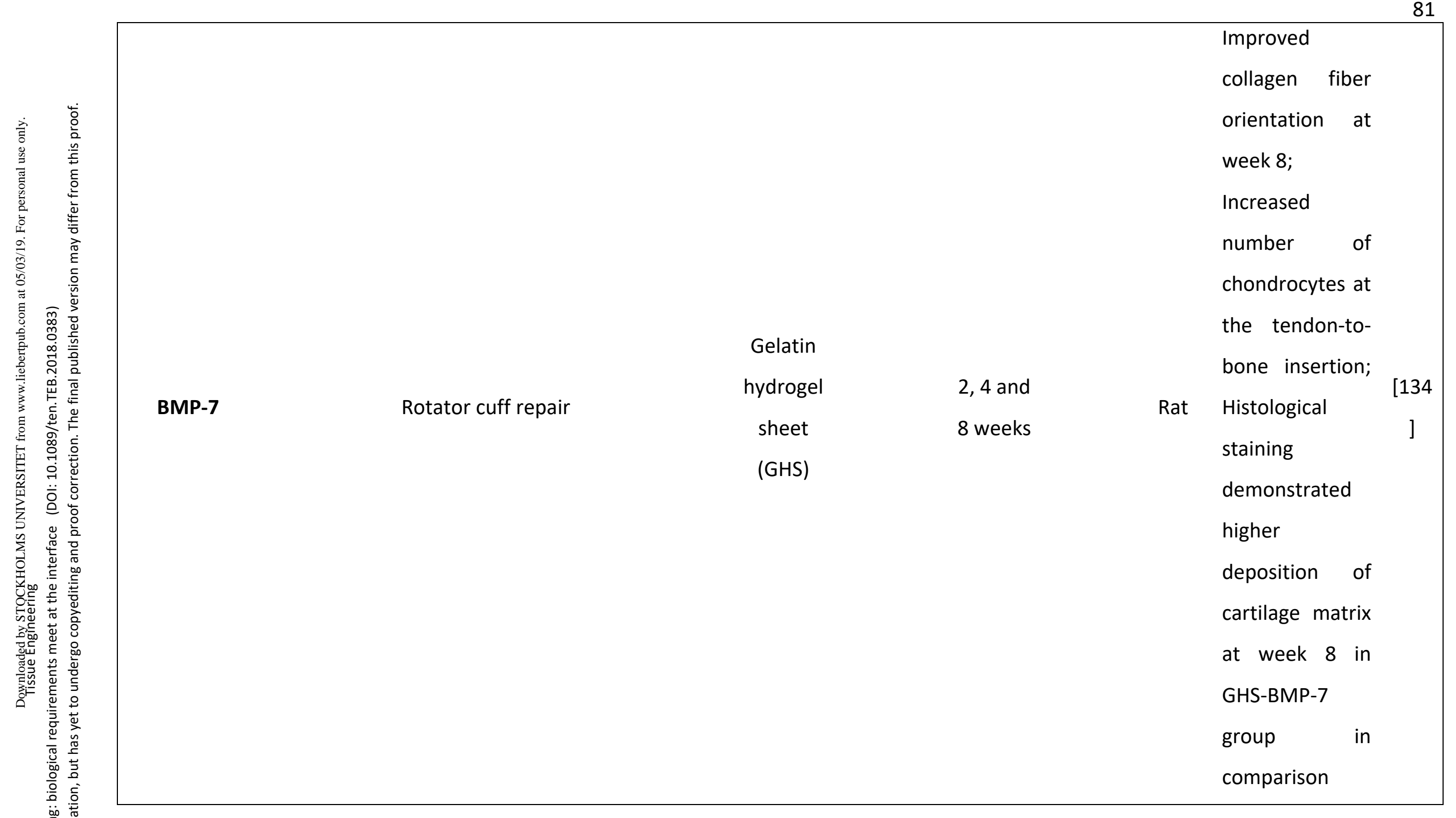




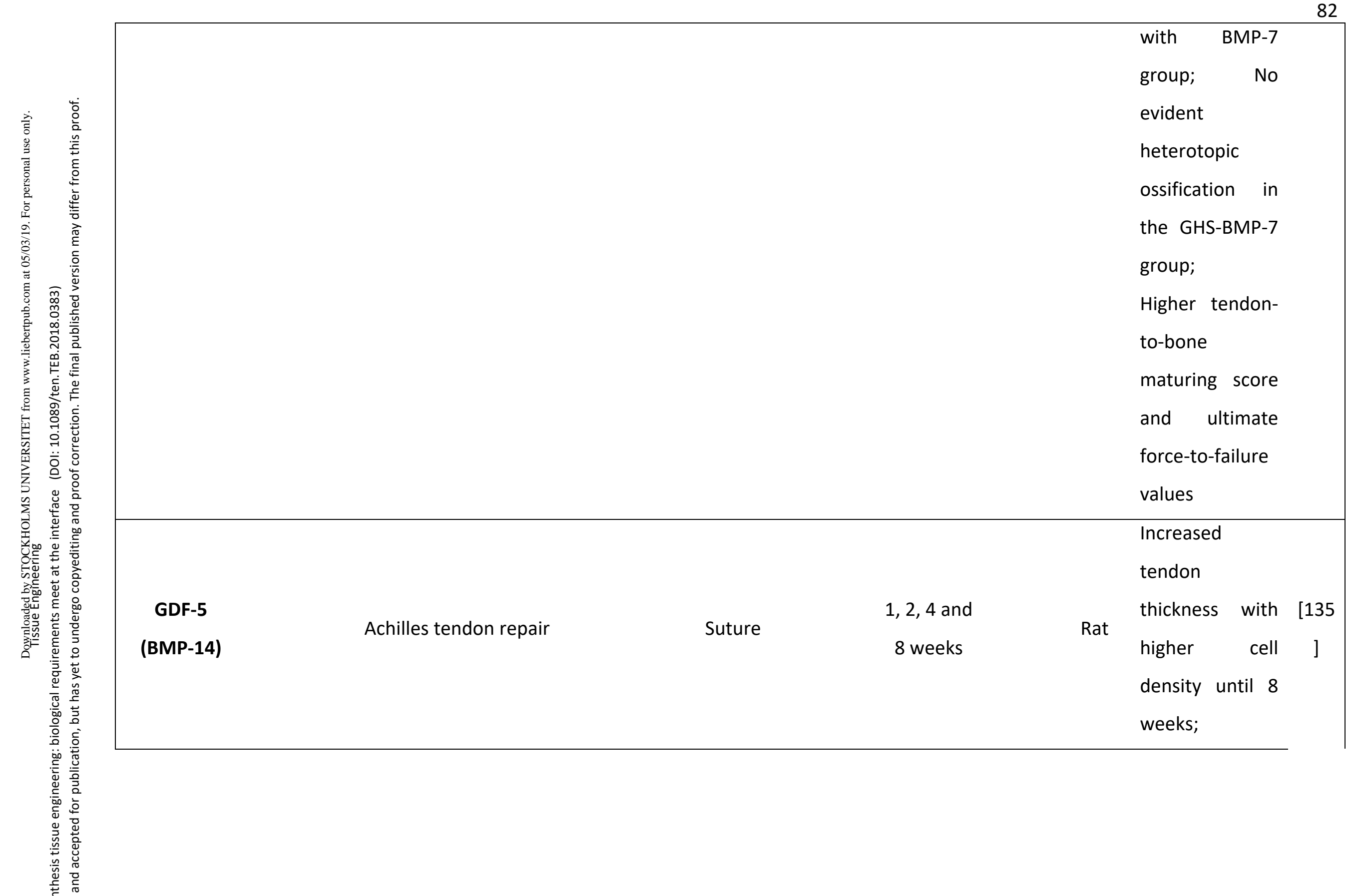




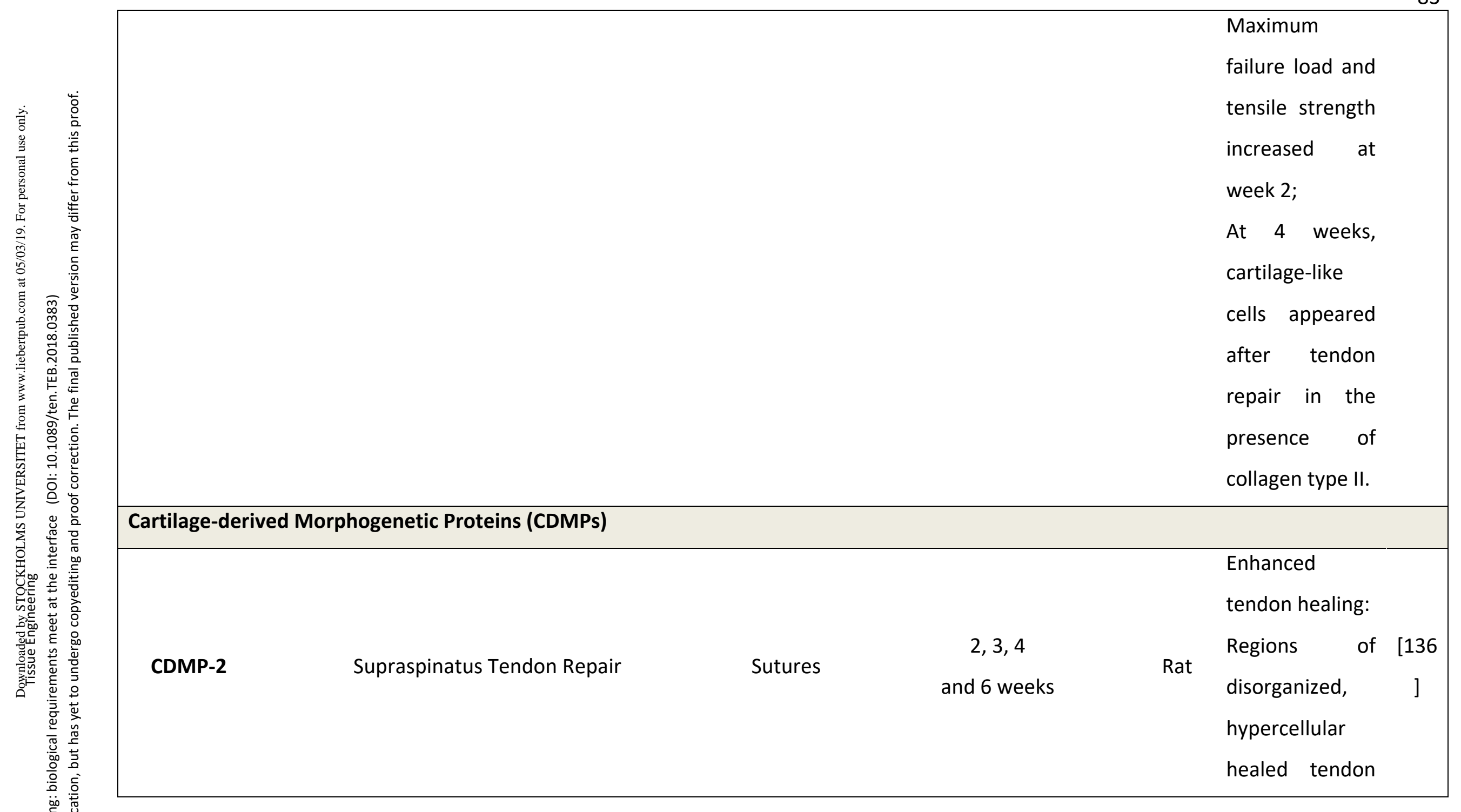




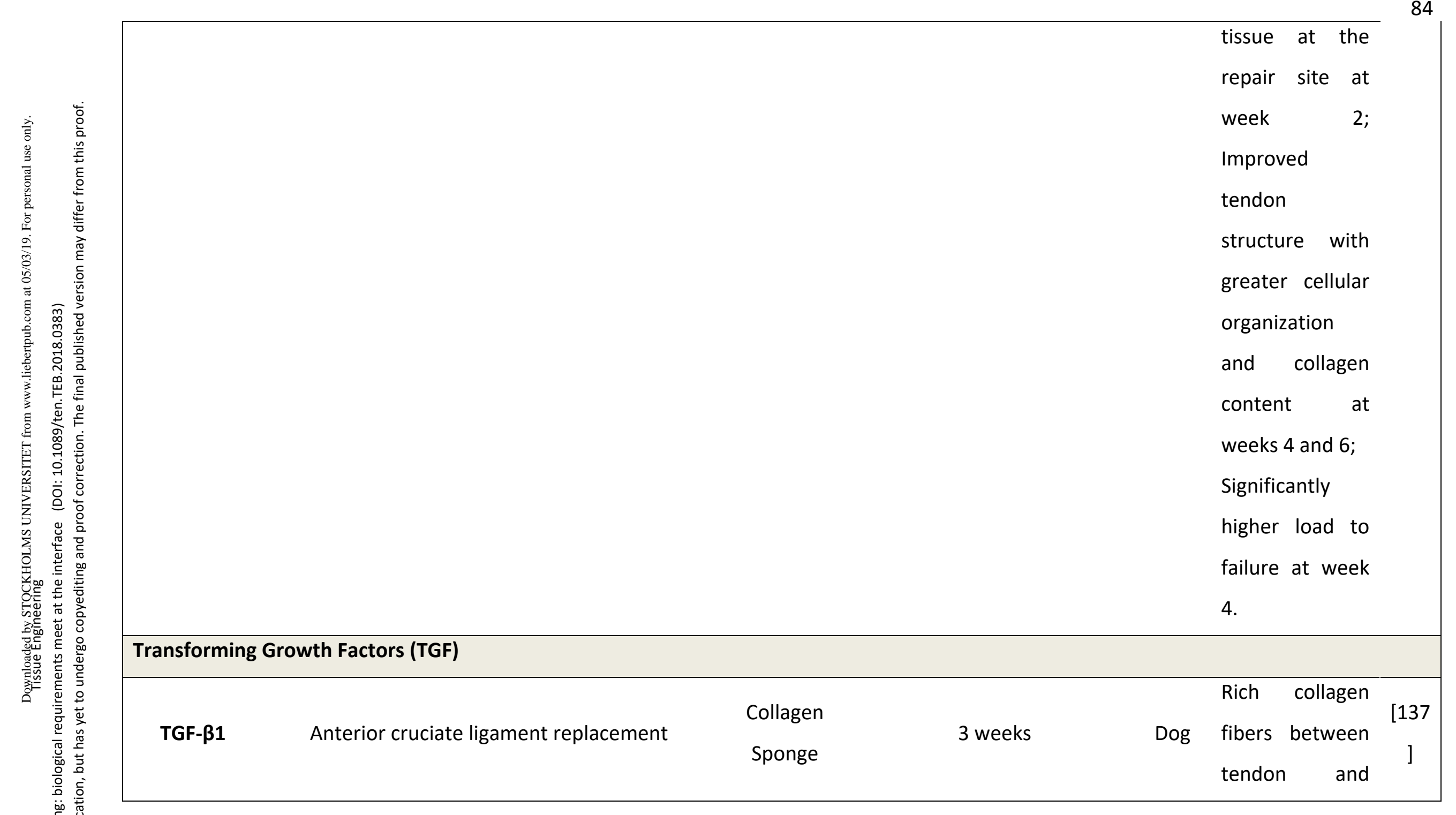




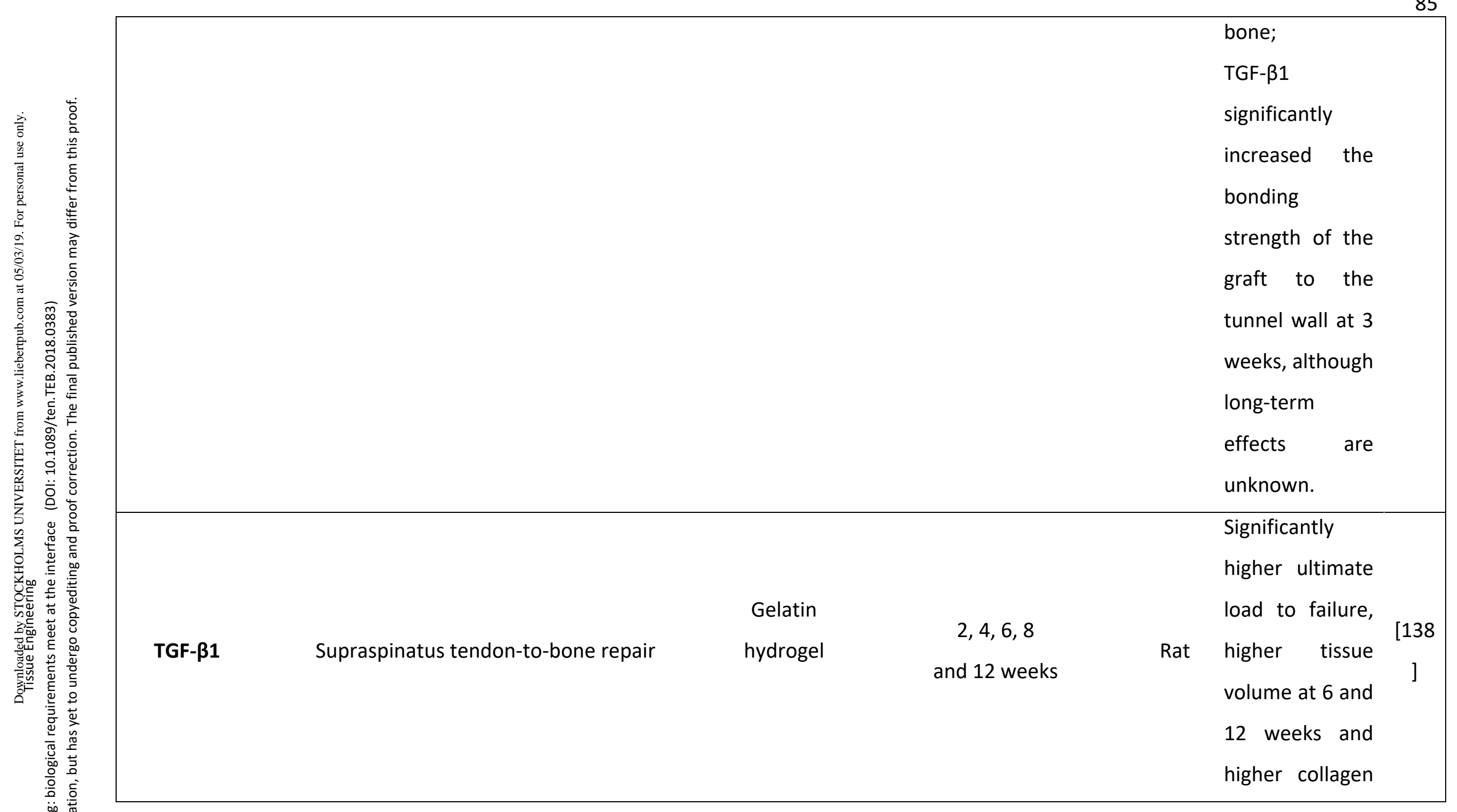




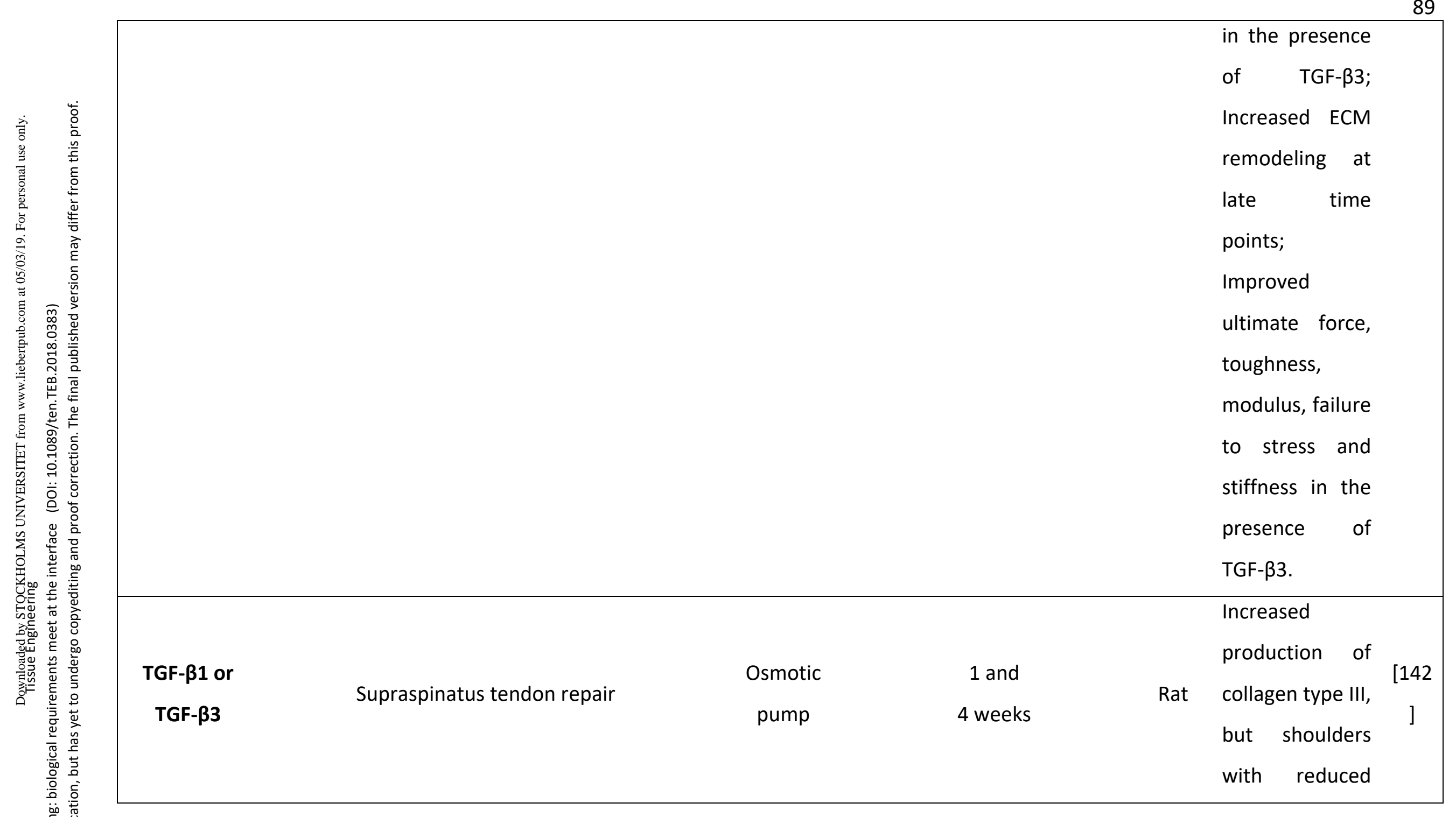




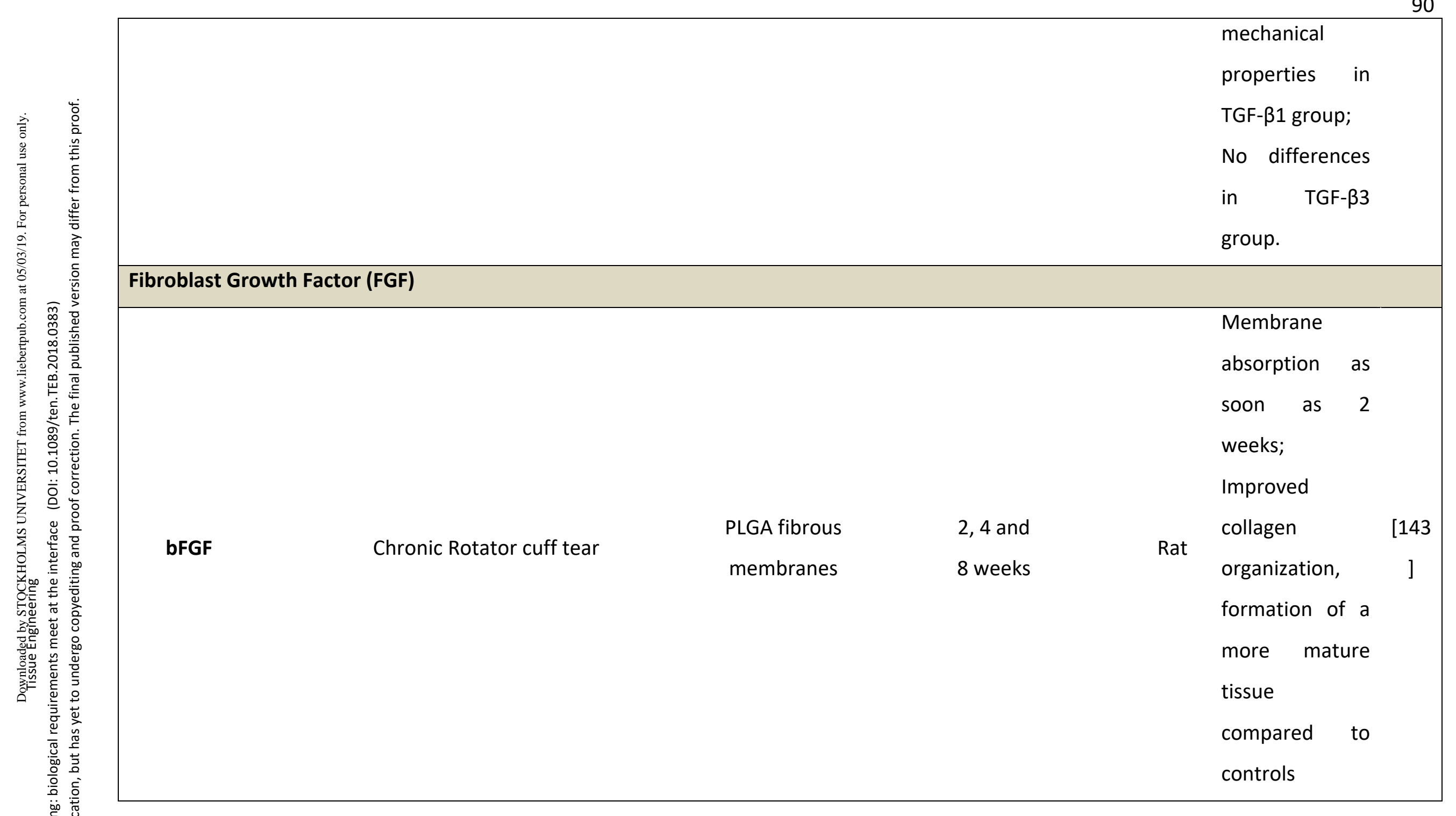




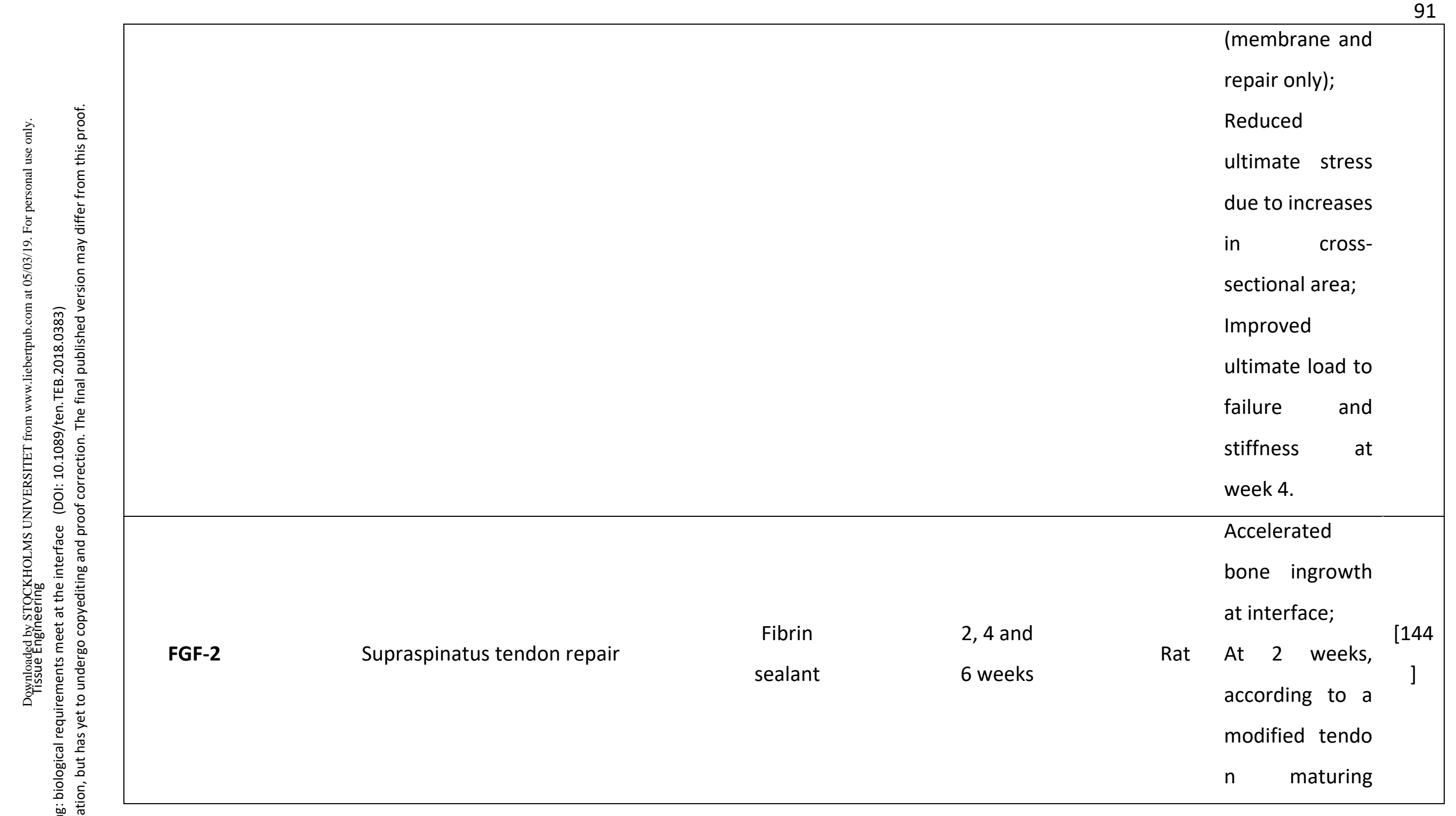




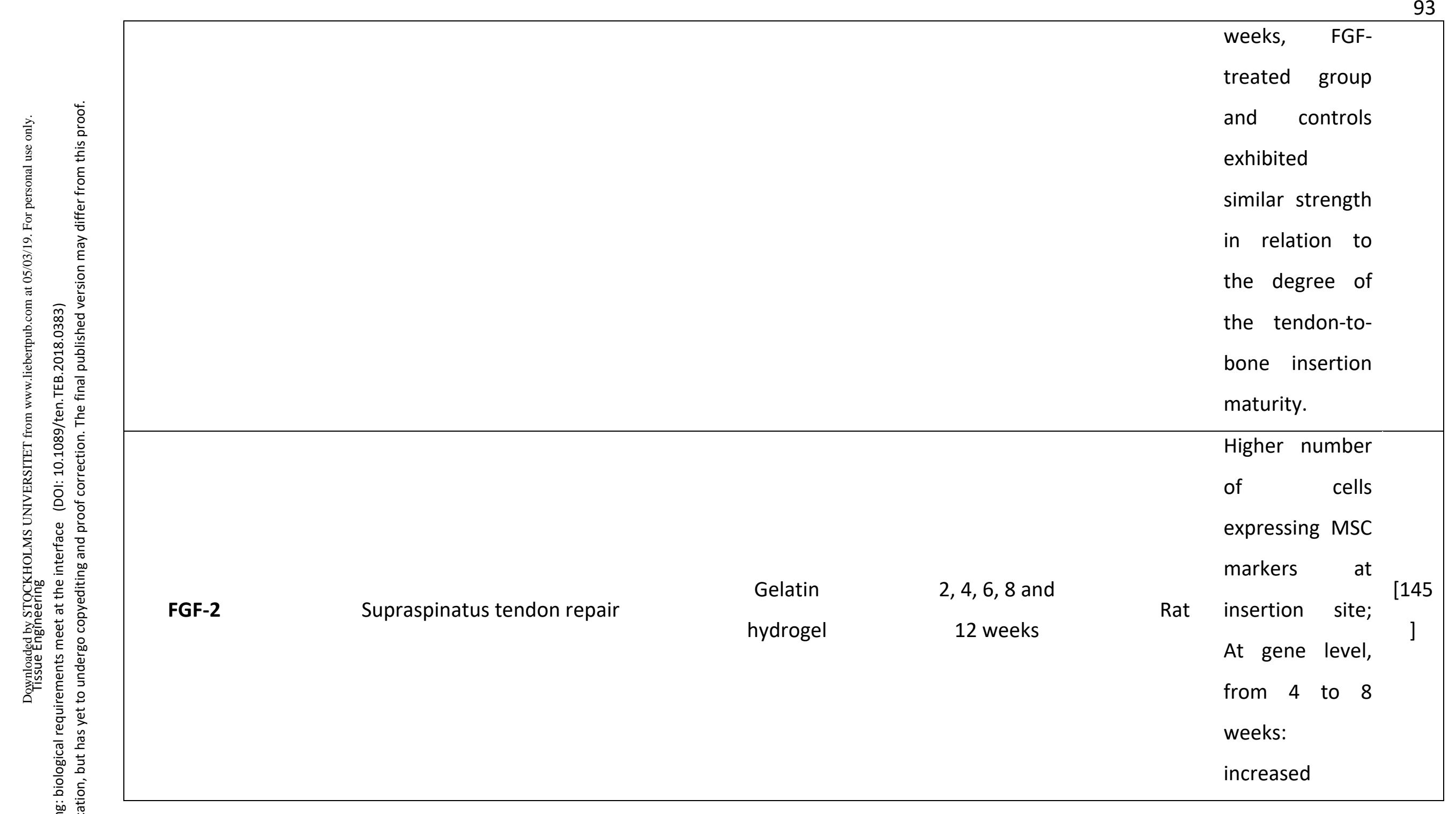




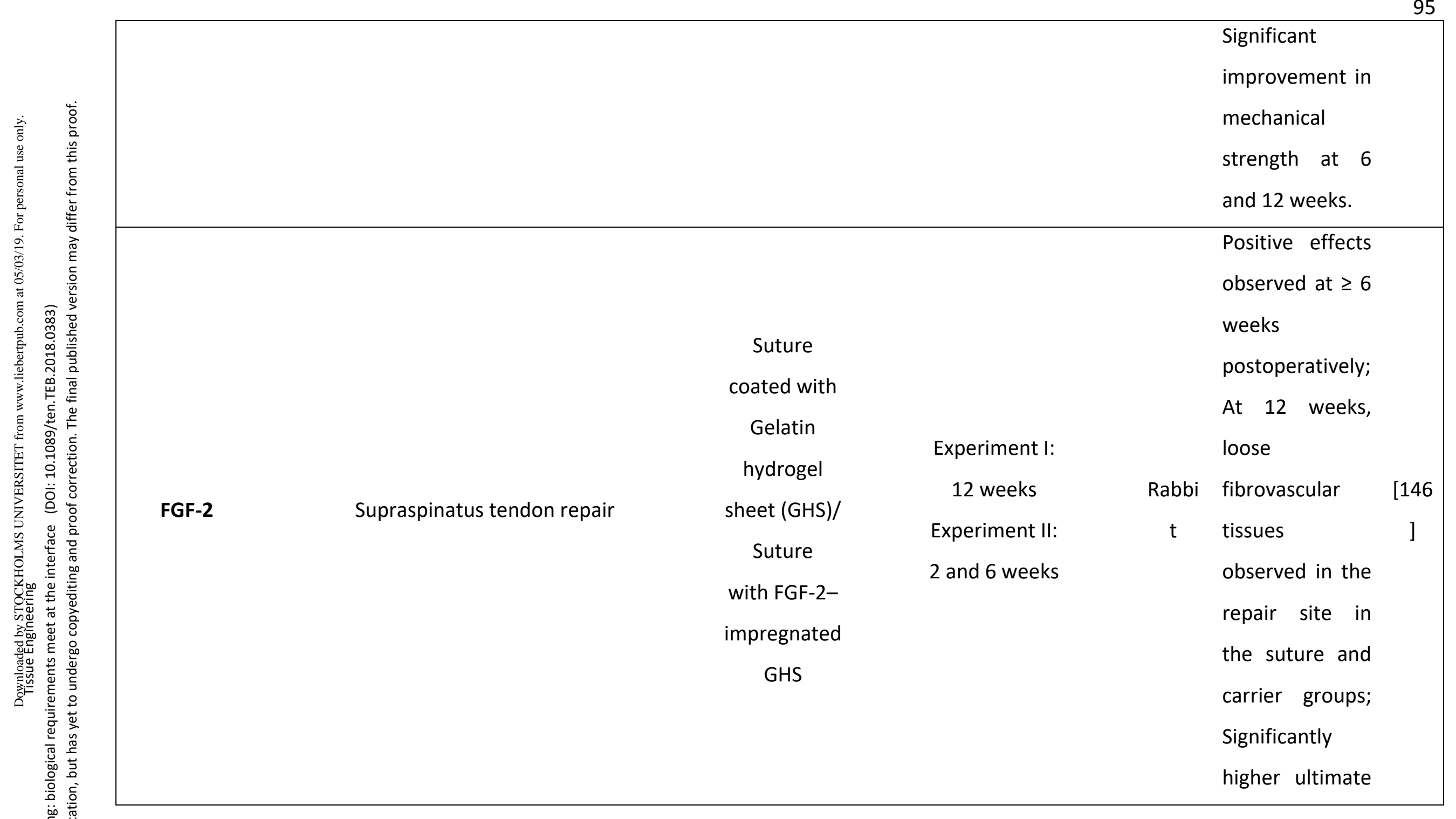




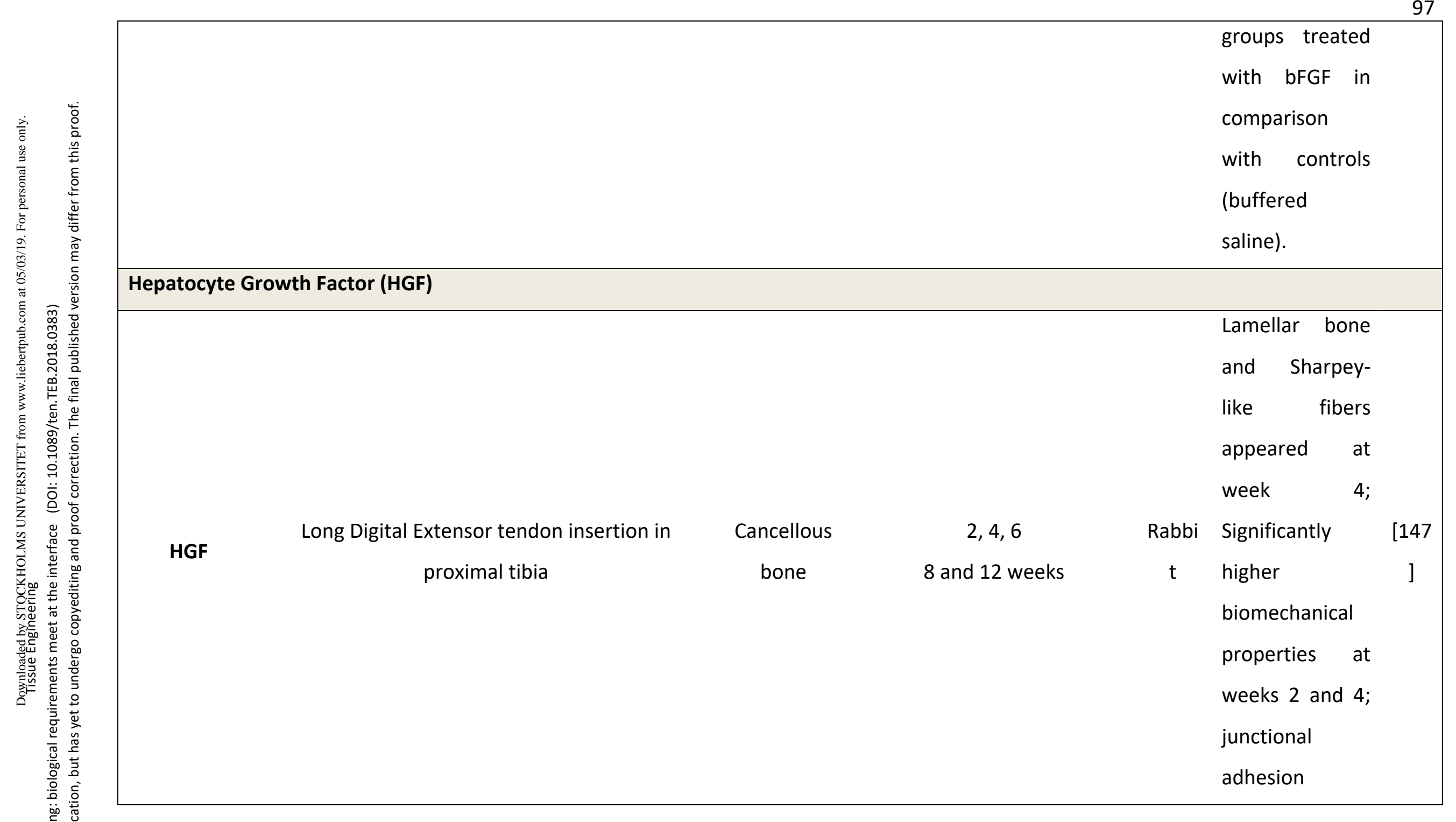




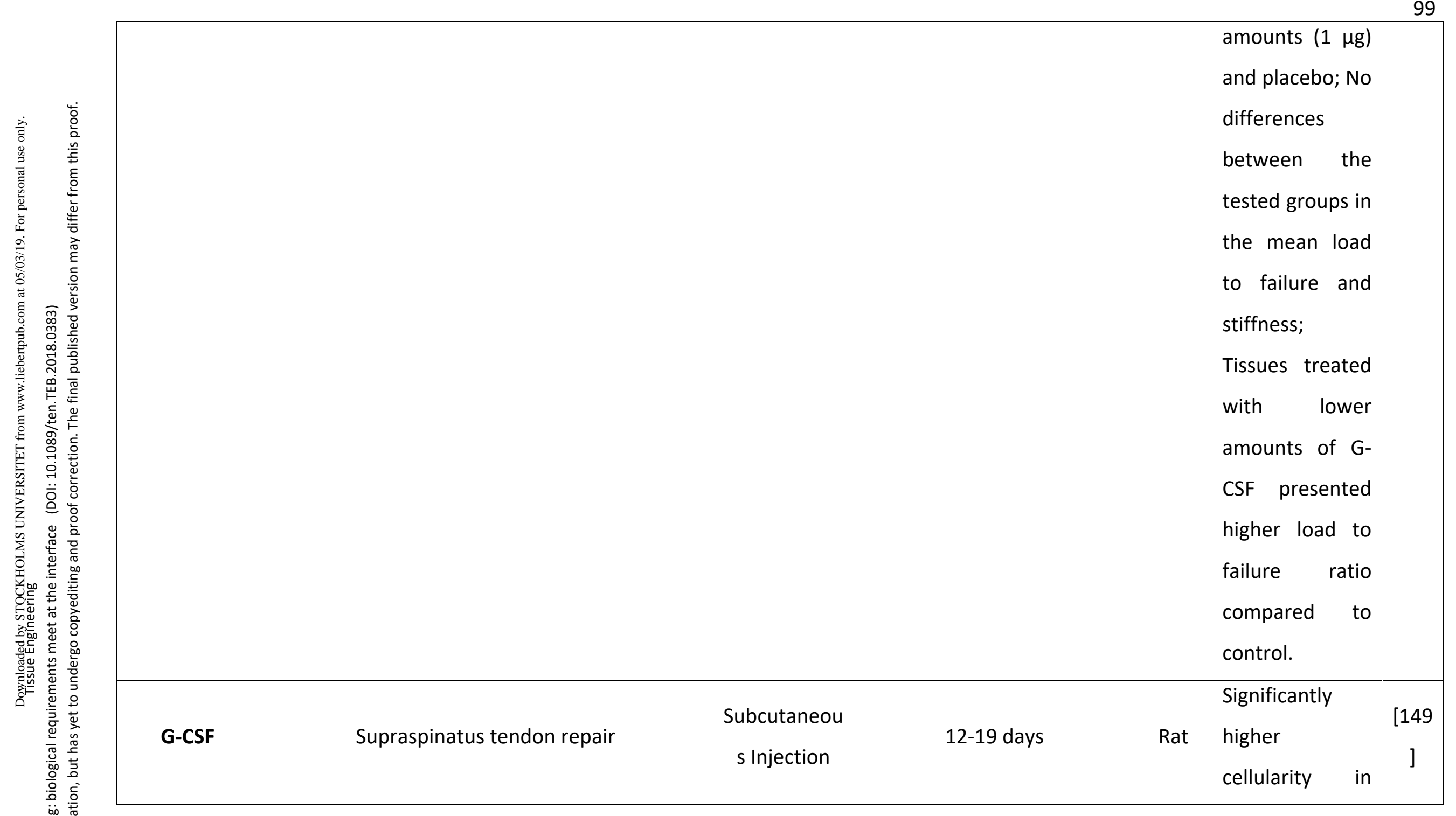


co-glycolic acid); SCX - scleraxis; rhBMP - recombinant human bone morphogenetic protein; TGF- $\beta 1 / 3$ - Transforming growth factor - beta 1/3; TNMD - tenomodulin; 
Table 4. In vivo studies using PRP for tendon-to-bone healing.

\begin{tabular}{|c|c|c|c|c|c|c|}
\hline 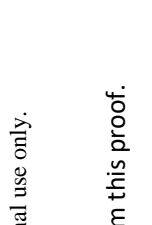 & $\begin{array}{l}\text { Injury anatomical } \\
\text { insertion location }\end{array}$ & $\begin{array}{l}\text { Animal } \\
\text { model }\end{array}$ & $\begin{array}{c}\text { Blood } \\
\text { derivative } \\
\text { preparation }\end{array}$ & Administration mode & Main outcomes & References \\
\hline 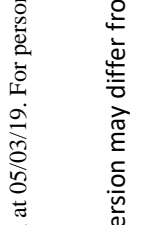 & & $\begin{array}{l}\text { New } \\
\text { Zealand } \\
\text { rabbits }\end{array}$ & PRP & $\begin{array}{l}\text { Injection into the bone } \\
\text { tunnel }\end{array}$ & $\begin{array}{l}\text { - Improved tissue integration and } \\
\text { reduced cellularity after } 56 \text { days }\end{array}$ & {$[150]$} \\
\hline 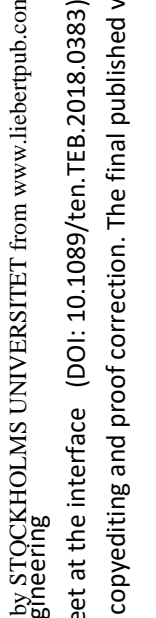 & Achilles tendon & $\begin{array}{c}\text { Female } \\
\text { Sprague } \\
\text { Dawley } \\
\text { rats }\end{array}$ & $\begin{array}{c}\text { PRP gel, } \\
\text { autologous }\end{array}$ & $\begin{array}{l}\text { Local injection of PRP } \\
\text { gel }\end{array}$ & $\begin{array}{l}\text { - Formation of a transition zone } \\
\text { with moderate collagen fiber } \\
\text { organization after } 3 \text { months, no } \\
\text { chondrocytes were observed; } \\
\text { - Complete healing (not observed in } \\
\text { controls); } \\
\text { - Proteoglycan expression; } \\
\text { - Improved mechanical strength }\end{array}$ & [151] \\
\hline 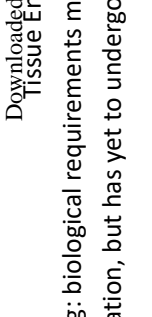 & Supraspinatus tendon & $\begin{array}{c}\text { Inbred } \\
\text { Fischer } 344 \\
\text { Adult male } \\
\text { rats }\end{array}$ & PRP & $\begin{array}{l}\text { Injection (pipped) onto } \\
\text { tendon-bone } \\
\text { approximation }\end{array}$ & $\begin{array}{l}\text { - Increased acute cellular } \\
\text { inflammation at day } 7 ; \\
\text { - } \text { Enhanced biomechanical } \\
\text { properties at day 21; }\end{array}$ & [152] \\
\hline
\end{tabular}


- Better collagen fiber organization and alignment at day 21

- Reparative fibrous and granulation tissue between tendon and bone tissue, in comparison to acute

Adult male PRP

Local injection inflammatory infiltrates and Wistar rats initiation of scar formation in controls;

- Higher maximum load and stiffness after 21 days

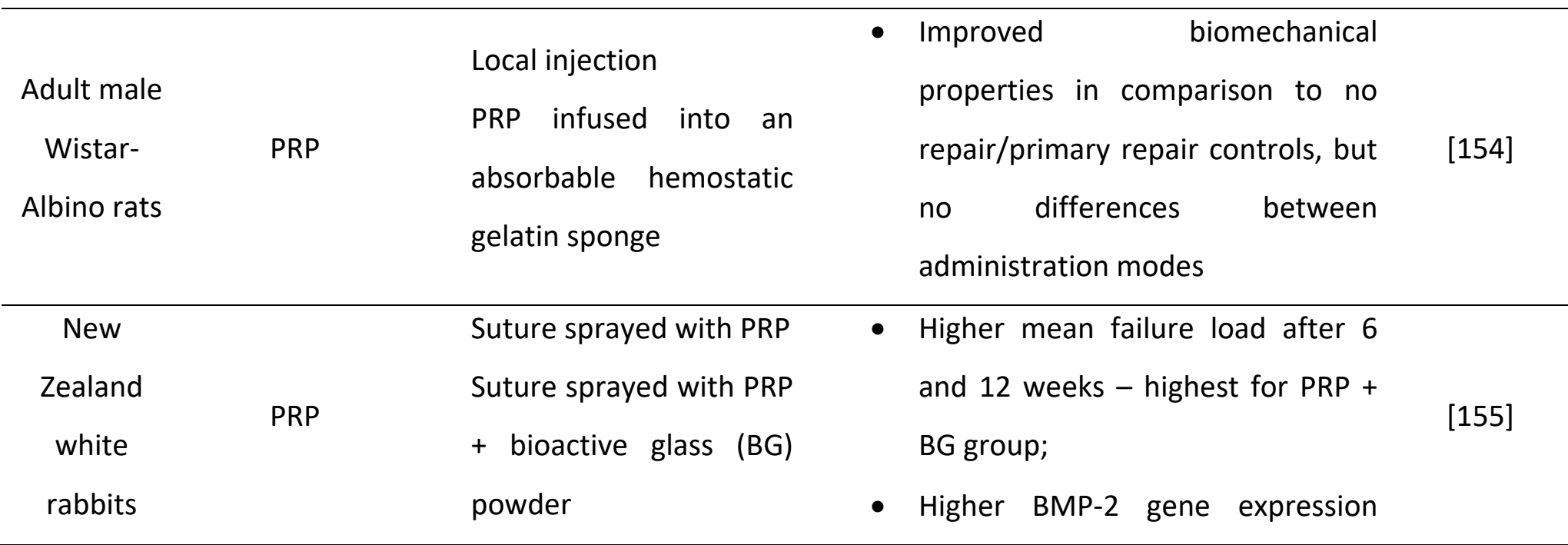


after 6 weeks

- Fibrous and vascularized tissue

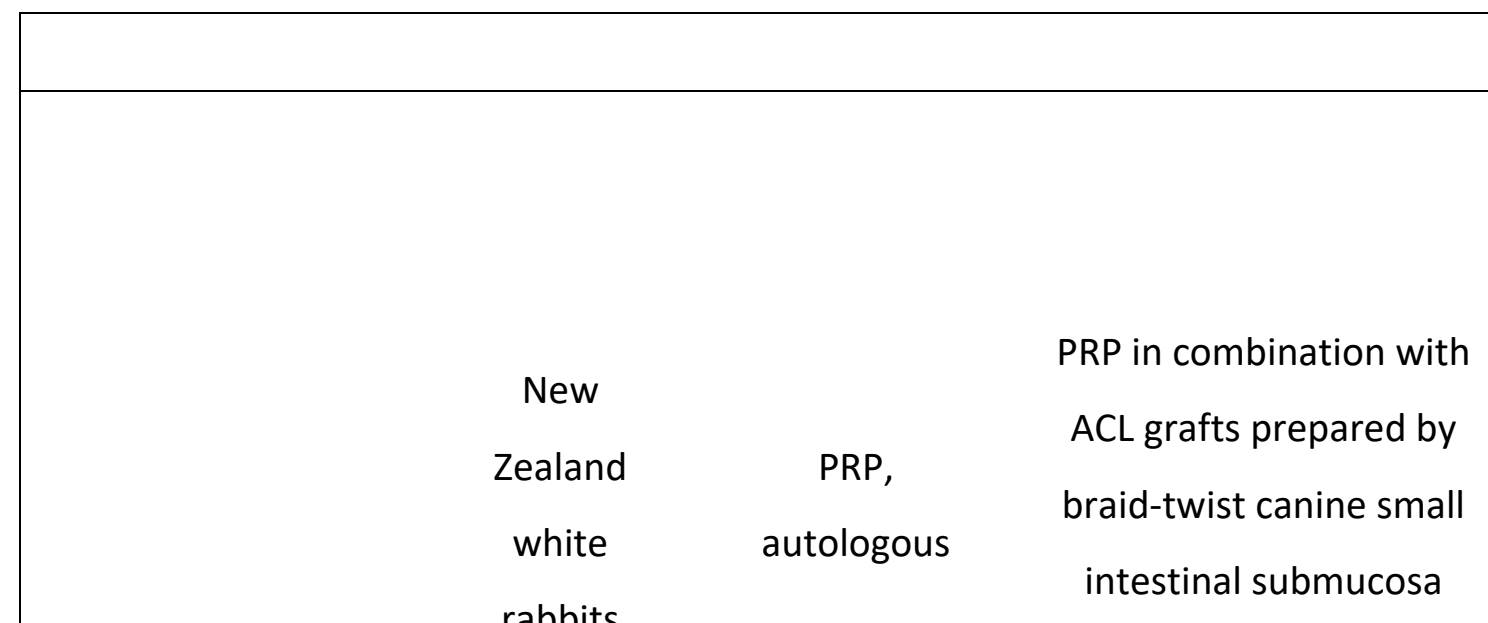

(SIS)
Anterior cruciate ligament $(A C L)$ formed around SIS graft in SIS+PRP group;

- More adhesions in SIS control;

- Lower mechanical properties in SIS+PRP group, compared to SIS alone;

- Improved cellular response, chondrocyte cell infiltration, and collagen fibers loosely attached to the bone

- Aligned connective tissue, newly formed bone and cartilage at the

$\begin{array}{ccc}\text { New } & \text { PRP } & \text { Hamstring tendon graft } \\ \text { Zealand } & \text { immobilized in } & \text { wrapped with PRP } \\ \text { white } & \text { fibrin glue } & \text { immobilized in fibrin glue } \\ \text { rabbits } & & \end{array}$
tendon-to-bone interface after 8 weeks;

- Formation of mineralized tissue at the tendon-to-bone interface after 8 weeks; 
Figure legends

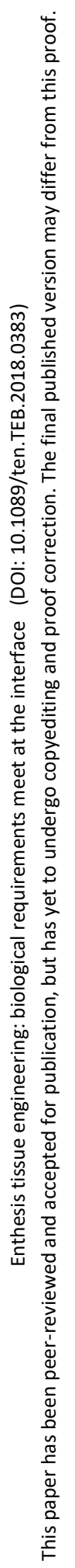

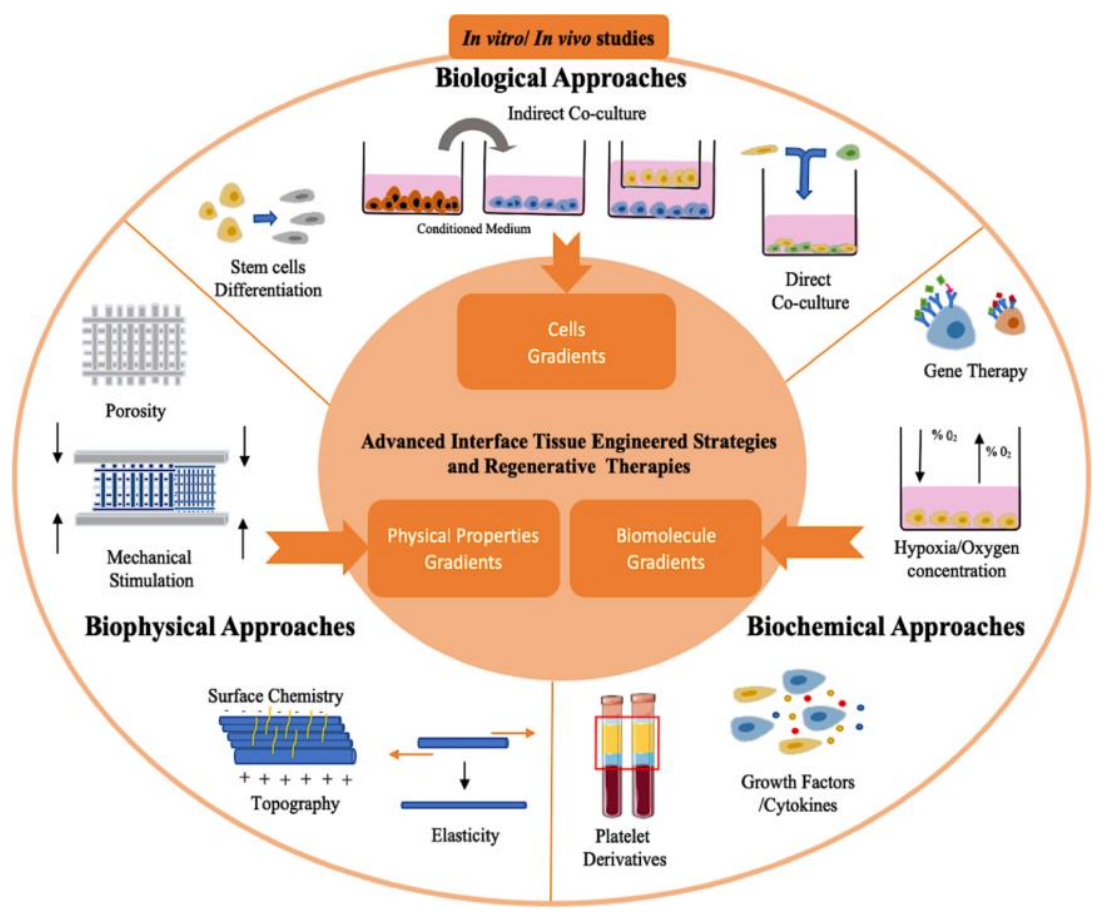

Figure 1. Schematic representation of biological, biophysical and biochemical components for tendon-to-bone tissue engineering and regenerative strategies. 


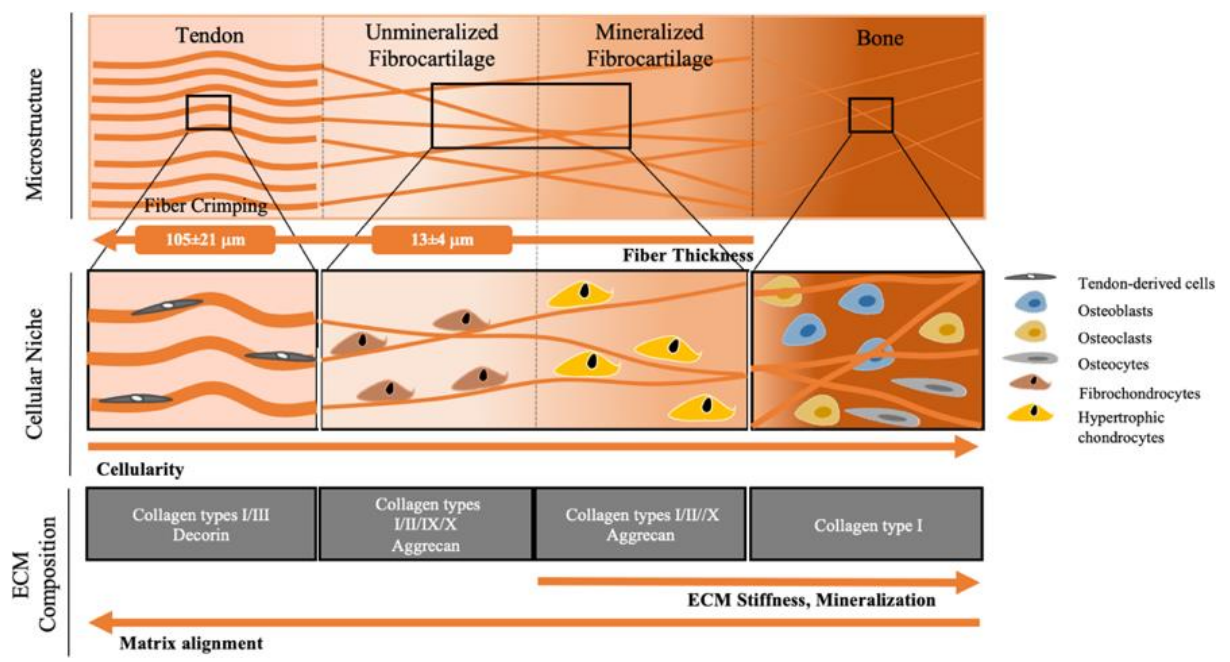

Figure 2. Structure and composition of tendon-to-bone interface. Values of mean fiber diameter were obtained from Rossetti et al. [16]. 

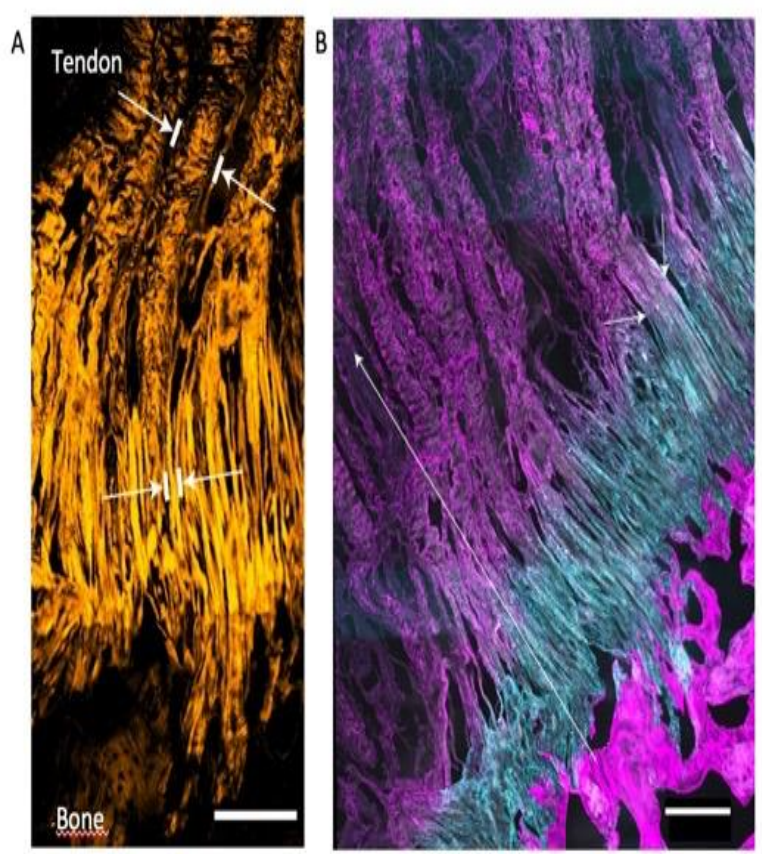

Figure 3. The structure and collagen composition of tendon-to-bone attachment. (A) Confocal reflection microscopy image of enthesis cryosection demonstrating that tendon fibers unravel into thinner fibers at the interface preceding bone attachment. Scale bar, $250 \mu \mathrm{m}$. (B) Confocal image immunostained for collagen type I (magenta) and collagen type II (cyan) showing a fiber composition change at $\sim 500 \mu \mathrm{m}$ before reaching the bone. Scale bar, $300 \mu \mathrm{m}$. From Rossetti et al. [16]. All rights reserved Copyright (C) 2017, Springer Nature. 


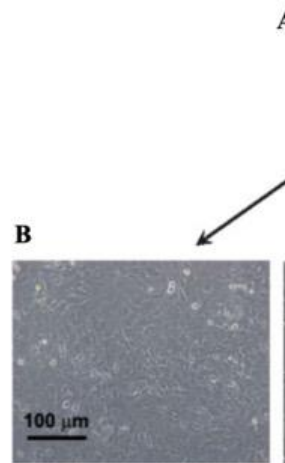

Fibroblasts

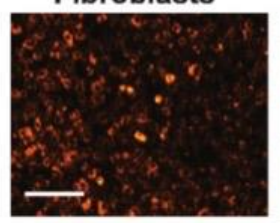

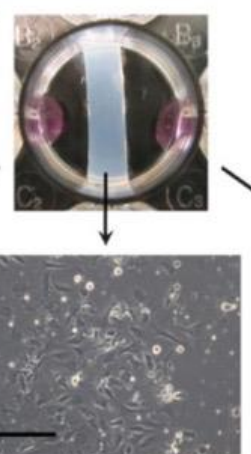
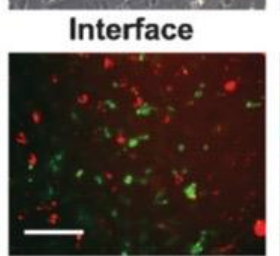

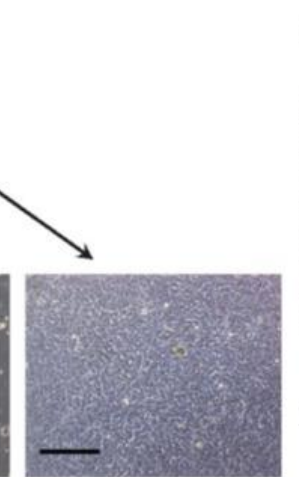

Osteoblasts

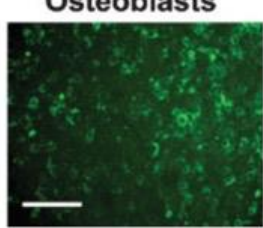

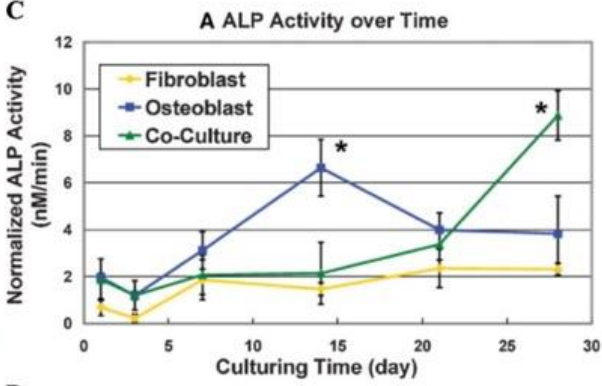

D

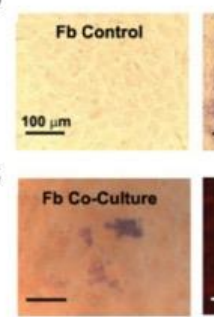

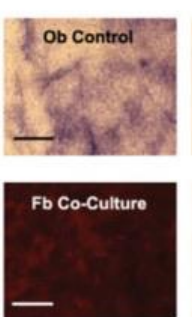

Ob Co-Culture

Figure 4. Co-culture setup of fibroblasts and osteoblasts and effect on alkaline phosphatase activity. (A) Co-culture system using a hydrogel divider; (B) Light microscopy and fluorescence images of the three different regions. Fibroblasts are shown in red and osteoblasts in green after 14 days of culture. (C) Normalized ALP activity over time in culture revealed an increase in ALP levels in co-culture. ${ }^{*}$ denotes significance at $p<0.05$. (D) Fast-Blue staining for ALP of the co-cultured osteoblasts and the correspondent control groups (fibroblasts and osteoblasts) and (E) fluorescence tracking of osteoblasts (CM-Dil) demonstrated an ALP positive staining of fibroblasts in the co-cultured well. Adapted from Wang et al. [64] 

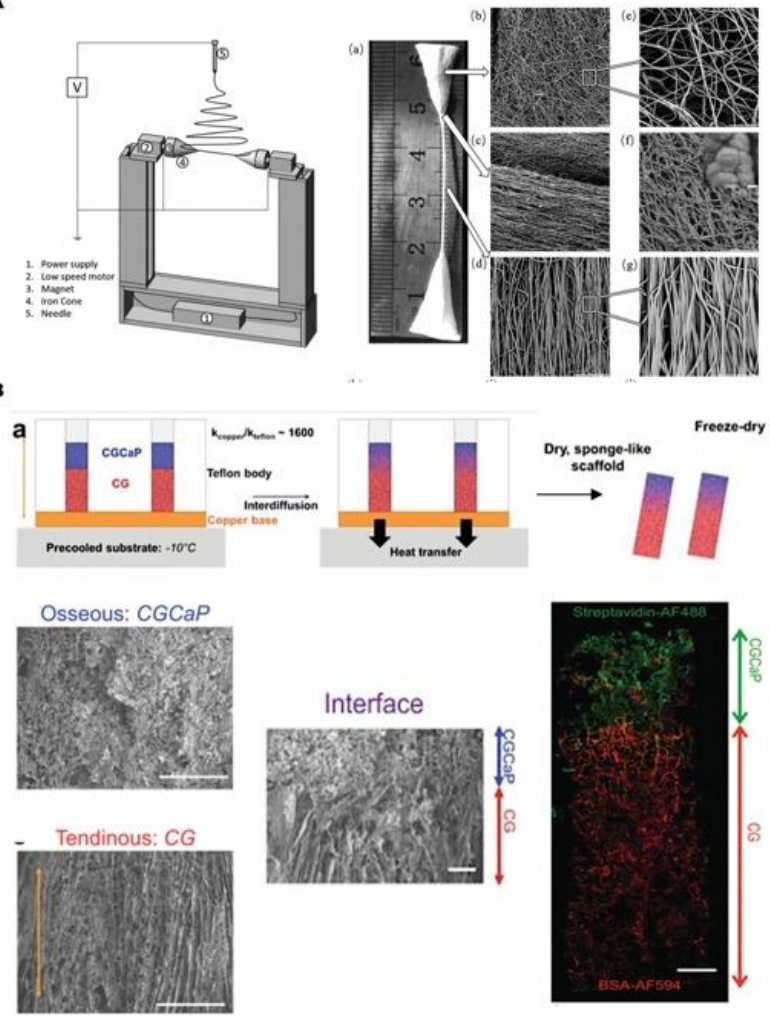

Figure 5. Production setups of 3D cylindrical scaffold and osteotendinous scaffold. (A) Schematics of an electrospinning dual-motor collector for the production of randomaligned-random PCL fibrous scaffolds for ligament to bone application. Scale bars: $10 \mathrm{um}$ and $100 \mathrm{~nm}$. Reproduced from Lin et al. [170] with permission from The Royal Society of Chemistry. (B) Schematic setup of the multicomparted osteotendinous scaffolds production with distinct regions of pore anisotropy and mineral content. Scanning electron micrographs showing an isotropic porosity in the mineralized area (CGCaP) and aligned porosity in the tendinous region (CG). Scale bars, $200 \mu \mathrm{m}$. Confocal micrograph of the scaffold stained with AlexaFluor 488-streptavidin conjugate in the osseous (CGCaP) part and AlexaFluor 594-BSA conjugate in the tendinous (CG) compartment. Scale bar, $1 \mathrm{~mm}$. Adapted from Caliari et al. [172]. All rights reserved (c) 2015 WILEY-VCH Verlag GmbH \& Co. KGaA, Weinheim. 